\title{
Socioeconomic health inequalities
}

Citation for published version (APA):

Simons-Op het Veld, A. M. W. (2018). Socioeconomic health inequalities: exploring the role of social mobility, unhealthy homogenization, and perceived classism. [Doctoral Thesis, Maastricht University]. Datawyse / Universitaire Pers Maastricht. https://doi.org/10.26481/dis.20180705as

Document status and date:

Published: 01/01/2018

DOI:

10.26481/dis.20180705as

Document Version:

Publisher's PDF, also known as Version of record

\section{Please check the document version of this publication:}

- A submitted manuscript is the version of the article upon submission and before peer-review. There can be important differences between the submitted version and the official published version of record.

People interested in the research are advised to contact the author for the final version of the publication, or visit the DOI to the publisher's website.

- The final author version and the galley proof are versions of the publication after peer review.

- The final published version features the final layout of the paper including the volume, issue and page numbers.

Link to publication

\footnotetext{
General rights rights.

- You may freely distribute the URL identifying the publication in the public portal. please follow below link for the End User Agreement:

www.umlib.nl/taverne-license

Take down policy

If you believe that this document breaches copyright please contact us at:

repository@maastrichtuniversity.nl

providing details and we will investigate your claim.
}

Copyright and moral rights for the publications made accessible in the public portal are retained by the authors and/or other copyright owners and it is a condition of accessing publications that users recognise and abide by the legal requirements associated with these

- Users may download and print one copy of any publication from the public portal for the purpose of private study or research.

- You may not further distribute the material or use it for any profit-making activity or commercial gain

If the publication is distributed under the terms of Article $25 \mathrm{fa}$ of the Dutch Copyright Act, indicated by the "Taverne" license above, 

Cover design: Audrey Simons

Cover photography: MEMORIES Lisa Teuwen Fotografie Production: Datawyse | Universitaire Pers Maastricht

ISBN: 978-94-6295-942-2

C Copyright Audrey Simons, Maastricht 2018

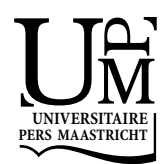




\title{
Socioeconomic health inequalities: exploring the role of social mobility, unhealthy homogenisation, and perceived classism
}

\author{
PROEFSCHRIFT
}

ter verkrijging van de graad van doctor aan de Universiteit Maastricht, op gezag van de Rector Magnificus, Prof. dr. Rianne M. Letschert, volgens het besluit van het College van Decanen, in het openbaar te verdedigen op donderdag 5 juli 2018 om 14.00 uur door Audrey Maria Wilhelmina Simons-Op het Veld 


\section{Promotor:}

Prof. dr. H. Bosma

\section{Co-promotor:}

Dr. ir. A. Koster

\section{Beoordelingscommissie:}

Prof. dr. K. Horstman (voorzitter)

Prof. dr. M. Huisman (VUmc/LASA, Amsterdam)

Prof. dr. G.I.J.M Kempen

Prof. dr. D. van de Mheen (Tilburg University/Tranzo, Tilburg)

Dr. A. Oenema

The research presented in this thesis was conducted at the Care and Public Health Research Institute: CAPHRI, Department of Social Medicine, of Maastricht University. CAPHRI participates in the Netherlands School for Primary Care Research, CaRe. The research was funded by the Graduate Programme 2012 of the Netherlands Organisation for Scientific Research (NWO), received by CAPHRI. 


\section{Table of contents}

$\begin{array}{lll}\text { Chapter } 1 \text { General introduction } & 7\end{array}$

Chapter 2 Socioeconomic inequalities in all-cause mortality in

Europe: an exploration of the role of heightened social mobility.

Chapter 3 An EU cross-country comparison of unhealthy homogenisation of lower socioeconomic groups: Findings from EU-SILC panel data.

Chapter 4 Income-related health inequalities: does perceived discrimination matter?

Chapter 5 Perceived classism and its relation with socioeconomic status, health, health behaviours and perceived inferiority: the Dutch LISS panel.

Chapter 6 The silent burden of stigmatisation: a qualitative study among Dutch people with a low socioeconomic position.

Chapter 7 General discussion

Chapter 8

Summary

Samenvatting

Valorisatie

Dankwoord

Curriculum Vitae 



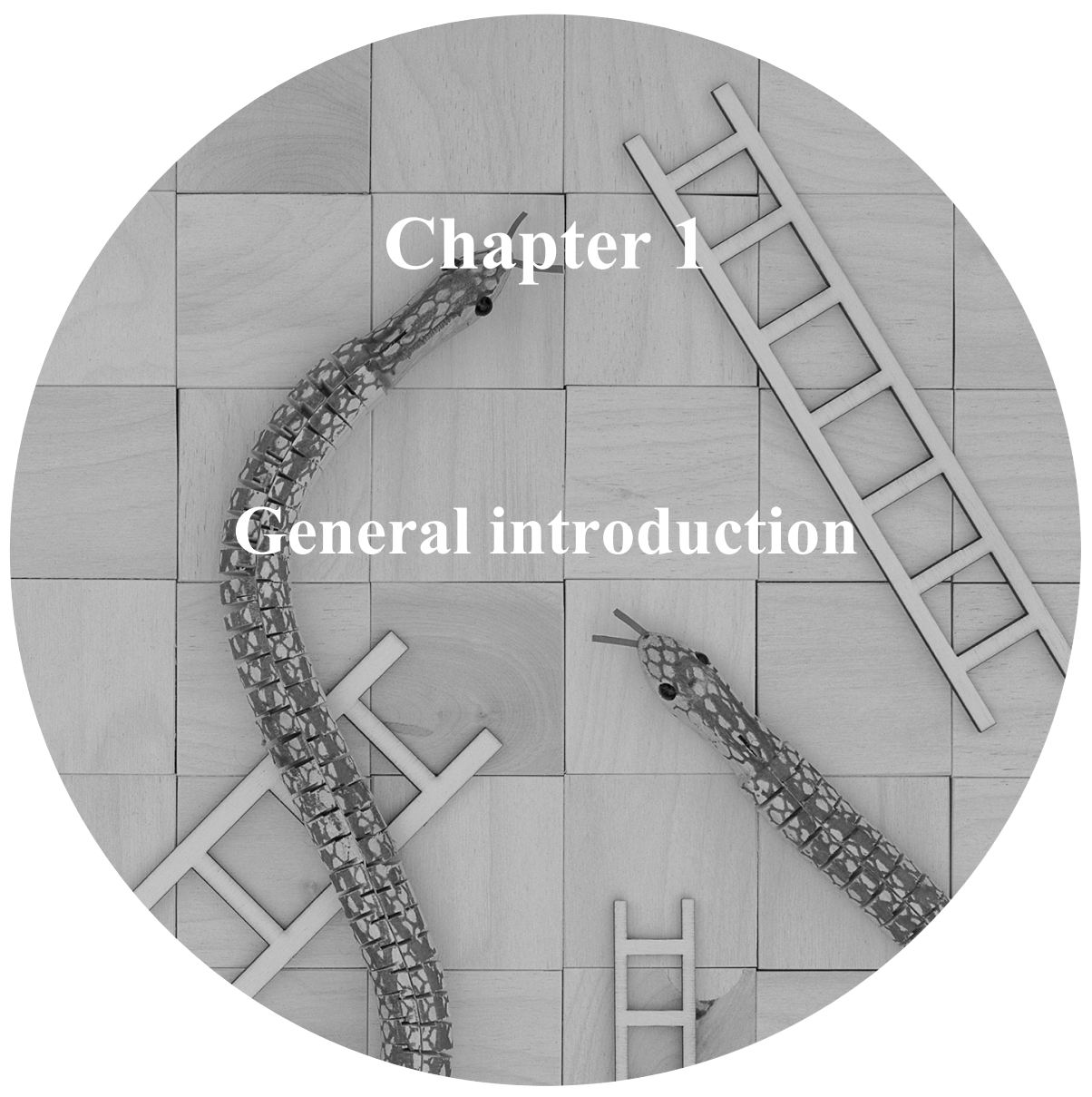





\section{Introduction}

\section{Socioeconomic health inequalities}

Socioeconomic position (SEP) refers to the societal position of individuals, households or neighbourhoods within a society. These positions can be resource-based (e.g. income, wealth or education), more prestige-based (i.e. referring to a status in the social hierarchy) or based on the structural position within the economy (i.e. social/occupational class) $(1,2)$. Regardless of which SEP indicator is used, worldwide differences in health are found between people with a high SEP and people with a low SEP; in general, people with lower SEPs report poorer general health, die earlier, live a shorter life in good health, and suffer more often from diseases and mental health problems (3-8). These gaps in health tend to follow a social gradient; each step on the socioeconomic ladder is related to better health outcomes (9).

In the Netherlands, life expectancy between people in the highest income quintile and people in the lowest income quintile differs 8.2 years for men and 6.7 years for women. The differences are even more pronounced when looking at healthy life expectancy, namely 17.5 years for men and 18.8 years for women (10). At the same time, people in the lowest income quintile more often report less than good health (30\% vs. $13 \%)$ and mental complaints $(22 \%$ vs. $7 \%)$ than their higher income counterparts (11).

\section{Explanations for socioeconomic health inequalities}

Causes of socioeconomic health inequalities can be looked at from two different perspectives: the causation and selection perspective (Figure 1). The causation perspective suggests that low SEP negatively affects health and thereby causes socioeconomic health differences $(12,13)$. The factors that underlie the association between SEP and health can be clustered into material, behavioural and psychosocial factors. The lack of financial resources (i.e. material factors) limits access to goods that are promoting health (e.g. good housing or healthy foods) (14-16). People in lower SEP groups are also more often exposed to health risks related to occupation, housing or the living environment (17-20). At the same time, behaviours with negative health effects, such as smoking, alcohol consumption, physical inactivity and inadequate diets are more prevalent in lower SEP groups $(13,21-23)$. Furthermore, living in an unequal society is stressful because people in low SEP groups are more exposed to psychosocial stressors, 


\section{Chapter 1}

such as accumulating negative life events, the lack of (financial) resources, the lack of control over life and work, and relative deprivation (24-28). These stressors affect health through biological effects (e.g. chronic stress responses) or through unhealthy behaviours $(26,29)$.

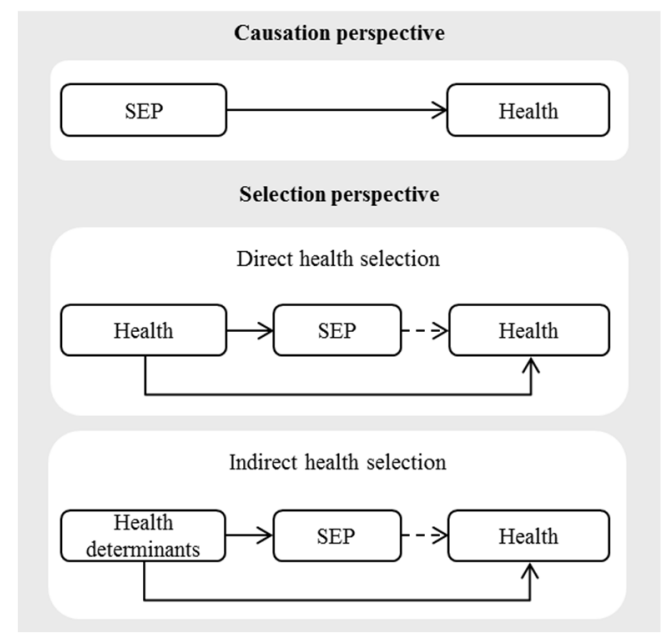

Figure 1 Causation and selection perspective

Although material, behavioural and psychosocial factors explain a large part of the health inequalities between different SEP groups, they cannot fully explain these gaps $(4,30,31)$. The selection perspective might help to explain another part (Figure 1). The selection perspective suggests that health or health-related determinants will determine both someone's SEP and future health $(12,13,32)$. Unhealthy people might have fewer opportunities for upward mobility and might even move down the socioeconomic hierarchy, while for healthy people it might be easier to move upwards (i.e. direct health selection). Indirect health selection is possible via health-related determinants like personality and cognitive functioning (33-35). These determinants are hypothesised to affect both SEP and future health. A simultaneous upward mobility of healthier people with higher abilities and "favourable" personalities and downward mobility of less healthy people with lower abilities and "unhealthy" personalities might create more homogeneous SEP groups. The lowest SEP group might increasingly become a group of unhealthy people with lower cognitive abilities and less favourable personalities (i.e. unhealthy homogenisation), while the highest SEP group might increasingly consist out of healthy people with higher cognitive 
abilities and personalities that favour health. This process might widen the health gap between SEP groups $(12,13,34,36-38)$.

More recently, the life-course perspective became more popular: causation and selection are not hypothesised to be two independent mechanisms, but to interact with each other starting at birth with an accumulation of risks and disadvantages towards adulthood and older age $(13,39)$.

\section{Persisting health inequalities within Europe}

The explanations for socioeconomic health inequalities, particularly related to the causation perspective, led to varying approaches aimed at reducing socioeconomic health inequalities $(12,40,41)$. Countries, for example, attempted to reduce income inequalities and (childhood) poverty, to improve living and working conditions and health and life chances of children, and to implement health behaviour interventions. In 1997, the UK started to work on some substantial policy changes in order to reduce their worrying socioeconomic health inequalities. However, the efforts were only partially successful. Even though health of all SEP groups improved, it was difficult to reduce the persisting and sometimes still widening health inequalities between the SEP groups (42).

In 1997, Mackenbach presented his findings of wider than expected health inequalities in the Nordic countries, known by their advanced welfare arrangements and social mobility (43). However, it was not until ten years later that new results showed similar findings and received more attention: not only Mackenbach (Figure 2), but also others showed that the Nordic countries came out less favourable than expected (44-48).

After this paradoxical finding, researchers suggested some explanations that could explain why countries with well advanced welfare arrangements still had socioeconomic health inequalities that sometimes were even wider compared to countries with less advanced welfare arrangements $(34,49-51)$. One of the most likely proposed explanations was health selection during social mobility. In countries with more social mobility, such as the Nordic countries, there might be more room for an influence of health or health-related determinants on individual social mobility $(33,36,37,50)$. In these countries, lower SEP groups might thus be negatively affected by unhealthy homogenisation, creating wider health inequalities. Revisiting the selection hypothesis might thus be needed to further explain country differences in health inequalities and thereby also to 


\section{Chapter 1}

help to develop other interventions that are not solely based on the causation perspective.

Below we explore the wider socioeconomic context in European societies and propose an additional hypothesis for the explanation of wider than expected health inequalities in more socially mobile countries, such as is common in more advanced welfare arrangements.

\section{An additional hypothesis on classism}

In the 1970s, neoliberal ideologies started to affect many European societies. This entailed a focus on an international free market economy with minimal interference by the state in economic and social activities $(52,53)$. The stronger emphasis on individualism, self-reliance and individual responsibility, together with cuts in welfare arrangements, increased poverty and larger income inequalities, had substantial consequences for the more vulnerable groups in the society (e.g. those in need for care or financial support) (52-57). While income inequality until that time by many was seen as unfair, the neoliberal ideology saw income inequality not as a bad thing, but as an incentive for citizens to work harder and achieve more (58). At the same time, the meritocratic ideology of equal opportunities in achieving an economically successful life, based on personal merits (i.e. effort and abilities), became more popular and societies became more 'open' regarding the SEP someone could achieve $(59,60)$. Living in an individualised society with prevailing neoliberal and meritocratic beliefs, a strong focus on self-reliance and own responsibility, and increased opportunities for social mobility $(59,61,62)$, might have consequences that further explain the link between low SEP and poor health (63-65). Therefore, we propose that in the context as described here, not only unhealthy homogenisation might become salient. Classism might be an additional downside of the increased opportunities for social mobility in current Western societies $(37,59,66)$.

Even in countries with well advanced welfare arrangements, the increased influence of neoliberal or meritocratic ideologies and increased opportunities for social mobility, can have psychosocial consequences for people ending up at the bottom of the socioeconomic hierarchy $(59,67)$. In socially mobile societies, permeated by meritocratic ideologies, people might increasingly think that inequality is justified because economic success is based upon individual merits, such as having the right talents and having worked hard. These beliefs create - often unrealistic — expectations of upward mobility and 


\section{General introduction}

negative stereotypes about the ones who cannot meet these expectations $(59,67$, 68). Classism might therefore be the downside of the increasingly accepted belief in earned success, individual responsibility, and increased opportunities for social mobility $(59,69,70)$.

Classism refers to the marginalisation (i.e. labelling, prejudice, discrimination, and stigmatisation) of those who are perceived to be in a different class, most often lower class (71). People in lower SEP groups are often labelled as lazy, incapable or unmotivated (72-75). Perceived classism refers to how this stigmatisation/discrimination/unequal treatment is perceived and experienced by an individual (76). Just as other forms of '-isms' (e.g. racism), perceived classism can have serious physical and mental health consequences (77-85) and may therefore contribute to the persisting and even widening health inequalities $(37,82,86)$. However, research into the health effects of perceived classism is scarce, especially in European countries. Part of this thesis aims to provide a first exploration of the role of classism in socioeconomic health inequalities. 


\section{Chapter 1}
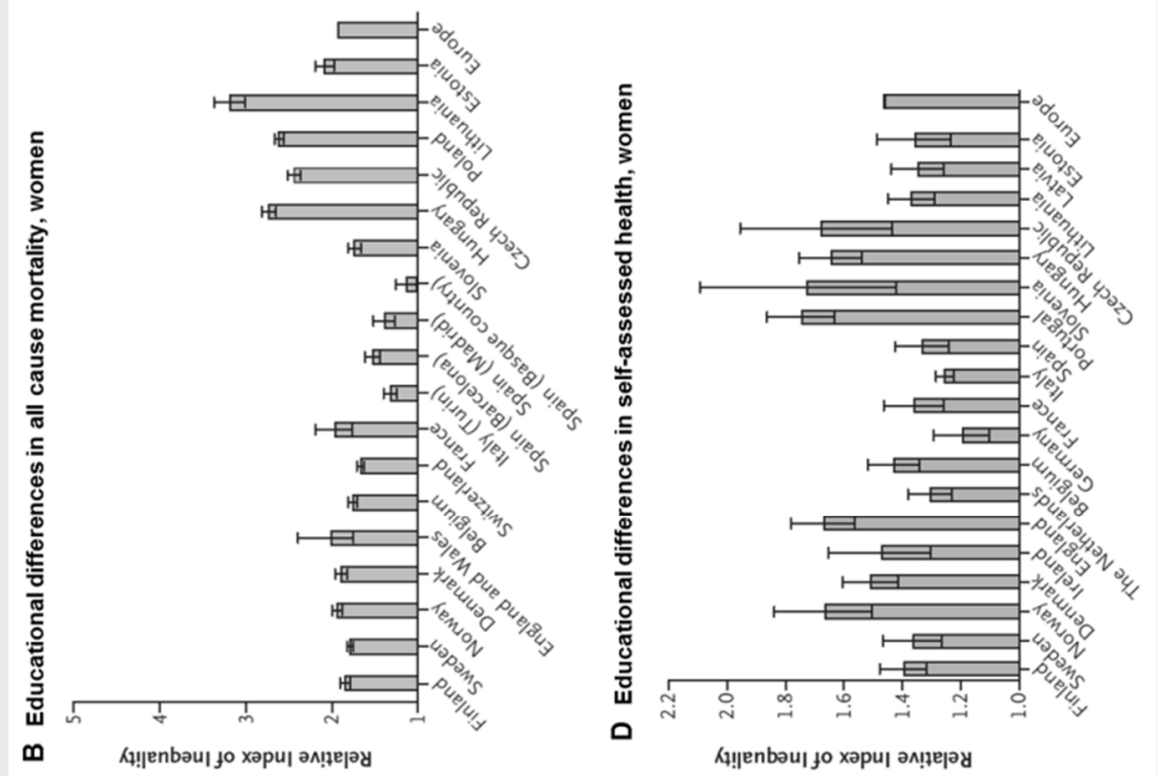

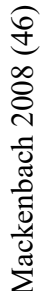
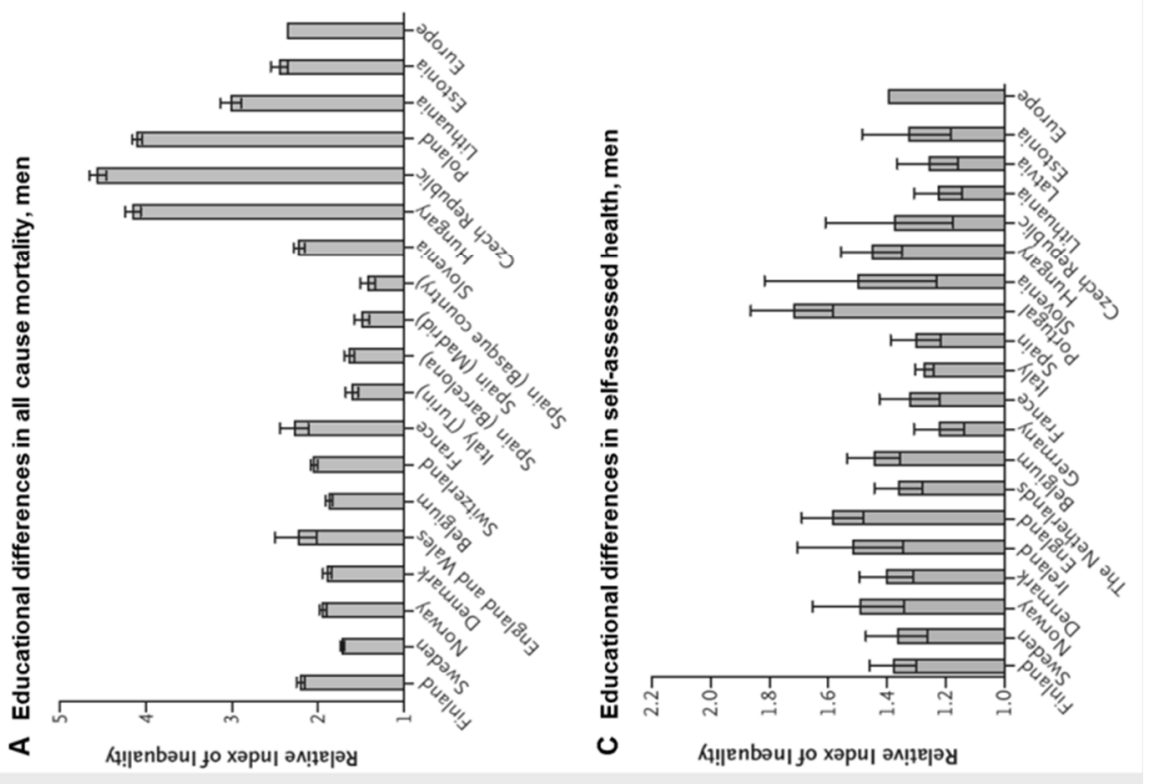

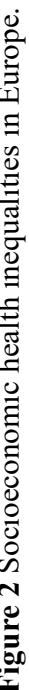




\section{General introduction}

\section{Research model and research questions}

More knowledge is needed about the role of unhealthy homogenisation and perceived classism in explaining country differences in socioeconomic health inequalities, as we think these might be two understudied explanations for the country differences in socioeconomic health inequalities. In this thesis, we explored classism as a possible candidate downside of social mobility and possible contributor to socioeconomic differences in health. We thought that first more knowledge is needed about its prevalence, health effects and potential role in socioeconomic health inequalities within countries.

Therefore, the aims of this thesis were to 1) better understand the role of unhealthy homogenisation during social mobility and its contribution to explaining country differences in socioeconomic health inequalities and 2) to get an in-depth understanding of perceived classism in the Netherlands and its association with health and health inequalities. Figure 3 shows the research model of this thesis. This model illustrates how country-level social mobility within modern Western societies might contribute to health inequalities.

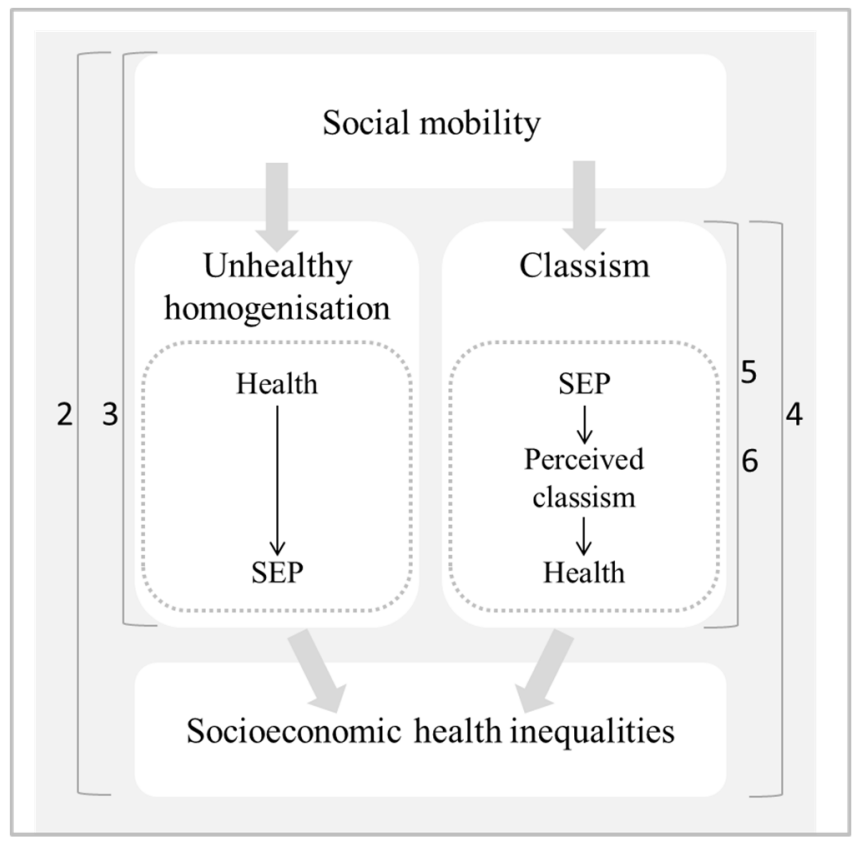

Figure 3 Research model. Numbers indicate the chapters of this thesis. 


\section{Chapter 1}

The research questions derived from this model:

1) Can unhealthy homogenisation during social mobility help to explain country differences in socioeconomic health inequalities? (Chapter 2 and 3)

a. Do countries with more social mobility have wider socioeconomic health inequalities than countries with less social mobility? (Chapter 2)

b. Does direct health selection play a role within countries? (Chapter 3)

c. Are direct health selection effects stronger in more socially mobile countries? (Chapter 3)

2) What are the health effects of perceived classism in the Netherlands? (Chapter 4- 6)

a. Do people in lower SEP groups perceive more classism than people in higher SEP groups? (Chapter 4- 6)

b. What are the consequences of perceived classism for people in low SEP groups? (Chapter 5 and 6 )

c. Does perceived classism mediate the association between SEP and health? (Chapter 4)

\section{Outline of this thesis}

To answer the research questions, five different studies were performed using both qualitative and quantitative methods, cross-sectional and longitudinal data, and country- and individual-level data.

Chapter 2 describes a study in which we examined the associations between country-level social mobility and socioeconomic inequalities in mortality, using country-level secondary data from 12 European countries. Data on health inequalities came from a previous study of Mackenbach (2008) and social mobility was derived from occupational data of the International Social Survey Programme (2009).

Chapter 3 elaborates on Chapter 2 and describes a study in which we examined unhealthy homogenisation on the individual level and the moderating role of social mobility in explaining country differences in health-related income mobility. Longitudinal data on income and health were used from EUSILC (2007-2010) and country-level social mobility was used from the first study (ISSP).

Chapter 4 describes a longitudinal study in which we investigated the role of perceived income-related discrimination within socioeconomic health 


\section{General introduction}

inequalities by using representative survey data of the Dutch Longitudinal Internet Studies for the Social sciences (LISS 2008-2010).

Chapter 5 describes a cross-sectional study in which we further investigated perceived classism in the Netherlands and its association with self-assessed health and health behaviours, by using data from LISS (2013).

Chapter 6 gives a more detailed insight into perceived classism and its consequences, by describing a qualitative study (2014) in which we conducted semi-structured interviews with people from lower SEP groups in the Netherlands.

Finally, chapter 7 provides a summary of the main findings and discussion about the implications of the results. 


\section{Chapter 1}

\section{References}

1. Krieger N, Williams DR, Moss NE. Measuring social class in US public health research: concepts, methodologies, and guidelines. Annu Rev Public Health. 1997;18(1):341-78.

2. Marmot M. Social justice, epidemiology and health inequalities. Eur $\mathbf{J}$ Epidemiol. 2017;32(7):537-46.

3. Präg P, Mills MC, Wittek R. Subjective socioeconomic status and health in cross-national comparison. Soc Sci Med. 2016;149:84-92.

4. Mackenbach JP, Bopp M, Deboosere P, Kovacs K, Leinsalu M, Martikainen $\mathrm{P}$, et al. Determinants of the magnitude of socioeconomic inequalities in mortality: A study of 17 European countries. Health Place. 2017;47:44-53.

5. Bambra C, Netuveli G, Eikemo TA. Welfare state regime life courses: the development of western European welfare state regimes and age-related patterns of educational inequalities in self-reported health. Int $\mathrm{J}$ Health Serv. 2010;40(3):399-420.

6. Schütte S, Chastang J-F, Parent-Thirion A, Vermeylen G, Niedhammer I. Psychosocial work exposures among European employees: explanations for occupational inequalities in mental health. J Public Health. 2015;37(3):373-88.

7. Wilkinson RG, Pickett K. The Spirit Level: Why Equality is Better for Everyone. New York: Penguin Group; 2010.

8. Organisation for Economic Co-operation and Development (OECD). Health at a Glance: Europe 2014. OECD Publishing; 2014.

9. Marmot M, Allen J, Goldblatt P, Boyce T, McNeish D, Grady M, et al. The Marmot review: Fair society, healthy lives. London: Institute of Health Equity; 2010.

10. Statistics Netherlands. Healthy life expectancy 2011-2014 [January 24, 2018]. Available from:

http://statline.cbs.nl/Statweb/publication/?VW=T\&DM=SLNL\&PA=802 98NED\&D1 $=1-$

$2 \& \mathrm{D} 2=\mathrm{a} \& \mathrm{D} 3=0,6,14 \& \mathrm{D} 4=0,1 \& \mathrm{D} 5=0 \& \mathrm{D} 6=1 \& \mathrm{HD}=180123-$

$1359 \& \mathrm{HDR}=\mathrm{T} \& \mathrm{STB}=\mathrm{G} 1, \mathrm{G} 2, \mathrm{G} 3, \mathrm{G} 4, \mathrm{G} 5$.

11. Statistics Netherlands. Health and Health Care 2016 [January 24, 2018]. Available from: 
https://opendata.cbs.nl/statline/\#/CBS/nl/dataset/83005NED/table?dl=62

CF.

12. Mackenbach JP, Bakker MJ. Reducing inequalities in health: a European perspective. London: Routledge; 2003.

13. Mackenbach JP. Socioeconomic inequalities in health in high-income countries: the facts and the options. Oxford Textbook of Global Public Health: Oxford University Press; 2015.

14. Pasqualini M, Lanari D, Minelli L, Pieroni L, Salmasi L. Health and income inequalities in Europe: What is the role of circumstances? Econ Hum Biol. 2017;26:164-73.

15. Robertson T, Benzeval M, Whitley E, Popham F. The role of material, psychosocial and behavioral factors in mediating the association between socioeconomic position and allostatic load (measured by cardiovascular, metabolic and inflammatory markers). Brain Behav Immun. 2015;45:419.

16. Aldabe B, Anderson R, Lyly-Yrjanainen $\mathrm{M}$, Parent-Thirion A, Vermeylen G, Kelleher CC, et al. Contribution of material, occupational, and psychosocial factors in the explanation of social inequalities in health in 28 countries in Europe. $\mathrm{J}$ Epidemiol Community Health. 2011;65(12):1123-31.

17. Boylan JM, Robert SA. Neighborhood SES is particularly important to the cardiovascular health of low SES individuals. Soc Sci Med. 2017;188:60-8.

18. Bambra C. Work, worklessness and the political economy of health inequalities. J Epidemiol Community Health. 2011;65(9):746-50.

19. McNamara CL, Balaj M, Thomson KH, Eikemo TA, Bambra C. The contribution of housing and neighbourhood conditions to educational inequalities in non-communicable diseases in Europe: findings from the European Social Survey (2014) special module on the social determinants of health. Eur J Public Health. 2017;27(suppl_1):102-6.

20. Schrijvers CTM, van de Mheen HD, Stronks K, Mackenbach JP. Socioeconomic inequalities in health in the working population: the contribution of working conditions. Int J Epidemiol. 1998;27(6):1011-8.

21. Huisman M, Kunst A, Mackenbach J. Educational inequalities in smoking among men and women aged 16 years and older in 11 European countries. Tob Control. 2005;14(2):106-13. 


\section{Chapter 1}

22. Huijts T, Gkiouleka A, Reibling N, Thomson KH, Eikemo TA, Bambra C. Educational inequalities in risky health behaviours in 21 European countries: findings from the European social survey (2014) special module on the social determinants of health. Eur J Public Health. 2017;27(suppl_1):63-72.

23. Peña S, Mäkelä P, Valdivia G, Helakorpi S, Markkula N, Margozzini P, et al. Socioeconomic inequalities in alcohol consumption in Chile and Finland. Drug Alcohol Depend. 2017;173:24-30.

24. Marmot M, Wilkinson RG. Psychosocial and material pathways in the relation between income and health: a response to Lynch et al. BMJ. 2001;322(7296):1233.

25. Stronks K, van de Mheen H, Looman CWN, Mackenbach JP. The importance of psychosocial stressors for socio-economic inequalities in perceived health. Soc Sci Med. 1998;46(4-5):611-23.

26. Buttrick NR, Oishi S. The psychological consequences of income inequality. Soc Personal Psychol Compass. 2017;11(3).

27. Bosma H, Van Jaarsveld C, Tuinstra J, Sanderman R, Ranchor A, Van Eijk JTM, et al. Low control beliefs, classical coronary risk factors, and socio-economic differences in heart disease in older persons. Soc Sci Med. 2005;60(4):737-45.

28. Wilkinson RG, Pickett KE. The problems of relative deprivation: why some societies do better than others. Soc Sci Med. 2007;65(9):1965-78.

29. Adler NE, Tan JJX. Commentary: Tackling the health gap: the role of psychosocial processes. Int J Epidemiol. 2017;46(4):1329-31.

30. Skalicka V, van Lenthe F, Bambra C, Krokstad S, Mackenbach J. Material, psychosocial, behavioural and biomedical factors in the explanation of relative socio-economic inequalities in mortality: evidence from the HUNT study. Int J Epidemiol. 2009;38(5):1272-84.

31. Moor I, Spallek J, Richter M. Explaining socioeconomic inequalities in self-rated health: a systematic review of the relative contribution of material, psychosocial and behavioural factors. J Epidemiol Community Health. 2016;71(6):565-75.

32. West P. Rethinking the health selection explanation for health inequalities. Soc Sci Med. 1991;32(4):373-84. 
33. Mackenbach JP. Nordic paradox, Southern miracle, Eastern disaster: persistence of inequalities in mortality in Europe. Eur J Public Health. 2017;27(suppl_4):14-7.

34. McCartney G, Collins C, Mackenzie M. What (or who) causes health inequalities: Theories, evidence and implications? Health Policy. 2013;113(3):221-7.

35. Huisman M, Kunst A, Mackenbach J. Intelligence and socioeconomic inequalities in health. Lancet. 2005;366(9488):807-8.

36. Dibben C, Popham F. Are socio-economic groupings the most appropriate method for judging health equity between countries? J Epidemiol Community Health. 2011;65(1):4-5.

37. Bosma H, Simons A, Groffen D, Klabbers G. Stigmatisation and socioeconomic differences in health in modern welfare states. Eur $\mathrm{J}$ Public Health. 2012;22:616-7.

38. Boyle PJ, Norman P, Popham F. Social mobility: evidence that it can widen health inequalities. Soc Sci Med. 2009;68(10):1835-42.

39. Yang YC, Gerken K, Schorpp K, Boen C, Harris KM. Early-life socioeconomic status and adult physiological functioning: a life course examination of biosocial mechanisms. Biodemography Soc Biol 2017;63(2):87-103.

40. Pons-Vigués M, Diez È, Morrison J, Salas-Nicás S, Hoffmann R, Burstrom B, et al. Social and health policies or interventions to tackle health inequalities in European cities: a scoping review. BMC Public Health. 2014;14(1):198.

41. Barsanti S, Salmi L-R, Bourgueil Y, Daponte A, Pinzal E, Ménival S. Strategies and governance to reduce health inequalities: evidences from a cross-European survey. Glob Health Res Policy. 2017;2(1):18.

42. Mackenbach JP. Can we reduce health inequalities? An analysis of the English strategy (1997-2010). J Epidemiol Community Health. 2011;65(7):568.

43. Mackenbach JP, Kunst AE, Cavelaars AE, Groenhof F, Geurts JJ. Socioeconomic inequalities in morbidity and mortality in western Europe. The EU Working Group on socioeconomic inequalities in health. Lancet. 1997;349(9066):1655-9. 


\section{Chapter 1}

44. Eikemo TA, Bambra C, Joyce K, Dahl E. Welfare state regimes and income-related health inequalities: a comparison of 23 European countries. Eur J Public Health. 2008;18(6):593-9.

45. Eikemo TA, Huisman M, Bambra C, Kunst AE. Health inequalities according to educational level in different welfare regimes: a comparison of 23 European countries. Sociol Health Illn. 2008;30(4):565-82.

46. Mackenbach JP, Stirbu I, Roskam AJR, Schaap MM, Menvielle G, Leinsalu M, et al. Socioeconomic inequalities in health in 22 European countries. N Engl J Med. 2008;358(23):2468-81.

47. Popham F, Dibben C, Bambra C. Are health inequalities really not the smallest in the Nordic welfare states? A comparison of mortality inequality in 37 countries. J Epidemiol Community Health. 2013;67(5):412-8.

48. McNamara CL, Toch-Marquardt M, Balaj M, Reibling N, Eikemo TA, Bambra C. Occupational inequalities in self-rated health and noncommunicable diseases in different regions of Europe: findings from the European Social Survey (2014) special module on the social determinants of health. Eur J Public Health. 2017;27(suppl_1):27-33.

49. Bambra C. Health inequalities and welfare state regimes: theoretical insights on a public health 'puzzle'. J Epidemiol Community Health. 2011;65(9):740-5.

50. Mackenbach JP. The persistence of health inequalities in modern welfare states: the explanation of a paradox. Soc Sci Med. 2012;75(4):761-9.

51. Huijts T, Eikemo TA. Causality, social selectivity or artefacts? Why socioeconomic inequalities in health are not smallest in the Nordic countries. Eur J Public Health. 2009;19(5):452-3.

52. Labonté R, Stuckler D. The rise of neoliberalism: how bad economics imperils health and what to do about it. J Epidemiol Community Health. 2016;70(3):312-8.

53. Navarro V. Neoliberalism as a class ideology; or, the political causes of the growth of inequalities. Int J Health Serv. 2007;37(1):47-62.

54. Peacock M, Bissell P, Owen J. Dependency denied: health inequalities in the neo-liberal era. Soc Sci Med. 2014;118:173-80.

55. Ravindran TS. Poverty, food security and universal access to sexual and reproductive health services: a call for cross-movement advocacy against neoliberal globalisation. Reprod Health Matters. 2014;22(43):14-27. 


\section{General introduction}

56. Sakellariou D, Rotarou ES. The effects of neoliberal policies on access to healthcare for people with disabilities. Int $\mathrm{J}$ Equity Health. 2017;16(1):199.

57. Abrahamson P. European welfare states beyond neoliberalism: toward the social investment state. Dev Soc. 2010;39(1):61-95.

58. Rogers-Vaughn B. Neoliberalism, inequality, and the erosion of social well-being. Caring for Souls in a Neoliberal Age. New York: Palgrave Macmillan 2016. p. 35-65.

59. De Botton A. Statusangst [Status anxiety]. Amsterdam: Olympus 2004.

60. Shildrick T, Rucell J. Sociological perspective on poverty. York: Joseph Rowntree Foundation; 2015.

61. Breen R, Luijkx R. Social mobility in Europe between 1970 and 2000. In: Breen R, editor. Social mobility in Europe. 1. Oxforsd: Oxford University Press; 2004. p. 37-75.

62. Mackenbach JP. Persistence of social inequalities in modern welfare states: Explanation of a paradox. Scand J Public Health. 2017;45(2):11320.

63. Williams WR. Struggling with poverty: implications for theory and policy of increasing research on social class-based stigma. Anal Soc Issues Public Policy. 2009;9(1):37-56.

64. Courtwright AM. Justice, stigma, and the new epidemiology of health disparities. Bioeth. 2009;23(2):90-6.

65. Hatzenbuehler ML, Phelan JC, Link BG. Stigma as a fundamental cause of population health inequalities. Am J Public Health. 2013;103(5):81321.

66. Ramon S. Neoliberalism and its implications for mental health in the UK. Int J Law Psychiatry. 2008;31(2):116-25.

67. Dahl E, Fritzell J, Lahelma E, Martikainen P, Kunst AE, Mackenbach JP. Welfare state regimes and health inequalities. In: Siegrist J, Marmot M, editors. Social inequalities in health New evidence and policy implications. Oxford: Oxford University Press 2006.

68. Åberg Yngwe M, Fritzell J, Lundberg O, Diderichsen F, Burström B. Exploring relative deprivation: Is social comparison a mechanism in the relation between income and health? Soc Sci Med. 2003;57(8):1463-73.

69. Saunders P. Unequal but fair: a study of class barriers in Britain. London: IEA Health and Welfare Unit; 1996. 


\section{Chapter 1}

70. Swierstra T, Tonkens E. Meritocratie en de erosie van zelfrespect [Meritocracy and the erosion of self respect]. Krisis. 2006;3:3-23.

71. Liu WM. Introduction to Social Class and Classism in Counseling Psychology. The Oxford Handbook of Social Class in Counseling. Oxford Oxford University Press.; 2013.

72. Lott B. The social psychology of class and classism. Am Psychol. 2012;67(8):650-8.

73. Kwate NO, Meyer IH. The myth of meritocracy and African American health. Am J Public Health. 2010;100(10):1831-4.

74. McCoy SK, Major B. Priming meritocracy and the psychological justification of inequality. J Exp Soc Psychol. 2007;43(3):341-51.

75. Cozzarelli C, Wilkinson AV, Tagler MJ. Attitudes toward the poor and attributions for poverty. J Soc Issues. 2001;57(2):207-27.

76. Baumberg B. The stigma of claiming benefits: a quantitative study. J Soc Policy. 2016;45(2):181-99.

77. Caputo RK. The effects of socioeconomic status, perceived discrimination and mastery on health status in a youth cohort. Soc Work Health Care. 2003;37(2):17-42.

78. Ahmed AT, Mohammed SA, Williams DR. Racial discrimination \& health: pathways \& evidence. Indian J Med Res. 2007;126(4):318-27.

79. Krieger N, Kosheleva A, Waterman PD, Chen JT, Koenen K. Racial discrimination, psychological distress, and self-rated health among USborn and foreign-born Black Americans. Am J Public Health. 2011;101(9):1704-13.

80. Mickelson KD, Williams SL. Perceived stigma of poverty and depression: examination of interpersonal and intrapersonal mediators. $\mathrm{J}$ Soc Clin Psychol. 2008;27(9):903-30.

81. Roy J-P. Socioeconomic status and health: a neurobiological perspective. Med Hypotheses. 2004;62(2):222-7.

82. Fuller-Rowell TE, Evans GW, Ong AD. Poverty and health. Psychol Sci. 2012;23(7):734-39.

83. Matthews KA, Gallo LC, Taylor SE. Are psychosocial factors mediators of socioeconomic status and health connections? Ann N Y Acad Sci. 2010;1186(1):146-73. 
84. Liu WM. Social class, classism, and mental and physical health. Social class and classism in the helping professions: research, theory, and practice. California: Sage Publicationa, Inc.; 2010.

85. Langhout RD, Rosselli F, Feinstein J. Assessing Classism in Academic Settings. Rev High Ed. 2007;30(2):145-84.

86. Gamarel KE, Reisner SL, Parsons JT, Golub SA. Association between socioeconomic position discrimination and psychological distress: findings from a community-based sample of gay and bisexual men in New York City. Am J Public Health. 2012;102(11):2094-101. 



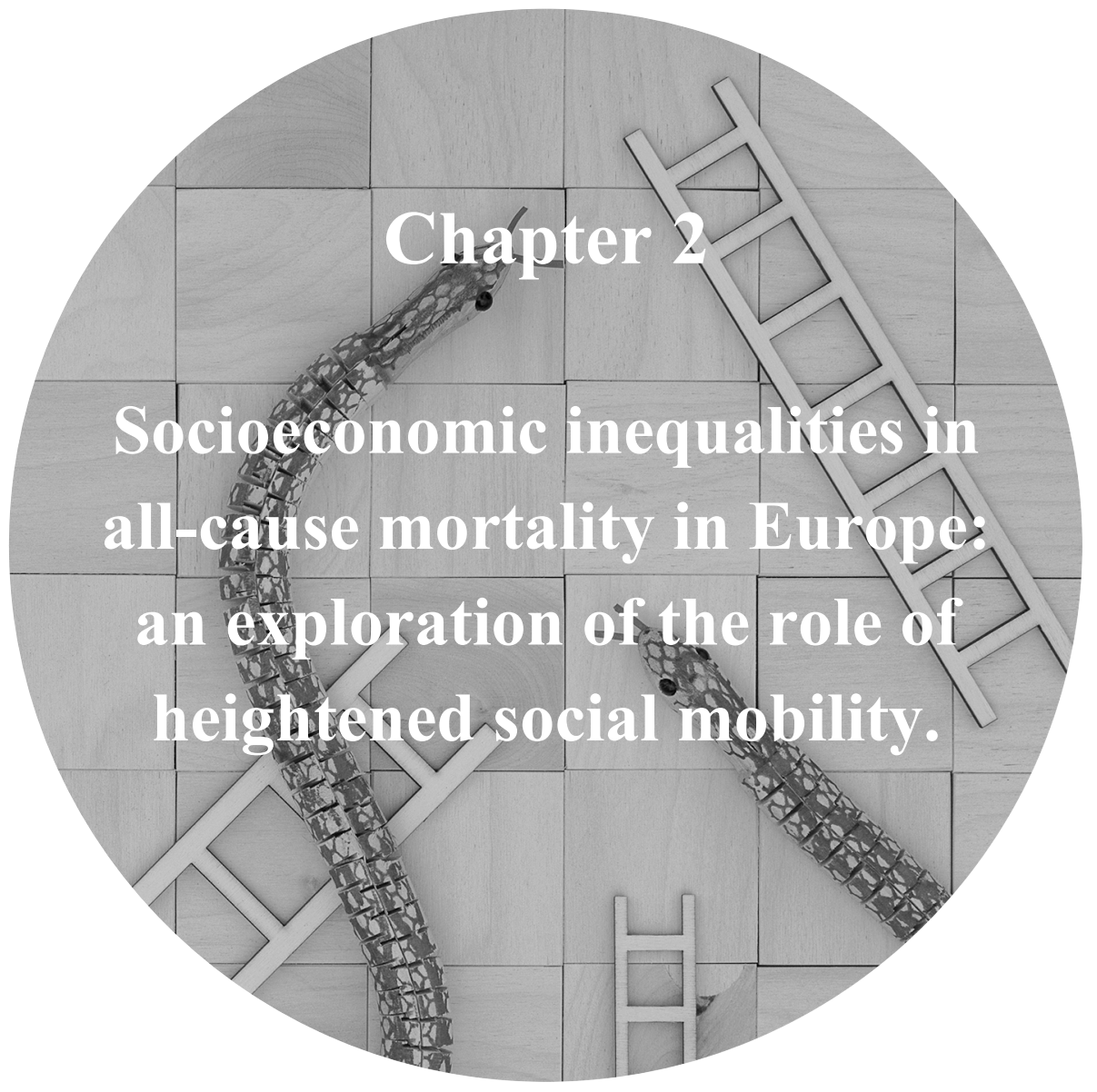

Published as:

Simons AMW, Groffen DAI, Bosma H. Socio-economic inequalities in allcause mortality in Europe: an exploration of the role of heightened social mobility. Eur J Public Health. 2013;23(6):1010-2. 


\section{Chapter 2}

\section{Abstract}

The larger than expected socioeconomic inequalities in health in more egalitarian countries might be explained by a heightened social mobility in these countries. Therefore, the aim of this explorative study was to examine the associations between country-level social mobility, income inequality and socioeconomic differences in all-cause mortality, using country-level secondary data from 12 European countries. Both income equality and social mobility were found to be associated with larger socioeconomic differences in mortality, particularly in women. These findings suggest that social mobility and income equality, beside their shiny side of improving population health, might have a shady side of increasing socioeconomic health inequalities. 


\section{Social mobility}

\section{Introduction}

Egalitarian countries, such as the Nordic countries, often show better health outcomes as compared to countries with wider income distributions $(1,2)$. Nonetheless, they do not necessarily have smaller socioeconomic health inequalities (3-5). The expected greater social mobility in these egalitarian countries is hypothesised to leave behind an increasingly homogeneous group of people that lack the physical and mental characteristics needed for getting ahead; this might underlie the wider than expected socioeconomic inequalities in health (6-8). This hypothesis of country-level social mobility underlying socioeconomic health inequalities has, however, not yet been empirically tested. Therefore, we examined 1) the patterns of association between social mobility and socioeconomic health inequalities and 2) the association between social mobility and income inequality.

\section{Methods}

Country-level data of 12 European countries were collected on socioeconomic inequality in mortality, income inequality, and social mobility. We sought data on hypothesised causes that - in time - were preferably measured prior to the data on hypothesised outcomes. Former communist countries were excluded because of their confounding contexts and histories, particularly in the early $90 \mathrm{~s}$ (9), and because of missing data. Relative and absolute socioeconomic inequality in mortality were measured by, respectively, the relative index of inequality (RII) and slope index of inequality (SII) regarding educational differences in all-cause mortality in the 90s (4). These data were only available for men and women separately. Income inequality was measured by the Gini coefficient (after taxes and transfers) in the mid-90s (10). Social mobility was measured by 1- the correlation of participant's and father's International Socio-Economic Index of occupational status score (ISEI-08; International Social Survey Programme, Social Inequality IV 2009; www.issp.org). Father's occupational status, on average, referred to the status in 1975. Pearson's correlations (r) were used to examine the associations between income inequality, social mobility, and socioeconomic inequalities in all-cause mortality. Since the study samples in the analyses were rather small, we mainly focussed on patterns in our find- 


\section{Chapter 2}

ings and less on the significance of the results. Therefore, our results have to be interpreted with caution.

\section{Results}

Social mobility correlated positively with relative and absolute educational inequalities in all-cause mortality, particularly in women (Figure 1, A and B). Income inequality was negatively correlated with relative and absolute educational inequalities in all-cause mortality (Figure 1, C and D). The association between income inequality and social mobility was negative $(r=-.700)$; the more egalitarian Nordic countries were more socially mobile than less egalitarian countries, such as Belgium, France and Spain.
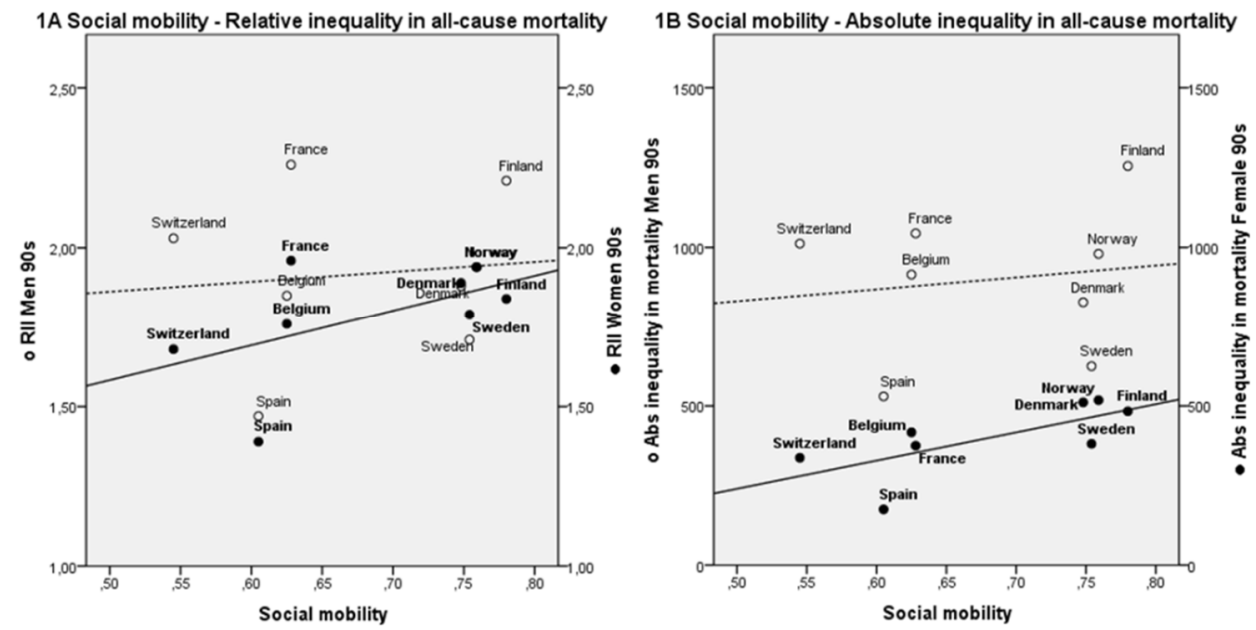

Figure 1 Associations between income inequality, social mobility and relative and absolute socioeconomic health inequalities in all-cause mortality, for men and women separately.

Dashed line $=$ men, solid line $=$ women

A. Social mobility ${ }^{a}-$ relative inequality in all-cause mortality ${ }^{(4)}$ : women $r^{*}=.534$, men $r=.108$

B. Social mobility - absolute inequality in all-cause mortality ${ }^{(4)}$ : women $r=.702$ men $r=.143$

'Pearson's correlation, ${ }^{*}$ P-value $<0.05,{ }^{a}$ ISSP 2009. 

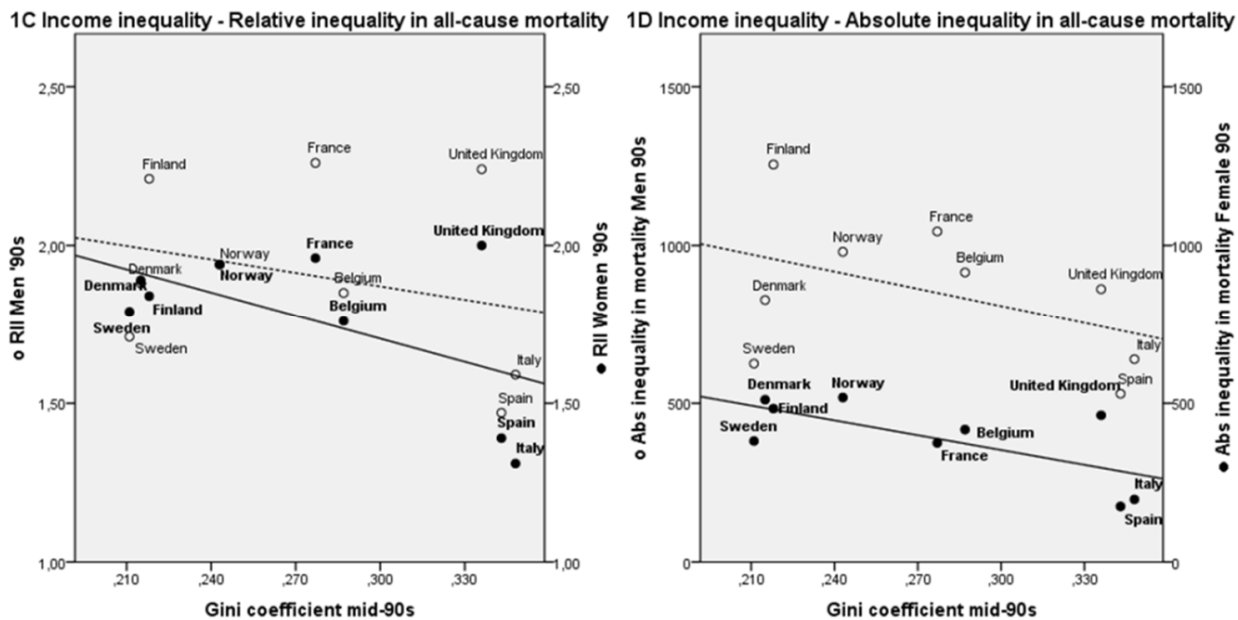

Figure 1 (Cont.) Associations between income inequality, social mobility and relative and absolute socioeconomic health inequalities in all-cause mortality, for men and women separately.

Dashed line $=$ men, solid line $=$ women

C. Income inequality ${ }^{(10)}-$ relative inequality in all-cause mortality: women $r=-.559$, men $r=-.280$

D. Income inequality - absolute inequality in all-cause mortality: women $r=-.694^{*}$, men $r=-.449$

Pearson's correlation, ${ }^{*} P$-value $<0.05,{ }^{a}$ ISSP 2009.

\section{Discussion}

Our findings suggest that egalitarian countries were more socially mobile, and that these more egalitarian and socially mobile countries had larger relative and absolute socioeconomic inequalities in all-cause mortality, especially in women. The finding that country-level income inequality is not positively associated with socioeconomic health inequalities confirms previous findings of Mackenbach and colleagues $(3,4)$. However, to our knowledge, we are the first to show that, at country-level and particularly in women, heightened social mobility is associated with larger relative and absolute socioeconomic health inequalities in all-cause mortality.

One could have expected smaller absolute socioeconomic health inequalities, given the better general population health in egalitarian countries, such as the Nordic countries $(1,2)$, but our findings were about similar for absolute and relative inequalities in all-cause mortality. Hence, even though more egalitarian and socially mobile countries have a shiny side of better general population health, as indicated by, for example, lower infant mortality rates (2) 


\section{Chapter 2}

and better self-rated health (1), there might be a more shady side of larger socioeconomic health inequalities. These findings might be two sides of the same medal; in more egalitarian and socially mobile countries, all socioeconomic status groups might on average enjoy good health, but the highest groups might enjoy even better health, resulting in larger than expected socioeconomic differences in health (11). Noteworthy is that, using Mackenbach's data on average all-cause mortality (4) and similar data from the European Detailed Mortality Database (12) as an indicator of general population health, we could not confirm better population health in the more socially mobile and egalitarian countries (not tabulated). The higher general all-cause mortality in more egalitarian and socially mobile countries might be the result of their successful prevention of infant mortality, resulting in an increased group of 'vulnerable' people surviving childhood (2). The larger than expected socioeconomic health inequalities in more egalitarian and socially mobile countries might also be explained by 'unhealthy homogenisation' and class-related stigmatisation (6-8). First, when upward and downward social mobility depend on health and healthdeterminants, such as personal characteristics like intellectual abilities, it might result in an 'unhealthy homogenisation' of the lower status groups (8). Second, perhaps because of their heightened social mobility, egalitarian countries may promote the meritocratic belief that being upwardly mobile is primarily determined by a person's efforts and abilities and less by the socioeconomic position of the parents. This might result in stigmatisation of people who stay behind in the socioeconomic ranking: they are blamed for not getting ahead due to their low efforts and poor abilities. Feeling stigmatised or discriminated against may have serious (stress-related) health consequences (13). Future studies should try to unravel the relative contribution of 'unhealthy homogenisation' and classrelated stigmatisation to the association between country differences in social mobility and socioeconomic health inequalities.

Some limitations of this study must be considered. First, the sample size was small and varied between analyses; this had its implications for significance testing. The small sample size also limited the possibilities to correct for possible important confounders, such as region- and country-differences in (health) policy (i.e. welfare state), gross domestic product (GDP), lifestyle (e.g. Mediterranean diet), and phase in the epidemiological transition (e.g. cardiovascular disease epidemic or smoking epidemic) $(3,4)$. Second, the measurements of socioeconomic health inequalities had some limitations. We combined measures 
based on different indicators of socioeconomic status; we used occupation (social mobility), education (health inequalities), and income (income inequality). Using different indicators of socioeconomic status may have biased our results to an unknown extent. More in-depth analyses with social mobility, based on education, showed the same pattern of results as social mobility based on occupation (14).

\section{Conclusion}

This study shows that more egalitarian countries are associated with heightened social mobility. It suggests that social mobility and income equality, beside their shiny side of improving population health, might have a shady side of increasing socioeconomic health inequalities. The findings emphasise the importance of taking into account country-level social mobility when interpreting betweencountry differences in socioeconomic health inequalities.

\section{Acknowledgements}

The authors thank Professor Dr. J.P. Mackenbach and Dr. A. Kunst for their useful comments on a previous draft of this article. 


\section{Chapter 2}

\section{References}

1. Eikemo TA, Bambra C, Judge K, Ringdal K. Welfare state regimes and differences in self-perceived health in Europe: a multilevel analysis. Soc Sci Med. 2008;66(11):2281-95.

2. Coburn D. Beyond the income inequality hypothesis: class, neoliberalism, and health inequalities. Soc Sci Med. 2004;58(1):41-56.

3. Mackenbach JP, Kunst AE, Cavelaars AE, Groenhof F, Geurts JJ. Socioeconomic inequalities in morbidity and mortality in western Europe. The EU Working Group on socioeconomic inequalities in health. Lancet. 1997;349(9066):1655-9.

4. Mackenbach JP, Stirbu I, Roskam AJR, Schaap MM, Menvielle G, Leinsalu $\mathrm{M}$, et al. Socioeconomic inequalities in health in 22 European countries. N Engl J Med. 2008;358(23):2468-81.

5. Eikemo TA, Bambra C, Joyce K, Dahl E. Welfare state regimes and income-related health inequalities: a comparison of 23 European countries. Eur J Public Health. 2008;18(6):593-9.

6. Dibben C, Popham F. Are socio-economic groupings the most appropriate method for judging health equity between countries? J Epidemiol Community Health. 2011;65(1):4-5.

7. Mackenbach JP. The persistence of health inequalities in modern welfare states: the explanation of a paradox. Soc Sci Med. 2012;75(4):761-9.

8. Bosma H, Simons A, Groffen D, Klabbers G. Stigmatisation and socioeconomic differences in health in modern welfare states. Eur J Public Health. 2012;22:616-7.

9. Yaish M, Andersen R. Social mobility in 20 modern societies: The role of economic and political context. Soc Sci Res. 2012;41(3):527-38.

10. Organisation for Economic Co-operation and Development (OECD). Income Distribution: Income distribution: inequality, OECD Social Expenditure Statistics (database). 2010 [October 9, 2012]. Available from: http://dx.doi.org/10.1787/data-00199-en.

11. Vågerö D, Erikson R. Socioeconomic inequalities in morbidity and mortality in western Europe. Lancet. 1997;350(9076):516.

12. World Health Organization. European Detailed Mortality Database 2013 [August 6, 2013]. Available from:

http://datanew.euro.who.int/DMDBPHP5/cbparams.php. 
13. Simons AMW, Groffen DAI, Bosma H. Income-related health inequalities: does perceived discrimination matter? Int J Public Health. 2013;58(4):513-20.

14. Hertz T, Jayasundera T, Piraino P, Selcuk S, Smith N, Verashchagina A. The inheritance of educational inequality: International comparisons and fifty-year trends. Be J Econ Anal Poli. 2007;7(2). 



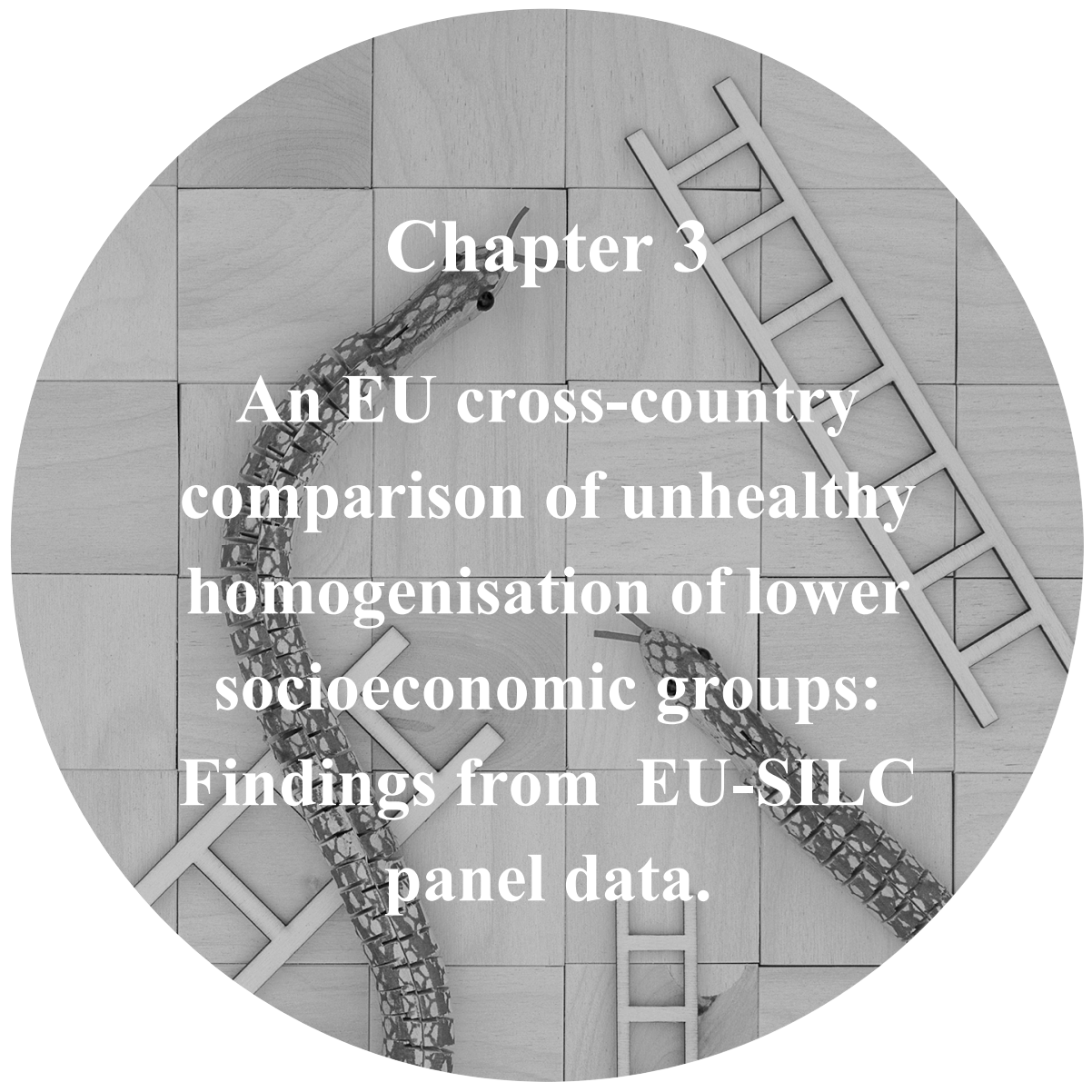

Simons AMW, Koster A and Bosma H. 


\section{Chapter 3}

\section{Abstract}

Background. Health-related selection during social mobility was suggested as an explanation for the paradox of wider than expected socioeconomic health inequalities in the Nordic countries. In these countries the heightened opportunities for upward mobility might have the drawback of creating a larger scope for health selection processes, which might lead to unhealthy homogenisation of the groups with the lowest socioeconomic positions and a wider health gap. In this study we examined the effect of self-assessed health on income mobility and compared these effects in 19 European countries which were different in respect to social mobility.

Methods. Ecological and multilevel analyses were performed using data of more than 55,000 individuals on self-assessed health and income, from $19 \mathrm{Eu}-$ ropean countries (EU-SILC 2007-2010). Country-level social mobility was extracted from occupational data from the ISSP (2009).

Results. Significant health-related income mobility was found in over half of the included countries and the multilevel analyses showed a significant effect of health on income mobility $(\mathrm{B}=759.41, \mathrm{SE}=51.88)$; better health was associated with higher income growth. However, health-related income mobility was not stronger in more socially mobile countries. Corrections for country-specific characteristics (GINI, GPD, and even social protection expenditures) did not change our results.

Conclusions. Our findings suggest that, although significant health-related income mobility has been found in more than half of the countries included in this study, unhealthy homogenisation of lower SEPs was not more common in more mobile countries. Future research might need to assess both homogenisation in terms of cognitive abilities or personality and classism as possible explanations for the remaining puzzle regarding cross-country differences in socioeconomic health inequalities. 


\section{Unhealthy homogenisation}

\section{Introduction}

It is well-known that people at the bottom of the socioeconomic hierarchy face shorter life expectancies and more health problems than people with higher socioeconomic positions (SEP) $(1,2)$. These health inequalities are found worldwide, however, the size of the gaps differ between countries. Mackenbach and colleagues (3) showed - against all expectations - that health inequalities in Europe were not necessarily smaller in more advanced welfare states, such as the Nordic countries; they found the smallest health inequalities in more Southern countries. Later, Mackenbach found similar findings using more recent data (4), just as some other researchers (5-8). To explain the country differences in socioeconomic health inequalities and the paradoxical findings of larger than expected health inequalities in more advanced welfares states, different hypotheses were suggested (9-15). One of these relates to health-related selection during social mobility.

Higher social mobility might indicate that individual SEP becomes less strongly affected by parental SEP and increasingly depends on individual characteristics like one's own health, but also on other, often health-related abilities (e.g. cognitive abilities) and efforts. To the extent that these individual characteristics are health-related, this may cause unhealthy homogenisation of people in the lower socio-economic groups (15-17). Unable to benefit from the provided opportunities that stimulate upward mobility, unhealthy people might end up in a lower SEP than their parents and/or face a loss of income or have less income growth compared to others in better health. At the same time, people with better health might be more often upwardly mobile (e.g. ending up in a higher SEP than their parents or themselves start to earn more money) (9-18).

Social mobility differs between countries, for example, depending on economic development, income inequality, educational policies and social policies (19-21), and therefore the scope for unhealthy homogenisation might differ between countries and welfare states $(15,17)$. Especially in the more advanced welfare states with more social mobility, social stratification might be less a product of reproduced social positions, but more of personal health and healthrelated characteristics, creating a larger health gap between high and low SEP groups (14).

Using longitudinal cross-country data from the EU-Statistics on Income and Living Conditions (EU-SILC) (22) and the International Social Survey Pro- 


\section{Chapter 3}

gramme (23), we 1) examined the effect of self-assessed health on income mobility (i.e. change in income; individual level) and 2) compared these health effects in 19 European countries which are different with respect to social mobility (Figure 1). We expected that, on the individual level, there would be a direct health effect on individual income mobility in all countries. Furthermore, we hypothesized these direct health effects to be stronger in more socially mobile countries - assuming to be the countries with more advanced welfare arrangements - since the scope for health-related selection might be larger in these countries.

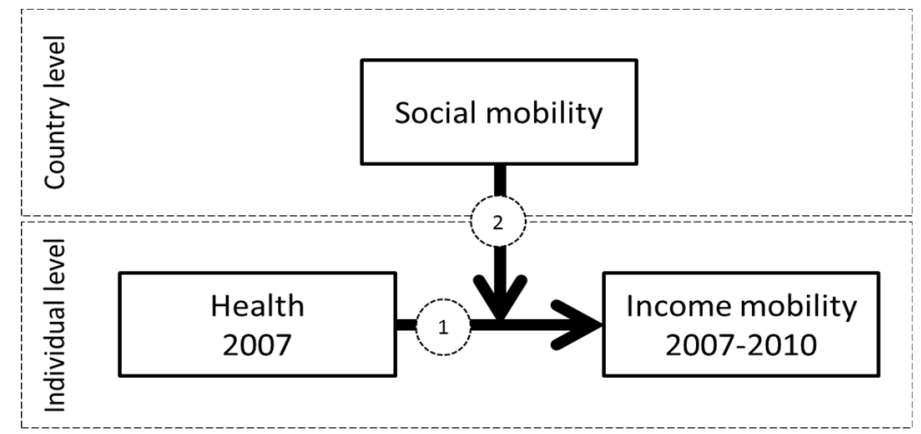

Figure 1 Health-related income mobility and the moderating effect of social mobility

\section{Methods}

\section{Study population}

EU-SILC collects cross-sectional and longitudinal comparative data on income distribution and social inclusion at the household- and individual-level. The research population consist of a representative sample of households and individuals from 27 European countries. EU-SILC has a rotational design; each year a new panel starts and participates for a maximum of four years $(22,24)$. For this study, we included 19 of 27 countries based on their availability of social mobility data. Participants were selected based on their participation in 2007 $(\mathrm{n}=97,785)$. Longitudinal data on personal and household level (2007 \& 2010) was available for 65,287 participants $(n=66.8 \%)$, but 8,984 participants (13.8\%) had to be excluded because of missing data on important variables. The final study population consisted of 56,303 participants (26,118 men (46.4\%)) from 19 countries. The mean age in the population was 47.61 years $(\mathrm{SD}=17.37$, range $=17$ to 78 years). 


\section{Measures}

\section{Health}

Self-rated health was measured using a 5-points Likert scale in 2007. The question was 'How is your health in general?', scored very bad (1), bad (2), fair (3), good (4), or very good $(5)(22,24)$.

\section{Socioeconomic position and individual income mobility}

Individual SEP was based on equivalised income and was measured annually; disposable income was collected at household level, corrected for household size and composition. Individual income mobility was measured by the change in equivalised income between 2007 and 2010 (i.e. equivalised income 2010 minus equivalised income 2007).

\section{Country-level social mobility}

Social mobility data were extracted from the International Social Survey Programme (ISSP) of 2009 (12, 23). Data of participant's (2008) and father's $( \pm 1980)$ occupational status were coded in International Standard Classification of Occupations 1988 scores (ISCO-88) and recoded into the International SocioEconomic Index of occupational status 2008 (ISEI-08) with use of a conversion tool developed by Ganzeboom and Treiman $(12,25)$. Country-level social mobility was calculated by 1 - the log correlation of participant's and father's ISEI08 score $(12,26)$; higher scores indicate higher social mobility within a country.

\section{Covariates}

Potential confounders on the individual-level were: age in 2007 (in years) and sex. Income inequality in 2007 and 2010 (Gini coefficient) (27) and gross domestic product in 2007 and 2010 (GDP per cap constant US \$)(27) were considered separate covariates.

\section{Statistical analysis}

First, for the ecological analysis, country-specific individual effects of health (2007) on income mobility (2007-2010) were assessed by using linear regression analysis, adjusted for equivalised income in 2007, age, and sex. Second, by using the coefficients of the regression above, associations between country-level social mobility and health-related income mobility were plotted 


\section{Chapter 3}

and a Pearson's correlation was computed. Third, the moderating effect of country-level social mobility on the relation between health and income mobility was assessed using multilevel analyses with individuals $(\mathrm{n}=56,303)$ as level 1 and country $(n=19)$ as level 2 . These analyses were adjusted for individual covariates age, sex and equivalised income in 2007. Separate adjustments were made for country-level GDP $(2007+2010)$ and GINI $(2007+2010)$. Fourth, we performed sensitivity analyses to check the robustness of our findings, by using a dichotomised health outcome 'less than good health' and SEP outcomes 'ending up in lowest income quintile 2010' and 'less than median change in income' in the ecological analyses, and by using standardised variables in both ecological and multilevel analyses. All analyses were performed with IBM SPSS Statistics for Windows, Version 24.0 (IBM corp., Armonk, NY).

\section{Results}

The sample size in the 19 selected countries ranged from 518 participants in Iceland to 9,766 participants in France (Table 1). The distribution of men and women and mean age were similar in all countries. Mean equivalised income differed between countries, with Iceland and Norway having the highest mean income and Bulgaria and Latvia the lowest. Iceland was the only country with a negative mean change in income between 2007 and 2010. On average, people assessed their own health as better than fair (3); people in Latvia reported the poorest health status $(\mathrm{M}=3.14, \mathrm{SD}=0.86)$ and people in Iceland the best $(\mathrm{M}=$ $4.25, \mathrm{SD}=0.86$ ). 


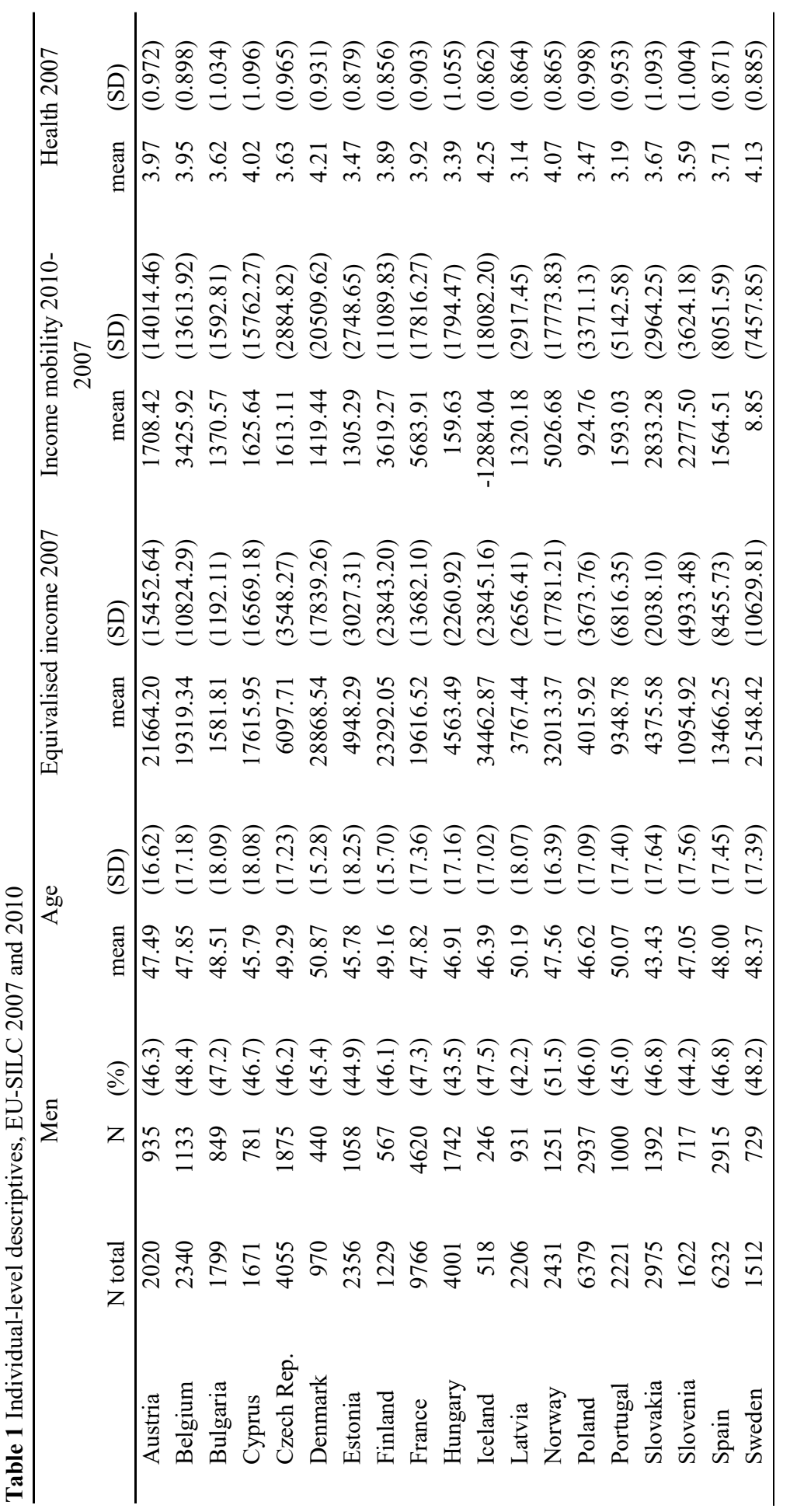




\section{Chapter 3}

Country-level descriptives are shown in Table 2. In Portugal and Cyprus were the least socially mobile countries, while Estonia and the Nordic countries were the most mobile countries.

Table 2 Country-level descriptives

\begin{tabular}{llllll}
\hline & Social mo- & GDP & GDP & GINI & GINI \\
& bility & 2007 & 2010 & 2007 & 2010 \\
\hline Austria & 0.582 & 47240.53 & 46657.06 & 30.60 & 30.30 \\
Belgium & 0.625 & 45013.07 & 44380.24 & 29.20 & 28.40 \\
Bulgaria & 0.657 & 6625.03 & 6843.26 & 36.10 & 35.70 \\
Cyprus & 0.518 & 32236.59 & 30818.46 & 31.10 & 31.50 \\
Czech Rep. & 0.690 & 20104.77 & 19764.02 & 26.00 & 26.60 \\
Denmark & 0.748 & 61174.55 & 58041.41 & 26.20 & 27.30 \\
Estonia & 0.820 & 17627.03 & 14638.60 & 31.20 & 32.00 \\
Finland & 0.780 & 49239.19 & 46202.42 & 28.30 & 27.70 \\
France & 0.628 & 41696.69 & 40703.34 & 32.40 & 33.70 \\
Hungary & 0.577 & 13648.64 & 13025.53 & 27.90 & 29.40 \\
Iceland & 0.734 & 46695.21 & 41676.45 & 29.50 & 26.20 \\
Latvia & 0.725 & 13590.50 & 11326.22 & 37.50 & 35.00 \\
Norway & 0.759 & 91594.18 & 87646.75 & 27.10 & 25.70 \\
Poland & 0.615 & 11322.05 & 12599.52 & 33.50 & 33.20 \\
Portugal & 0.511 & 22817.32 & 22538.65 & 36.80 & 35.80 \\
Slovakia & 0.727 & 15868.80 & 16600.61 & 24.70 & 27.30 \\
Slovenia & 0.660 & 24673.44 & 23437.47 & 24.40 & 24.90 \\
Spain & 0.605 & 32459.92 & 30736.00 & 33.10 & 35.30 \\
Sweden & 0.754 & 53421.02 & 52076.26 & 26.40 & 26.50 \\
\hline
\end{tabular}

\section{Ecological analyses}

Table 3 shows the unstandardized regression coefficient of the association of self-rated health with income mobility between 2007 and 2010 (i.e. healthrelated income mobility), adjusted for income, sex and age in 2007. Except for Iceland, all health effects went in the same direction; better health was related to a higher income growth between 2007 and 2010. These direct health effects were statistically significant for more than half of the countries and were strongest in Cyprus, Austria and Norway. The smallest health effects were found in Czech Republic, Estonia and Latvia. 
Table 3 Unstandardized regression coefficients self-rated health on income mobility 2007-2010, EU-SILC

\begin{tabular}{lrl} 
& \multicolumn{2}{c}{ Health-related income mobility ab } \\
\hline Austria & $\mathrm{B}^{* *}$ & $(\mathrm{SE})$ \\
Belgium & $1750.80^{* *}$ & $(275.61)$ \\
Bulgaria & $957.74^{*}$ & $(334.79)$ \\
Cyprus & $206.61^{* *}$ & $(46.87)$ \\
Czech Rep. & $1528.83^{* *}$ & $(298.35)$ \\
Denmark & $33.08^{*}$ & $(56.79)$ \\
Estonia & $879.98^{*}$ & $(573.54)$ \\
Finland & $132.62^{*}$ & $(76.27)$ \\
France & $798.02^{*}$ & $(401.53)$ \\
Hungary & $1479.32^{* *}$ & $(212.78)$ \\
Iceland & $193.19^{* *}$ & $(29.04)$ \\
Latvia & $-166.72^{*}$ & $(528.08)$ \\
Norway & $137.85^{* *}$ & $(88.57)$ \\
Poland & $2446.40^{* *}$ & $(381.99)$ \\
Portugal & $269.11^{* *}$ & $(42.47)$ \\
Slovakia & $267.24^{*}$ & $(141.17)$ \\
Slovenia & $161.80^{*}$ & $(64.53)$ \\
Spain & $159.84^{* *}$ & $(105.16)$ \\
Sweden & $717.58^{* *}$ & $(127.97)$ \\
\hline
\end{tabular}

*P-value $<0.005,{ }^{* *}$ P-value $<0.001,{ }^{a}$ Income mobility $=$ equivalised income 2010 - equivalised income 2007 ,

${ }^{\mathrm{b}}$ corrected for age, gender and income 2007

Based on the estimated coefficients for the health-related income mobility and the level of social mobility in Table 2, Figure 2 shows the scatterplot of the association between both characteristics. The association was negative, indicating less health-related income mobility in more mobile countries, but not statistically significant $(r=-0.147, \mathrm{p}$-value $=0.55)$.

\section{Multilevel analyses}

Table 3 shows the results of the multilevel analyses examining the effect of health on income mobility and the moderating effect of social mobility. In model 1, the effect of health on income mobility between 2007 and 2010 was statistically significant $(\mathrm{B}=759.41, \mathrm{SE}=51.88)$ : better health led to more income growth. Model 3 tested whether health had a different effect depending on countries' social mobility; this interaction was not statistically significant. Separate adjustments in the analyses for GDP (2007 and/or 2010) and GINI (2007 and/or 2010) did not affect the results. 


\section{Chapter 3}

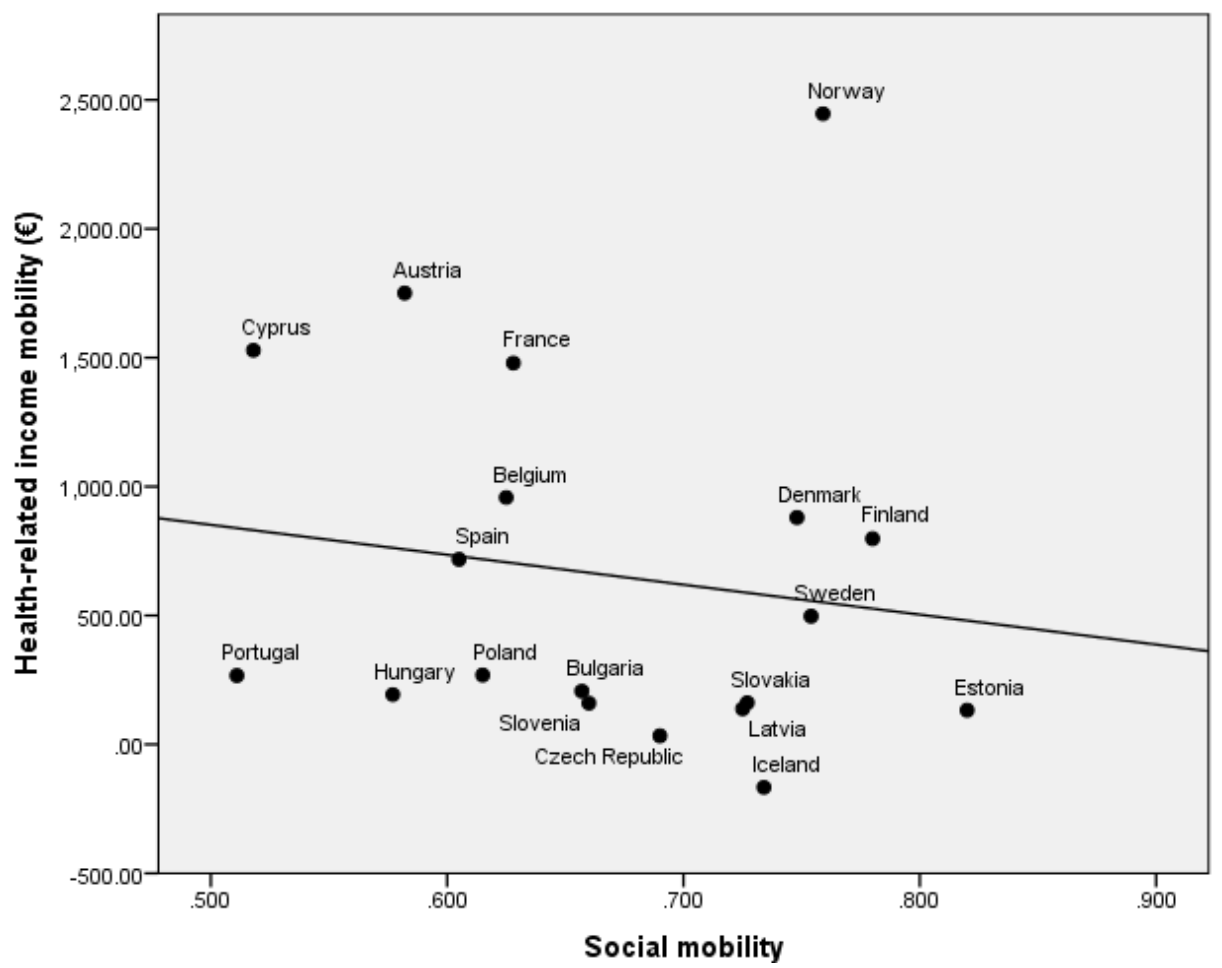

Figure 2 Scatterplot of social mobility with health-related income mobility $(r=-0.147$, p-value $=$ $0.547)$.

Table 4 Multilevel model on Income mobility 2007-2010.

Income mobility 2007-2010 a

\begin{tabular}{llrl} 
& & B & $(\mathrm{SE})$ \\
\hline Model 1 $^{\text {bc }}$ & Health & $759.41^{* *}$ & $(51.88)$ \\
Model 2 $^{\mathrm{d}}$ & Health & $759.29^{* *}$ & $(51.88)$ \\
& Social mobility & 5593.58 & $(12724.90)$ \\
Model $^{\mathrm{e}}$ & 388.45 & $(391.54)$ \\
& Health & 3456.01 & $(12909.97)$ \\
& Social mobility & 573.48 & $(600.15)$ \\
\hline
\end{tabular}

*P-value $<0.005,{ }^{*} *$ P-value $<0.001$, income mobility $=$ equivalised income 2010 - equivalised income 2007 , ${ }^{b}$ Model 1: health 2007, age, gender and equivalised income 2007, ${ }^{\mathrm{e}}$ Interclass Correlation $=18 \%$, ${ }^{\mathrm{d}}$ Model 2: model $1+$ social mobility, ${ }^{e}$ Model 3 : model $2+$ interaction health*social mobility

\section{Sensitivity analyses}

Using standardised variables confirmed that health selection was not stronger in more socially mobile countries. Additional ecological analyses with dichotomous outcomes showed that in most countries the probability of ending up in the worst income quintile in 2010 or having a change of income of less than the 


\section{Unhealthy homogenisation}

median change in income (country-specific) was higher for people who reported less than good health in 2007. Again, the corresponding odds ratios were, however, not stronger in countries with more social mobility.

\section{Discussion}

The aim of this study was 1) to examine the effect of self-assessed health on income mobility (individual level) and 2) to compare these health effects in 19 European countries differing in social mobility. As expected, in 12 out of 19 countries we found significant direct health effects on income mobility after three years of follow-up (2007-2010): better health was associated with higher income growth, less healthy people were less upwardly socially mobile than their healthier counterparts. Although we expected that this effect would be stronger in more socially mobile countries, our results did not confirm our expectations; country-level direct health selection effects were not stronger in more socially mobile countries. Our findings thus seem to suggest that country differences in direct health selection (i.e. unhealthy homogenisation) are an unlikely explanation for the paradox of wider than expected socioeconomic health inequalities in more socially mobile countries, such as the Nordic countries.

Bambra (10) and McCartney et al. (9) earlier already questioned the hypothesis of health selection during social mobility as an explanation for the wider than expected health inequalities in the more advanced welfare states. They argued that more advanced welfare states also have better social protection arrangements (e.g. protection against income loss for sick employees) that might suppress the effects of poor health and disadvantaged health-determinants (e.g. cognitive abilities) on income mobility. Also Campos-Matos and Kawachi found that the Nordic countries had the lowest health-related upward mobility and suggested that their finding could be explained by the protective policies in these countries (28). In, a post hoc analysis, we therefore adjusted in both the ecological analyses and the multilevel analysis (Table 3, interaction model 3) for countries' public spending on social protection of sick employeesmeasured as public spending on incapacity-related benefits as a percentage of GDP (29). Our findings indicated that the association between social mobility and health-related income mobility was not suppressed by social protection. 


\section{Chapter 3}

This was possibly due to an unexpected positive correlation (not significant) between spending on social protection and health-related income mobility $(\mathrm{r}=0.372)$.

In this study we looked at the relation between social mobility and unhealthy homogenisation. We did not assess the effects of unhealthy homogenisation on socioeconomic health inequalities. Although we assumed that health inequalities would widen because of health selections processes, in the literature there is no consensus about selection processes widening health inequalities. Some authors suggested that selection processes would even narrow the health gap $(13,30)$ : upwardly mobile people will be healthier than the group they leave, but less healthy than the group they end up in, and downwardly mobile people will be less healthy than the group they leave but healthier than the group they end up in.

Although our results seemed to suggest that unhealthy homogenisation (i.e. direct health selection) is an unlikely explanation for the paradox-when assuming that health selection effects widen health inequalities-we think that the selection mechanism could still explain part of the paradox via indirect health selection effects. This process of indirect health selection might cause a homogenisation of people with lower cognitive abilities, less favourable personalities or other disadvantaged health-related determinants in the lower SEP groups. Since these determinants (e.g. low cognitive ability or IQ) are related to poor health outcomes, homogenisation of these determinants in the lower SEP groups might widen the health gap $(14-17,31,32)$. Next to the selection mechanism, we would like to suggest classism as a possible explanation for the paradox. Classism (i.e. the marginalisation of lower SEP groups) might be more common in countries with more advanced welfare arrangements and more equal opportunities for social mobility; when society offers you all opportunities to live a successful life, ending up at the bottom of the socioeconomic ladder becomes a personal issue and individual responsibility (17, 33-35). Experiencing classism can have serious consequences for health (34) and individual mobility (e.g. lower educational achievements because of stereotype threats) (36). Therefore, it might also play a role in the persisting and even widening socioeconomic health inequalities and explain part of the paradox. Further international comparative studies into indirect health selection effects and classism, and their relation with county differences in socioeconomic health inequalities are needed. 


\section{Methodological considerations}

The strength of this study is its longitudinal design and the comparability of individual data from 19 countries with sample sizes mostly over 1000 people. However, some limitations of this study must also be considered. First, because of missing data on health and income in 2007 and 2010 we lost $42 \%$ of the initial sample. The largest part of this loss was due to the rotational design of EUSILCs data (33.2\%). The final sample differed from the participants that were excluded and may therefore not be fully representative anymore: compared to the excluded participants, the final sample was older (47.61 vs 45.23 years), included fewer men (46.4\% vs 49.4\%), reported better health (3.70 vs 3.66) and had a higher mean income growth (2273.79 vs 1812.89). Although these differences were statistically significant, we do not think they affected the conclusion of our results; the health effects might have been stronger, but we are unsure about how it might have affected the moderating effect of social mobility. Second, the unavailability of international comparable data limited the possibilities of our study. We would have preferred to include measures to also assess indirect health effects (i.e. personal characteristics like personality or cognitive ability), to additionally assess individual intergenerational social mobility (i.e. parental SEP), and to assess other health measures and indicators of SEP (e.g. health in childhood and education).

\section{Conclusion}

Our findings suggest that, although significant health-related income mobility has been found in more than half of the countries included in this study, unhealthy homogenisation of lower SEPs was not more common in more mobile countries. Future research might need to assess both homogenisation in terms of cognitive abilities or personality and classism as possible explanations for the remaining puzzle regarding cross-country differences in socioeconomic health inequalities. 


\section{Chapter 3}

\section{References}

1. Mackenbach JP. Health inequalities: Europe in profile. Produced by COI for the Dept. of Health.; 2006.

2. Wilkinson RG, Pickett K. The Spirit Level: Why Equality is Better for Everyone. New York: Penguin Group; 2010.

3. Mackenbach JP, Kunst AE, Cavelaars AE, Groenhof F, Geurts JJ. Socioeconomic inequalities in morbidity and mortality in western Europe. The EU Working Group on socioeconomic inequalities in health. Lancet. 1997;349(9066):1655-9.

4. Mackenbach JP, Stirbu I, Roskam AJR, Schaap MM, Menvielle G, Leinsalu $\mathrm{M}$, et al. Socioeconomic inequalities in health in 22 European countries. N Engl J Med. 2008;358(23):2468-81.

5. Eikemo TA, Bambra C, Joyce K, Dahl E. Welfare state regimes and income-related health inequalities: a comparison of 23 European countries. Eur J Public Health. 2008;18(6):593-9.

6. Popham F, Dibben C, Bambra C. Are health inequalities really not the smallest in the Nordic welfare states? A comparison of mortality inequality in 37 countries. J Epidemiol Community Health. 2013;67(5):412-8.

7. Eikemo TA, Huisman M, Bambra C, Kunst AE. Health inequalities according to educational level in different welfare regimes: a comparison of 23 European countries. Sociol Health Illn. 2008;30(4):565-82.

8. McNamara CL, Toch-Marquardt M, Balaj M, Reibling N, Eikemo TA, Bambra C. Occupational inequalities in self-rated health and noncommunicable diseases in different regions of Europe: findings from the European Social Survey (2014) special module on the social determinants of health. Eur J Public Health. 2017;27(suppl_1):27-33.

9. McCartney G, Collins C, Mackenzie M. What (or who) causes health inequalities: Theories, evidence and implications? Health Policy. 2013;113(3):221-7.

10. Bambra C. Health inequalities and welfare state regimes: theoretical insights on a public health 'puzzle'. J Epidemiol Community Health. 2011;65(9):740-5. 
11. Huijts T, Eikemo TA. Causality, social selectivity or artefacts? Why socioeconomic inequalities in health are not smallest in the Nordic countries. Eur J Public Health. 2009;19(5):452-3.

12. Simons AMW, Groffen DAI, Bosma H. Socio-economic inequalities in all-cause mortality in Europe: an exploration of the role of heightened social mobility. Eur J Public Health. 2013;23(6):1010-2.

13. Boyle PJ, Norman P, Popham F. Social mobility: evidence that it can widen health inequalities. Soc Sci Med. 2009;68(10):1835-42.

14. Mackenbach JP. The persistence of health inequalities in modern welfare states: the explanation of a paradox. Soc Sci Med. 2012;75(4):761-9.

15. Dibben C, Popham F. Are socio-economic groupings the most appropriate method for judging health equity between countries? J Epidemiol Community Health. 2011;65(1):4-5.

16. Mackenbach JP. Nordic paradox, Southern miracle, Eastern disaster: persistence of inequalities in mortality in Europe. Eur J Public Health. 2017;27(suppl_4):14-7.

17. Bosma H, Simons A, Groffen D, Klabbers G. Stigmatisation and socioeconomic differences in health in modern welfare states. Eur $\mathrm{J}$ Public Health. 2012;22:616-7.

18. West P. Rethinking the health selection explanation for health inequalities. Soc Sci Med. 1991;32(4):373-84.

19. Breen R, Jonsson JO. Inequality of opportunity in comparative perspective: recent research on educational attainment and social mobility. Annu Rev Sociol. 2005;31(1):223-43.

20. Organisation for Economic Co-operation and Development (OECD). A Family Affair: Intergenerational Social Mobility Across OECD Countries Economic Policy Reforms 2010 Going for Growth: OECD Publishing; 2010. p. 181-98.

21. Andrews D, Leigh A. More inequality, less social mobility. Appl Econ Lett. 2009;16(15):1489-92.

22. European Commission. Description of target variables: Cross-sectional and Longitudinal 2008 operation (EU-SILC). 2010.

23. ISSP Research Group. International Social Survey Programme: Social Inequality IV - ISSP 2009. Cologne: GESIS Data Archive; 2012.

24. European Commission. European Union Statistics on Income and Living Conditions: microdata longitudinal UDB SILC 2010 rev. 2. 2013. 


\section{Chapter 3}

25. Ganzeboom HBG, Treiman DJ. International Stratification and Mobility File: Conversion Tools Amsterdam: Department of Social Research Methodology; [October 24, 2012]. Available from: http://www.harryganzeboom.nl/ismf/index.htm.

26. Blanden J. How much can we learn from international comparisons of intergenerational mobility? London: Centre for the Economics of Education; 2009.

27. The World Bank. World Development Indicators 2012 [September 26, 2017]. Available from:

http://databank.worldbank.org/data/reports.aspx?source=worlddevelopment-indicators.

28. Campos-Matos I, Kawachi I. Social mobility and health in European countries: Does welfare regime type matter? Soc Sci Med. 2015;142:2418.

29. Organisation for Economic Co-operation and Development (OECD). Social Expenditure: Aggregated data 2017 [September 26, 2017]. Available from: http://dx.doi.org/10.1787/data-00166-en.

30. Bartley M, Plewis I. Does health-selective mobility account for socioeconomic differences in health? Evidence from England and Wales, 1971 to 1991. J Health Soc Behav. 1997:376-86.

31. Mackenbach JP. New trends in health inequalities research: now it's personal. Lancet. 2010;376(9744):854-5.

32. Foverskov E, Holm A. Socioeconomic inequality in health in the British household panel: Tests of the social causation, health selection and the indirect selection hypothesis using dynamic fixed effects panel models. Soc Sci Med. 2016;150(Supplement C):172-83.

33. Simons AMW, Groffen DAI, Bosma H. Income-related health inequalities: does perceived discrimination matter? Int J Public Health. 2013;58(4):513-20.

34. Simons AMW, Koster A, Groffen DAI, Bosma H. Perceived classism and its relation with socioeconomic status, health, health behaviours, and perceived inferiority: the Dutch LISS-panel. Int J Public Health. 2017;62(4):433-40.

35. De Botton A. Statusangst [Status anxiety]. Amsterdam: Olympus 2004. 


\section{Unhealthy homogenisation}

36. Croizet JC, Claire T. Extending the concept of stereotype threat to social class: the intellectual underperformance of students from low socioeconomic backgrounds. Pers Soc Psychol Bull. 1998;24(6):588-94. 



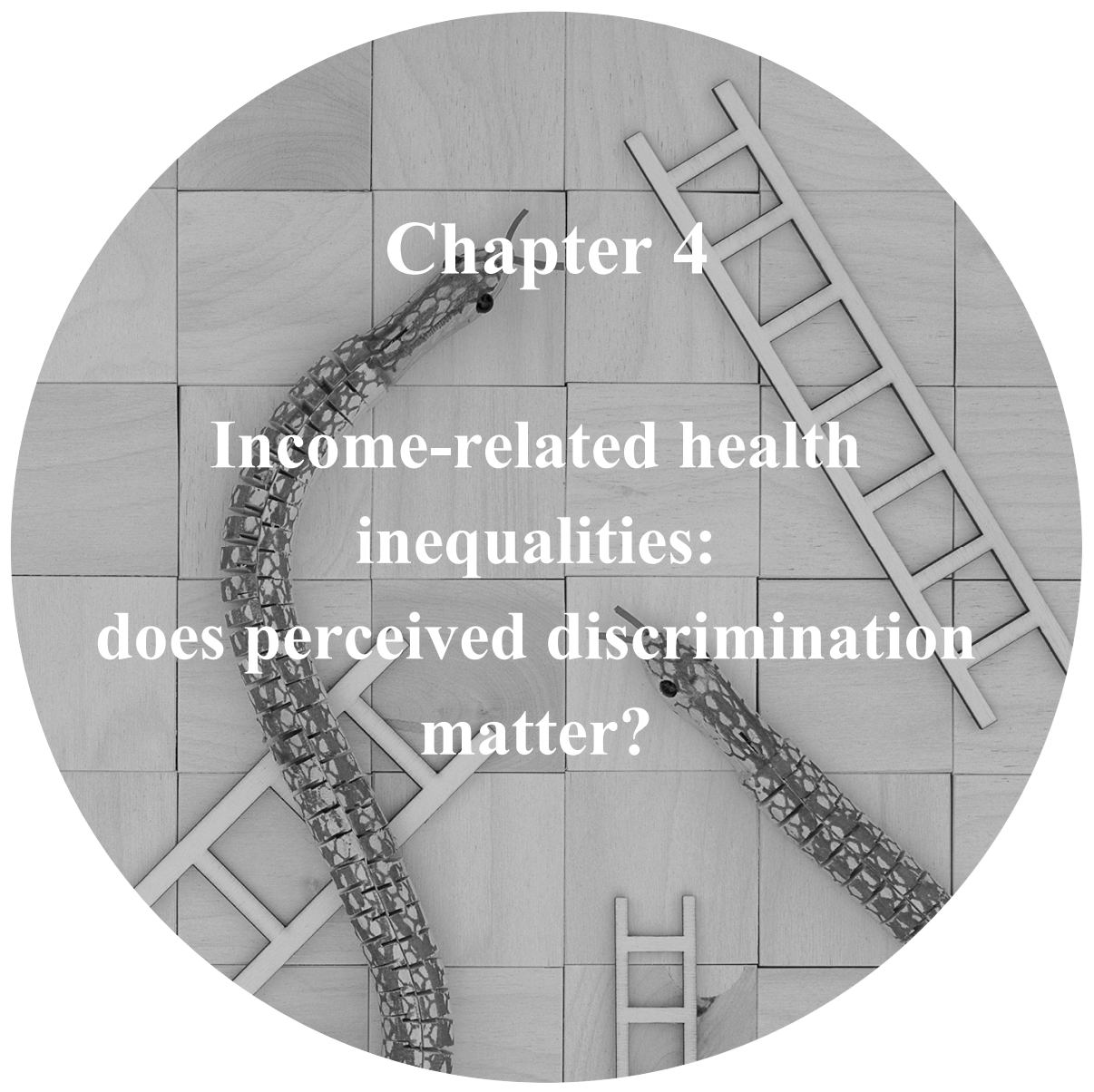

Published as:

Simons AMW, Groffen DAI, Bosma H. Income-related health inequalities: does perceived discrimination matter? Int J Public Health. 2013;58(4):513-20. 


\section{Chapter 4}

\section{Abstract}

Background. Because of their meritocratic ideology, Western countries might promote the belief that every individual is responsible for his or her socioeconomic position. These beliefs might enhance discrimination which, in turn, might affect health. Therefore, the aim of the study was to investigate the role of perceived discrimination within income-related health inequalities.

Methods. Two-year follow-up data (2008-2010) from the Dutch Longitudinal Internet Studies for the Social sciences panel $(\mathrm{N}=2,139)$ were used to examine the relation between income, perceived discrimination, and self-rated health and feeling hindered by health problems.

Results. Results showed that poor health was more prevalent in the low income and in the discriminated group. Participants from the low income group were also more likely to perceive discrimination $(\mathrm{OR}=1.57,95 \% \mathrm{CI}=1.03-2.42)$. However, there was no substantial evidence for a mediating effect of perceived discrimination on the income-health association.

Conclusions. The results emphasise the importance of a more in-depth study of discrimination in relation to socioeconomic health inequalities. Since ethnicity was a major confounder it is recommended to take account of the complex interplay between discrimination and both the socioeconomic and ethnic background. 


\section{Health inequalities and perceived discrimination}

\section{Introduction}

Health inequalities between people from lower and higher socioeconomic status (SES) groups are a persisting worldwide problem (1-5). Researchers have sought to explain the differences by studying the contribution of behavioural risk factors (e.g. smoking), psychosocial factors (e.g. perceived control), unfavourable material factors (e.g. housing conditions), and biological factors (e.g. inflammation markers). However, these factors cannot fully explain the health gap between low and high SES $(6,7)$. Given that lower SES groups might perceive themselves more stigmatised and discriminated against than higher SES groups, a largely neglected psychosocial pathway might be via discrimination and stigmatisation (8-13).

Based on the premises that financial success go to the ones who demonstrate the largest efforts and capabilities (i.e. merits), living in Western meritocratic countries might promote the belief that people at the bottom of the socioeconomic hierarchy are themselves responsible for their adverse position: they just 'did not work hard enough' or 'did not have the personal skills' to climb up the social ladder $(12,14-16)$. Believing in such internal attributions might possibly enhance discrimination and stigmatisation of people at the bottom of the socioeconomic hierarchy $(13,17)$. Status anxiety which concerns the fear of what others think of us when we do not meet the ideal that is expected by society (e.g. to be successful, to have a good job or to earn enough money) is closely related to these discriminatory and stigmatising processes (16). Stigmatisation and discrimination are also ways of symbolic violence by demonstrating superiority and preventing people with lower financial resources from improving their situation (18), thus contributing to a self-fulfilling prophecy by keeping people in stigmatised and discriminated positions (e.g. by withholding well-paid jobs to people from lower status groups); this, in turn, will further "confirm" their stigma (14).

Discrimination and stigmatisation can cause serious physical and psychological health problems $(10,19-22)$. One of the mechanisms through which perceived discrimination might affect health might be via chronic stress and its direct physiological consequences, such as increasing stress response hormones secretion ('allostatic load'), hypertension, impairing cognition, and inhibiting digestion, tissue repair, and immune function $(23,24)$. Additionally or alternatively, perceived discrimination - perhaps because of reduced self-control and 


\section{Chapter 4}

self-regulation (25) - might promote poor health behaviours, such as smoking, overeating, physical inactivity, and severe alcohol consumption $(23,26,27)$. These behaviours, in turn, can further promote stigmatisation and discrimination (e.g. stigmatisation of smokers and people with overweight) and result in a genuine negative spiral relating low socioeconomic status, discrimination, and poor health (behaviours) (28).

For this study, longitudinal data from 2,139 Dutch participants from the Longitudinal Internet Studies for the Social sciences panel (LISS panel) were used to answer the following research questions: 1) do people with low incomes more often perceive themselves discriminated against? 2) do people with low incomes and people who perceived themselves discriminated against more often report poor health?, and 3) can perceived discrimination explain the health gap between the lowest and highest income group?

\section{Methods}

\section{Study population}

The LISS panel is the core element of the Measurement and Experimentation in the Social Sciences project (MESS) of CentERdata. This panel is a representative sample of Dutch individuals (age 16 years and older), who participate in monthly Internet surveys (29). More information about the LISS panel can be found on www.lissdata.nl. In November 2008, 5,961 LISS panel members, including members of the same household, completed a baseline questionnaire. In December 2008, one household member per household $(n=4,788)$ was randomly selected to participate in a questionnaire including questions about perceived discrimination. The questionnaire was completed by 3,217 participants (67.2\%). After two years of follow-up, 867 participants were lost to follow-up (27\%) and longitudinal data were available for 2,350 participants, of whom 211 participants $(9 \%)$ were excluded because of missing data on important variables. The final study population consisted of 2,139 participants (969 (45.3\%) men and 1170 women). The mean age in the population was 50.45 years $(\mathrm{SD}=15.28$, range $=18$ to 88 years), $57.5 \%$ of the participants were married, and 1,905 (89.1\%) participants were of Dutch origin. 


\section{Health inequalities and perceived discrimination}

\section{Measures}

\section{Health outcomes}

In November 2008 and 2010 self-rated health was measured using a 5-point Likert scale with the question 'How would you describe your health, generally speaking?' $(1=$ poor, $5=$ excellent). Self-rated health was dichotomised defining poor and moderate health as 'less than good health' (1). Three additional questions were 'To what extent did your physical health or emotional problems hinder your daily activities over the past month?', 'To what extent did your physical health or emotional problems hinder your social activities over the past month?', and 'To what extent did your physical health or emotional problems hinder your work over the past month, for instance in your job, the housekeeping, or in school?' ( $1=$ very much, $5=$ not at all). These variables were combined in a 'feeling hindered by health problems' scale (Cronbach's alpha $=.88$ in both 2008 and 2010). 'Feeling hindered by health problems', computed as the mean across the three items, was dichotomised by defining those scoring 3 or lower as feeling hindered by health problems (1).

\section{Income}

The net monthly household income was based upon the sum of the personal net incomes of all household members (30). Equivalent net income, which takes account of the number of adults and children that had to live from the household income, was computed by dividing the net household income by an equivalence factor (31). The equivalence factor was: 1 (the first adult) $+0.5 *$ the number of extra adults that had to live from the household income $+0.3 *$ the number of children below the age of 18 that had to live from the household income. Equivalent net income was divided into three categories based on tertiles $(<€ 1333.33$ $=$ low income group, $€ 1333.33-€ 1937.83$ = moderate income group, and $>$ $€ 1937.83$ = high income group (reference category)).

\section{Perceived discrimination}

In 2008, participants were asked: 'Would you describe yourself as being a member of a group that is discriminated against in this country?' (yes $=1, n o=$ $0)$. 


\section{Chapter 4}

\section{Covariates}

Potential confounders were: age as measured in November 2008 (in years), gender $(0=$ man, $1=$ woman $)$, ethnicity (Dutch (= reference category), immigrant with Western background, and immigrant with non-Western background) and marital status ( $1=$ married, $0=$ not married). Additional analyses were adjusted for: smoking $(1=$ yes, $0=$ no) and body mass index $(B M I)$ calculated as weight $(\mathrm{kg})$ divided by height $(\mathrm{m})$ squared, and categorised into four categories $(<18.5=$ underweight, 18.5-24.9= normal weight (reference category), 25-29.9= overweight, and $>30=$ obese) .

\section{Statistical analysis}

First, $\mathrm{Chi}^{2}$ tests were computed to examine differences in self-rated health and feeling hindered by health problems by income and perceived discrimination. Second, logistic regression was performed to examine the effect of income on perceived discrimination. To find out why perceived discrimination was more common in lower income groups, separate analyses were done to examine the separate contribution of age, gender, ethnicity, and marital status. This was done by looking at the extent to which the odds ratio for low and moderate income decreased after introducing these covariates into the model. Mediation was assessed by comparing the odds ratio before and after control for covariate of interest: $\left(\mathrm{OR}_{\text {Model1 }}-\mathrm{OR}_{\text {Model } 2}\right) /\left(\mathrm{OR}_{\text {Model1 }}-1\right) * 100$. More than $10 \%$ change in effect was used as a criteria for mediation (32). Additionally, separate analyses were done to examine the contribution of the health indicators, smoking and BMI to the income - perceived discrimination association. Thirdly, logistic regression analyses were done to estimate the effect of perceived discrimination on self-rated health and feeling hindered by health problems. Separate analyses were carried out to examine the contribution of income, age, gender, marital status and ethnicity to the perceived discrimination - health outcome association. Fourthly, the effect of income on self-rated health and feeling hindered by health problems, controlling for age, gender, ethnicity, and marital status, was estimated, as well as the mediating effect by perceived discrimination. Finally, sensitivity analyses were performed by using five income groups based on quintiles instead of three (to create more extreme contrasts), by using linear regression analyses with continuous outcome measures, by examining the extent of mediation in 2008 cross-sectional data, by examining whether findings were similar when using persons' educational level instead of their income level, and 


\section{Health inequalities and perceived discrimination}

- to test the robustness across sub-groups - by testing interactions between income, ethnicity, age, gender, and perceived discrimination. Statistical Package for the Social Sciences (SPSS) version 17 was used for the analyses.

\section{Results}

In the total sample, $135(6.3 \%)$ participants perceived themselves discriminated against (Table 1). Reports of perceived discrimination varied across income groups: $7.9 \%$ of the low income group, $5.8 \%$ of the moderate income group, and $5.2 \%$ of the high income group (not tabulated). Participants from the low income group and participants who perceived themselves discriminated against were twice as likely to report less than good health and feeling hindered by health problems than participants from the high income group or participants who perceived no discrimination, respectively (all p-values $<.05$ ).

Table 1 Distribution of less than good health and feeling hindered by health problems within income groups and discriminated groups. Longitudinal Internet Studies for the Social sciences panel, the Netherlands, 2008-2010

\begin{tabular}{|c|c|c|c|c|c|}
\hline & \multirow[b]{2}{*}{ Total N } & \multicolumn{2}{|c|}{$\begin{array}{l}\text { Less than good } \\
\text { health }\end{array}$} & \multicolumn{2}{|c|}{$\begin{array}{l}\text { Feeling hindered by health } \\
\text { problems }\end{array}$} \\
\hline & & $\mathrm{N}$ & $\%$ & $\mathrm{~N}$ & $\%$ \\
\hline Total sample & 2,139 & 387 & $(18.1)$ & 333 & $(15.6)$ \\
\hline \multicolumn{6}{|c|}{ Income (2008) } \\
\hline High & 713 & 91 & $(12.8)^{a}$ & 69 & (9.7) \\
\hline Moderate & 720 & 135 & $(18.8)$ & 109 & $(15.2)$ \\
\hline Low & 706 & 161 & $(22.8)$ & 155 & $(22.0)$ \\
\hline \multicolumn{6}{|c|}{ Perceived discrimination (2008) } \\
\hline No & 2,004 & 346 & (17.3) & 292 & (14.6) \\
\hline Yes & 135 & 41 & $(30.4)$ & 41 & $(30.4)$ \\
\hline
\end{tabular}

${ }^{\mathrm{a}}$ Bold $=$ P-value $<.05$ (Pearsons Chi-square)

The low income group had a 1.57 higher odds of perceiving discrimination (95\% CI 1.03-2.42) than the high income group (Table 2). The adverse effect of income on perceived discrimination was mainly due to the higher number of immigrants in the low income group. After control for ethnicity, the odds ratio for low income was still 1.33, but lost its significance (95\% CI .86-2.07). Detailed, not tabulated analyses revealed that there were more immigrants with 


\section{Chapter 4}

non-Western backgrounds in the lower income groups and more perceived discrimination in immigrants compared to the non-immigrants. A higher prevalence of health problems, particularly feeling hindered by health problems, in the lower income group also contributed substantially to the relation between income and perceived discrimination (Table 2), even when corrected for ethnicity (not tabulated). Although smoking was more prevalent in the lower income group $(\mathrm{p}=0.010)$, it did not contribute to more frequent reports of perceived discrimination in the low income groups. BMI was not associated with income group and thus could not "explain" why perceived discrimination was more prevalent in the lower income group.

Over a two-year follow-up period, participants perceiving discrimination had a 1.58 higher odds (95\% CI 1.00-2.48) of feeling hindered by health problems (Table 3). For feeling hindered by health problems, controlling for covariates decreased the effect of perceived discrimination by more than $30 \%$. This decrease of effect was mainly due to the higher number of immigrants in the discriminated group: the effect of perceived discrimination decreased by $37.3 \%$. Perceived discrimination was not significantly related to self-rated less than good health.

Over a period of 2 years, participants from the low income group were significantly more likely to rate their health as less than good $(\mathrm{OR}=1.56,95 \%$ CI 1.11-2.19) and to report feeling hindered by health problems $(\mathrm{OR}=2.15$, 95\% CI 1.52-3.04) (Table 4). Mediation as assessed by comparing the income effect before and after control for perceived discrimination was small. The income effect on self-rated health in the low income group decreased by $0.9 \%$ and the effect of income on feeling hindered by health problems decreased by $0.3 \%$.

Using continuous health outcome measures in linear regression analyses showed similar results. Furthermore, the main finding of only minor evidence for mediation by perceived discrimination in the low income - poor health association was also substantiated when equivalent net income was divided into five categories based on quintiles, when education instead of income was used, and when models in 2008 cross-sectional data were estimated. Finally, no consistent statistically significant interactions between the main variables in the model were present, indicating similar findings across sub-groups. Hence, there was also no evidence for major mediation in either immigrants or non-immigrants. 


\section{Health inequalities and perceived discrimination}

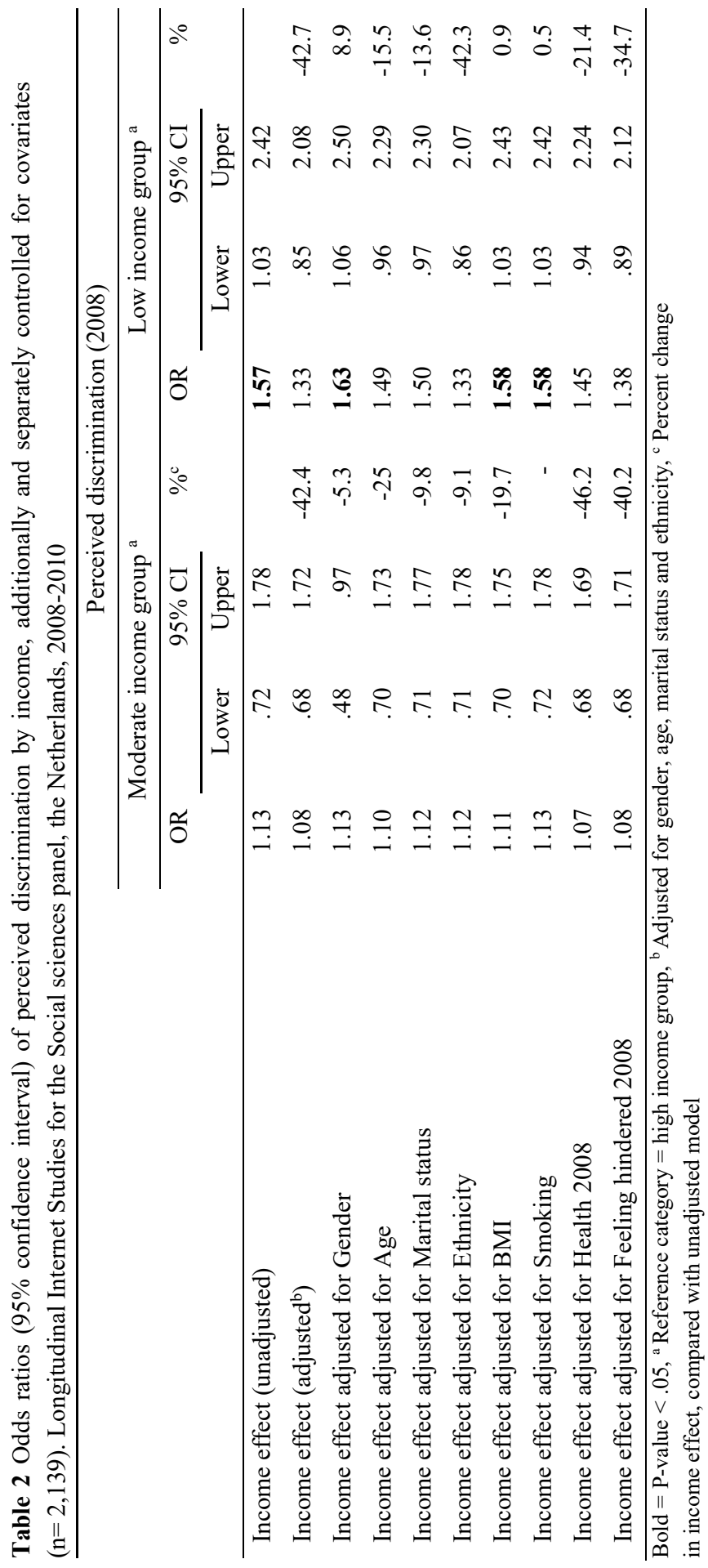




\section{Chapter 4}

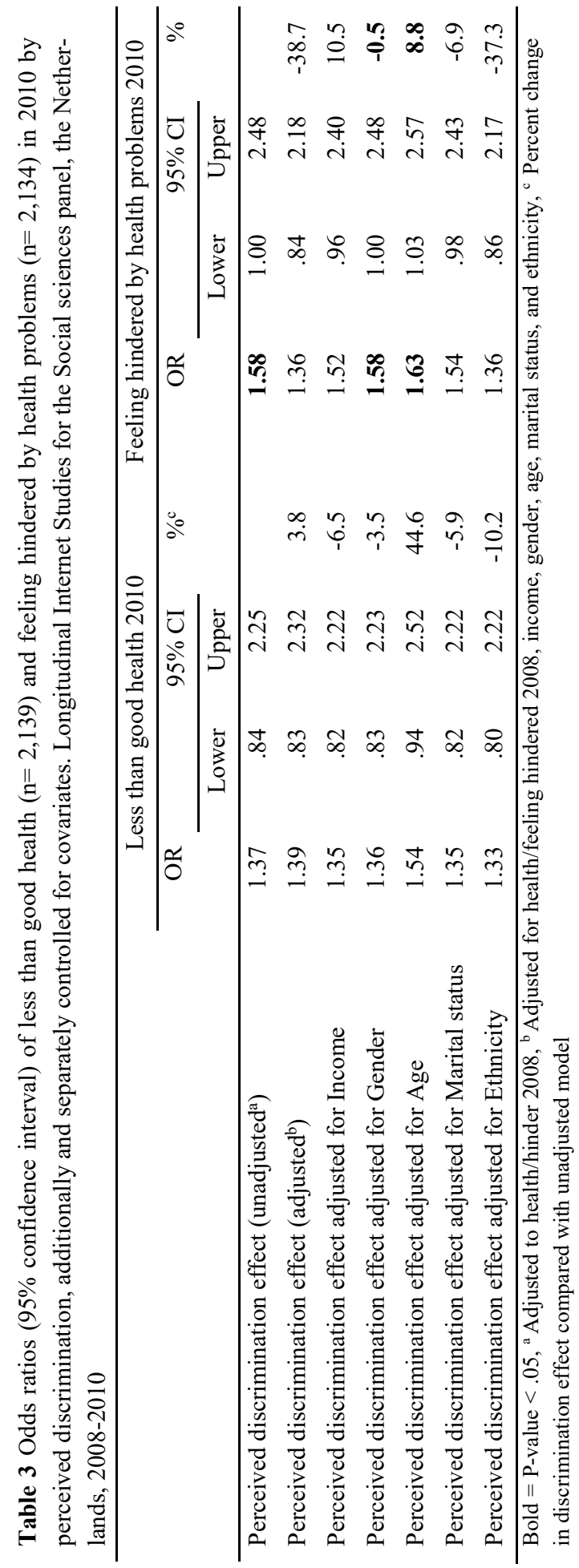


Health inequalities and perceived discrimination

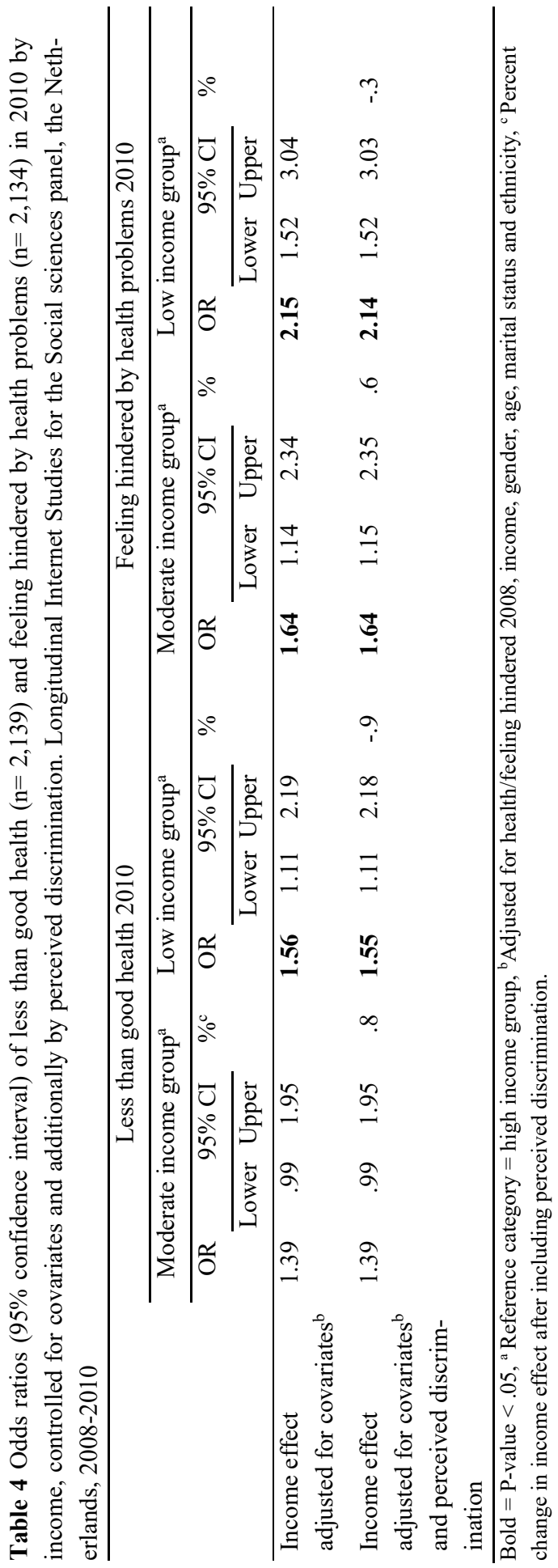




\section{Chapter 4}

\section{Discussion}

Even over a relatively short follow-up of two years, our study among Dutch men and women between 18 and 88 years of age was able to find evidence for income-related health inequalities, income-related perceived discrimination and perceived discrimination-related health inequalities. However, as immigrants were more common among the lower income groups, among the persons who perceived themselves discriminated against, and among those with poor health, ethnicity appeared an important confounder. After control for ethnicity, people from the lower income groups still had a 1.33 higher odds of perceiving discrimination, but this was no longer statistically significant. In addition, poor health partly "explained" why lower income groups were more likely to perceive discrimination. Possibly, these participants perceive themselves discriminated against because of their health status, and with perceived discrimination leading to poor health, this points to the possibility of a negative spiral between health and perceived discrimination. Most importantly, however, there was no substantial evidence for a mediating effect of perceived discrimination on the relation between low income and poor health. Although we only found small effects, the results were in line with a small number of previous studies (Kessler et al. 1999, Fuller-Rowell et al. 2012; Gamarel et al. 2012).

Results of this study showed that ethnicity is strongly related to low income, perceived discrimination, and poor health reports. Previous studies on racial health inequalities and discrimination already emphasised the importance of unravelling how low socioeconomic position, perceived discrimination, and ethnic background hang together in their influence on health outcomes $(33,34)$. Based on an extensive review, Myers (35) describing the SES - ethnicity interaction and the complex relation with health, concluded that it is still unclear whether there are additive or synergistic effects of ethnicity: the health damage caused by SES-related stressors might or might not be exacerbated for individuals with different ethnic backgrounds (35). Future studies should thus take account of the complex interplay between socioeconomic position and ethnic background underlying perceived discrimination and its consequences for health. The interplay even becomes more complex if one takes into account that adverse socioeconomic conditions (in the country of origin) might be the cause of being an immigrant in addition to the immigrant status influencing further socioeconomic attainment processes (in the country of destination). 


\section{Health inequalities and perceived discrimination}

Income-related perceived discrimination might vary between countries regarding its prevalence and impact on health and the socioeconomic differences therein. In more meritocratic countries, where there are many "objective" opportunities for upward (income) mobility, the stronger belief in such opportunities might also be related to stronger stigmatisation and discrimination of those who (still) end up in the lower economic ranks of society (36). It would thus be interesting to study whether in countries with stronger meritocratic beliefs than the Netherlands, discrimination of lower income groups would be more common and would have more substantial consequences for health and incomerelated differences in health.

The precise processes that are involved in how society looks at people at the bottom of the social hierarchy probably deserve a much broader conceptualisation and operationalisation than the single item that we had to rely on. Asking participants whether or not they belong to a discriminated group might not fully correspond with the participants' perception of themselves being discriminated against. Neither did this single item specifically measure incomerelated perceived discrimination. Our findings, for example, suggest that ethnicity and poor health might also be a reason why the lower income groups more often perceive discriminated against. Perhaps the concept should even be broadened to encompass social class-related discrimination, in which discrimination is also considered regarding the other aspects of social class, such as occupational and educational achievements and prestige. The 'Everyday Discrimination Scale' (Williams et al. 1997), for example, allows the measurement of different reasons for discrimination. In adapted form, this questionnaire has been used to examine the role of perceived discrimination within socioeconomic health inequalities (e.g. Kessler et al. 1999; Fuller-Rowell et al. 2012). Furthermore, conceptually and empirically, the discriminatory processes could additionally be looked at from the perspective of stigmatisation. Stigmatisation more explicitly includes negative attitudes towards and stereotyping of people from lower social classes and can be conceptualised from the perspective of either the "subordinated" groups ("felt stigma") or the whole society ("enacted stigma"), or both (37). In short, classism (class-related discrimination and stigmatisation) and its relation to socioeconomic differences in health need more theoretical consideration and better measurements. 


\section{Chapter 4}

\section{Further methodological considerations}

Because of the many self-reported measures, reporting bias could be a problem. Negative affectivity could have inflated our findings, although its bias would have been attenuated due to the longitudinal approach (controlling for baseline health). Furthermore, income has the drawback of being unreliable (38). By categorising income, however, the influence of (unreliable) extreme incomes was restricted. Finally, the LISS panel generally is a good representation of the Dutch society (39), e.g. participants without computer and Internet connection received a computer and Internet connection from CentERdata. However, the study population underrepresented immigrants: $19.9 \%$ of the Dutch population had an immigrant status (45\% non-Western background) (40), while only $10.9 \%$ of the LISS panel members had an immigrant status (31.6\% non-Western background). Non-Western immigrants were also more likely to be lost during the two-year follow-up. Being younger, however, was the dominant predictor of dropout. Baseline self-reported health, income, and perceived discrimination were not independently related to drop-out (not tabulated). It is unclear how this pattern of attrition might have biased our findings.

\section{Conclusion}

Although the lower income groups perceived themselves more often discriminated against and perceived discrimination heightened risks of poor health reports, perceived discrimination had only a small contribution to the higher risks of poor health reports in the lower income groups. This was mostly due to the complex interplay between socioeconomic status and ethnicity. By reflecting on possible between-country differences in meritocratic beliefs, this study emphasises the importance of a more in-depth study of stereotyping, stigmatisation, and discrimination in relation to socioeconomic health inequalities.

\section{Acknowledgement}

This paper draws on data of the Longitudinal Internet Studies for the Social sciences (LISS) panel of CentERdata. The LISS panel data were collected by CentERdata (Tilburg University, The Netherlands) through its Measurement and Experimentation in the Social Sciences (MESS) project funded by the Netherlands Organisation for Scientific Research. 


\section{Health inequalities and perceived discrimination}

\section{References}

1. Mackenbach JP, Stirbu I, Roskam AJR, Schaap MM, Menvielle G, Leinsalu M, et al. Socioeconomic inequalities in health in 22 European countries. N Engl J Med. 2008;358(23):2468-81.

2. Mackenbach JP, Kunst AE, Cavelaars AE, Groenhof F, Geurts JJ. Socioeconomic inequalities in morbidity and mortality in western Europe. The EU Working Group on socioeconomic inequalities in health. Lancet. 1997;349(9066):1655-9.

3. Aldabe B, Anderson R, Lyly-Yrjanainen $\mathrm{M}$, Parent-Thirion A, Vermeylen G, Kelleher CC, et al. Contribution of material, occupational, and psychosocial factors in the explanation of social inequalities in health in 28 countries in Europe. $\mathrm{J}$ Epidemiol Community Health. 2011;65(12):1123-31.

4. Eikemo TA, Bambra C, Judge K, Ringdal K. Welfare state regimes and differences in self-perceived health in Europe: a multilevel analysis. Soc Sci Med. 2008;66(11):2281-95.

5. Bambra C, Netuveli G, Eikemo TA. Welfare state regime life courses: the development of western European welfare state regimes and age-related patterns of educational inequalities in self-reported health. Int J Health Serv. 2010;40(3):399-420.

6. Mackenbach JP. Health inequalities: Europe in profile. Produced by COI for the Dept. of Health.; 2006.

7. Skalicka V, van Lenthe F, Bambra C, Krokstad S, Mackenbach J. Material, psychosocial, behavioural and biomedical factors in the explanation of relative socio-economic inequalities in mortality: evidence from the HUNT study. Int J Epidemiol. 2009;38(5):1272-84.

8. Ward PR, Meyer SB, Verity F, Gill TK, Luong TC. Complex problems require complex solutions: the utility of social quality theory for addressing the Social Determinants of Health. BMC Public Health. 2011;11:630.

9. Lott B. Cognitive and behavioral distancing from the poor. Am Psychol. 2002;57(2):100-10.

10. Phillips JE, Klein WM. Socioeconomic status and coronary heart disease risk: the role of social cognitive factors. Soc Personal Psychol Compass. 2010;4(9):704-27. 


\section{Chapter 4}

11. Reutter LI, Stewart MJ, Veenstra G, Love R, Raphael D, Makwarimba E. "Who do they think we are, anyway?": perceptions of and responses to poverty stigma. Qual Health Res. 2009;19(3):297-311.

12. Williams WR. Struggling with poverty: implications for theory and policy of increasing research on social class-based stigma. Anal Soc Issues Public Policy. 2009;9(1):37-56.

13. Cozzarelli C, Wilkinson AV, Tagler MJ. Attitudes toward the poor and attributions for poverty. J Soc Issues. 2001;57(2):207-27.

14. Kwate NO, Meyer IH. The myth of meritocracy and African American health. Am J Public Health. 2010;100(10):1831-4.

15. McCoy SK, Major B. Priming meritocracy and the psychological justification of inequality. J Exp Soc Psychol. 2007;43(3):341-51.

16. De Botton A. Statusangst [Status anxiety]. Amsterdam: Olympus 2004.

17. Rüsch N, Todd A, Bodenhausen G, Corrigan P. Do people with mental illness deserve what they get? Links between meritocratic worldviews and implicit versus explicit stigma. Eur Arch Psychiatry Clin Neurosci. 2010;260(8):617-25.

18. Wilkinson RG, Pickett K. The Spirit Level: Why Equality is Better for Everyone. New York: Penguin Group; 2010.

19. Caputo RK. The effects of socioeconomic status, perceived discrimination and mastery on health status in a youth cohort. Soc Work Health Care. 2003;37(2):17-42.

20. Mickelson KD, Williams SL. Perceived stigma of poverty and depression: examination of interpersonal and intrapersonal mediators. $\mathrm{J}$ Soc Clin Psychol. 2008;27(9):903-30.

21. Krieger N, Kosheleva A, Waterman PD, Chen JT, Koenen K. Racial discrimination, psychological distress, and self-rated health among USborn and foreign-born Black Americans. Am J Public Health. 2011;101(9):1704-13.

22. Ahmed AT, Mohammed SA, Williams DR. Racial discrimination \& health: pathways \& evidence. Indian J Med Res. 2007;126(4):318-27.

23. Liu WM. Social class, classism, and mental and physical health. Social class and classism in the helping professions: research, theory, and practice. California: Sage Publicationa, Inc.; 2010. 


\section{Health inequalities and perceived discrimination}

24. Matthews KA, Gallo LC, Taylor SE. Are psychosocial factors mediators of socioeconomic status and health connections? Ann N Y Acad Sci. 2010;1186(1):146-73.

25. Inzlicht M, McKay L, Aronson J. Stigma as ego depletion. Psychol Sci. 2006;17(3):262-9.

26. Baum A, Garofalo JP, Yali AM. Socioeconomic status and chronic stress. Does stress account for SES effects on health? Ann N Y Acad Sci. 1999;896:131-44.

27. Adler NE. Health Disparities Through a Psychological Lens. Am Psychol. 2009;64(8):663-73.

28. Shaw M, Tunstall H, Davey Smith G. Seeing social position: visualizing class in life and death. Int J Epidemiol. 2003;32(3):332-5.

29. CentERdata. Guidelines Tilburg: Tilburg University; 2011 [November 22, 2011]. Available from:

http://www.lissdata.nl/assets/uploaded/References_LISS.pdf.

30. De Vos K. Imputation of income in household questionnaire LISS panel. Tilburg: CentERdata; 2008.

31. Vrooman C, Hoff S, Otten F, Bos W. Armoedemonitor 2007 [Poverty monitor 2007]. The Hague Netherlands Institue for Social Research (SCP) and Statistics Netherlands (CBS); 2007.

32. Baron RM, Kenny DA. The moderator-mediator variable distinction in social psychological research: Conceptual, strategic, and statistical considerations. J Pers Soc Psychol. 1986;51(6):1173-82.

33. Weeks M, Lupfer MB. Complicating race: The relationship between prejudice, race, and social class categorizations. Pers Soc Psychol Bull. 2004;30(8):972.

34. D'Anna LH, Ponce NA, Siegel JM. Racial and ethnic health disparities: evidence of discrimination's effects across the SEP spectrum. Ethn Health. 2010;15(2):121-43.

35. Myers HF. Ethnicity- and socio-economic status-related stresses in context: an integrative review and conceptual model. J Behav Med. 2009;32(1):9-19.

36. Bosma H, Simons A, Groffen D, Klabbers G. Stigmatisation and socioeconomic differences in health in modern welfare states. Eur J Public Health. 2012;22:616-7. 


\section{Chapter 4}

37. Phelan JC, Link BG, Dovidio JF. Stigma and prejudice: one animal or two? Soc Sci Med. 2008;67(3):358-67.

38. Bradshaw J, Finch N. Overlaps in dimensions of poverty. J Soc Policy. 2003;32(04):513-25.

39. De Vos K. Representativeness of the LISS-panel 2008, 2009, 2010 : CentERdata; 2010 [April 18, 2012]. Available from: http://www.lissdata.n1/assets/uploaded/Representativeness\%20of\%20the \%20LISS\%20panel\%202008,\%202009,\%202010.pdf.

40. Statistics Netherlands. Bevolking; generatie, geslacht, leeftijd en herkomstgroepering, 1 januari 2009 (Population; generation, sex, age and origin, January 1, 2009) 2009 [March 9, 2012]. Available from: http://statline.cbs.nl/StatWeb/publication/?VW=T\&DM=SLNL\&PA=373 $25 \& \mathrm{D} 1=0-2 \& \mathrm{D} 2=0 \& \mathrm{D} 3=0 \& \mathrm{D} 4=0 \& \mathrm{D} 5=0-4 \& \mathrm{D} 6=13 \& \mathrm{HD}=120309-$ $1458 \& \mathrm{HDR}=\mathrm{G} 2, \mathrm{G} 3 \& \mathrm{STB}=\mathrm{G} 1, \mathrm{~T}, \mathrm{G} 5, \mathrm{G} 4$. 


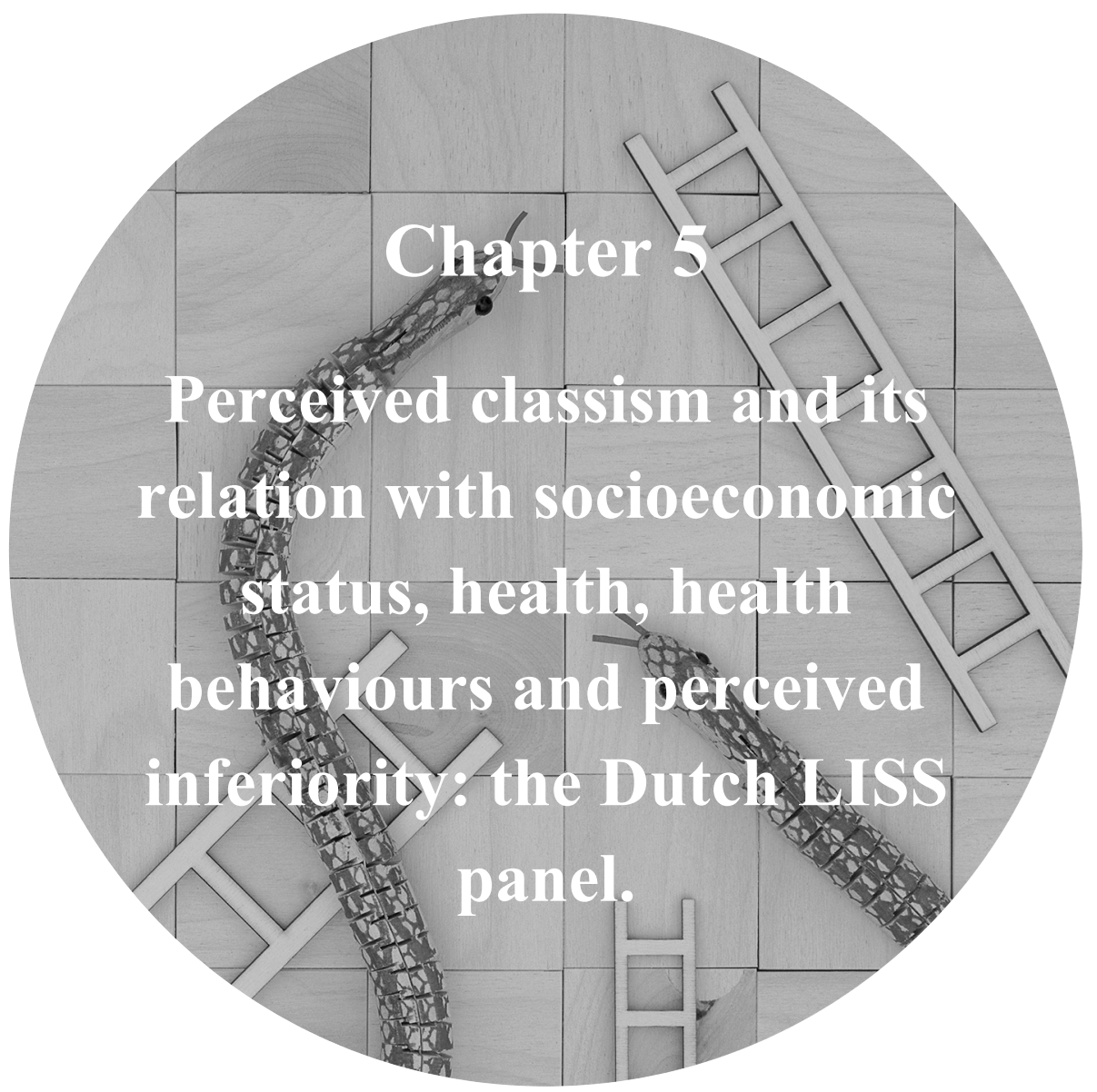

Published as:

Simons AMW, Koster A, Groffen DAI, Bosma H. Perceived classism and its relation with socioeconomic status, health, health behaviours and perceived inferiority: the Dutch Longitudinal Internet Studies for the Social Sciences (LISS) panel. Int J Public Health. 2017;62(4):433-40. 


\section{Chapter 5}

\section{Abstract}

Background. Classism might be the downside of the prevailing ideologies of individual responsibility for success. However, since studies into perceived classism have mainly been qualitative, little is known about its association with socioeconomic status, health, health behaviours and perceived inferiority, especially in more egalitarian countries. This study therefore examined the associations of perceived classism with socioeconomic status, health, health behaviours and perceived inferiority.

Methods. We used cross-sectional data (2012/2013) from the Dutch Longitudinal Internet Studies for the Social Sciences (LISS) ( $\mathrm{n}=1540$; age 16$90 ; 46.9 \%$ men).

Results. We found that classism was perceived by $18.2 \%$ of the participants, with the lowest income and occupation group most likely to perceive classism $(22.0 \%$ and $27.5 \%$, respectively). Perceived classism was significantly associated with poor health (e.g. self-rated health $\mathrm{OR}=2.44,95 \% \mathrm{CI}=1.76-3.38$ ) and feelings of inferiority (e.g. shame $\mathrm{OR}=4.64,95 \% \mathrm{CI}=3.08-6.98$ ). No significant associations were found with health behaviours.

Conclusions. To further examine the role of perceived classism for socioeconomic differences in health and its association with country-level socioeconomic inequalities, prevailing ideologies, and objective opportunities for social mobility, we recommend more longitudinal and international studies with comparable measures of perceived classism. 


\section{Introduction}

Western societies are increasingly permeated by both the meritocratic ideology (e.g. the 'American Dream') and the ideology of individual responsibility. According to this ideology, economic success is based upon individual merits, such as having the right talents and working hard (1). Simultaneously, many people think that modern life has yielded increased opportunities for upward mobility for children from lower socioeconomic backgrounds (2). Whether these ideologies are based on facts or myths is debatable, but, as a downside, these ideologies might induce people to negatively judge and stereotype those ending up at the bottom of the socioeconomic hierarchy (3).

Classism refers to the marginalisation (i.e. labelling, prejudice, discrimination, stigmatisation) of those who are perceived to be in a lower social class (4). People's experience of such classism (perceived classism) has been mainly investigated in qualitative studies. These studies found that people in poverty or low socioeconomic status groups feel negatively judged, degraded, isolated, devalued, put down, blamed and looked down on by others (5-9). Quantitative studies have been scarce and most studies into perceived classism have been conducted in the Anglo-Saxon context (e.g.(10)). Little is known about whether classism is also experienced in countries that are more egalitarian and perhaps less pervaded by the above ideologies, and whether perceived classism, just like other forms of stigmatisation and discrimination (e.g. racism) $(11,12)$, is also associated with poorer physical and mental health (13-17), perceptions of inferiority $(15,18-23)$ and unfavourable health behaviours (16).

Using cross-sectional data on more than 1,500 Dutch men and women, we assessed how, in the more egalitarian Dutch context (24), perceived classism relates to socioeconomic status (SES), health outcomes, perceptions of inferiority and health behaviours.

\section{Methods}

\section{Study population}

Data were collected from individuals participating in the Longitudinal Internet Studies for the Social sciences (LISS) panel (CentERdata, Tilburg, the Netherlands). This is a representative sample of the Dutch population (aged 16 years 


\section{Chapter 5}

and older) who participate in monthly Internet surveys. Every year, a longitudinal survey is fielded among a panel, covering a large variety of domains including work, education, income, housing, time use, political views, values and personality (25). More information about the LISS panel can be found at www.lissdata.nl. Ethical approval was not necessary for this study. LISS panel members have given informed consent to participate in monthly questionnaires.

In February 2013, 2656 randomly selected panel members, including multiple members of the same household, were invited to participate in a 'perceived classism' survey. Non-responders received two reminders for the questionnaire. The questionnaire was completed by 2096 participants (78.9\%). After excluding participants because of missing data on SES, outcome variables, or covariates measured between November 2012 and May 2013, the final sample consisted of 1540 participants $(73.5 \%)$. The mean age of the sample was 53.5 years $(\mathrm{SD}=15.6$, range $16-90), 722$ participants $(46.9 \%)$ were men and 172 participants (11.2\%) were of non-Dutch origin. The design of the current study was cross-sectional.

\section{Measures}

\section{Perceived Classism}

Perceived classism was measured with eight statements about perceived classrelated stigmatisation within the last six months: (1) I feel that I am odd or abnormal because of my financial situation, educational level or occupation; (2) There have been times when I have felt ashamed because of my ...; (3) I never feel self-conscious in public (R); (4) I never feel embarrassed about my ... (R); (5) I feel that others look down on me because of my ...; (6) People treat me differently because of my ...; (7) I have found that people say negative or unkind things about me behind my back because of my ... and (8) I have been excluded from work, school and/or family functions because of my .... Participants reported the extent to which they agreed or disagreed with each statement on a five-point Likert scale ( $1=$ definitely disagree to $5=$ definitely agree) (15). The questionnaire was translated in to Dutch and slightly adjusted to cover a broader definition of socioeconomic grouping. On the basis of factor and reliability analyses, we excluded two items from the original scale (items 3 and 4; these were the only negatively worded items that loaded onto a different factor). The Cronbach's alpha of the six-item scale is 0.83 . Scores were 


\section{Perceived classism and health}

dichotomised by categorising those scoring 4 or 5 on at least one of the six items as 'perceiving classism' ( $\mathrm{n}=280,18.2 \%)$.

\section{Socioeconomic status}

Participants' equivalent household income was defined as the net monthly household income in Euros corrected for the number of adults and children living in the household (26). Equivalent household income was categorised, based on tertiles, into high $(>€ 2000$, reference category), moderate (€1426$€ 2000)$ and low income $(<€ 1425)$. Education was divided into three categories: (1) higher vocational education and university (reference category; $\mathrm{n}=523$, $34 \%$ ), (2) higher secondary education and intermediate vocational education $(\mathrm{n}=529,34.4 \%)$ and (3) primary school and intermediate secondary education $(\mathrm{n}=488,31.7 \%)$. Occupational level was also divided into three categories: (1) higher academic or independent profession, and higher supervisory profession (reference category; $n=236,15.3 \%$ ), (2) intermediate academic or independent profession, and intermediate supervisory or commercial profession and other mental work, and skilled and supervisory manual work $(\mathrm{n}=1064,69.1 \%)$ and (3) semi-skilled manual work, and unskilled and untrained manual work $(\mathrm{n}=240$, $15.6 \%)$.

\section{Health outcomes}

Self-rated health was measured with the question 'How would you describe your health, generally speaking?' (scores ranging from 1=poor to $5=$ excellent) and dichotomised by categorising poor and moderate health as 'less than good health'. Perceived difficulties because of health problems were measured with three questions asking the participants to what extent their physical or emotional problems had impeded their daily activities, social activities and work (e.g. in their job, housekeeping or at school) over the past month (scores ranging from $1=$ very much to $5=$ not at all, Cronbach's alpha $=0.89$ ). These variables of perceived difficulties were averaged. Scores were dichotomised by categorising those scoring 3 or lower as 'impeded by health'. Participants were also asked to indicate whether their health was better or worse than last year (scores ranging from $1=$ considerably poorer to $5=$ considerably better). Scores were dichotomised by categorising those scoring less than 3 as 'worse subjective health'. Perceived negative emotions were measured with five items asking how often participants felt anxious, down, depressed, calm (reversed) and happy (reversed) 


\section{Chapter 5}

(scores ranging from $1=$ never to $6=$ continuously, Cronbach's alpha $=0.86$ ). The five items were averaged and dichotomised by categorising those scoring 4 or higher as 'perceiving negative emotions'.

\section{Perceived inferiority}

Generalised shame was measured by the three-item subscale of the Differential Emotions Scale (DES) (27) (Cronbach's alpha=0.83). One of the items was: 'In your daily life, how often do you feel embarrassed when somebody sees you make a mistake' (scores ranging from $1=$ never to $5=$ very often). Scores were dichotomised by categorising those scoring 4 or 5 on one of the items as 'perceiving shame'. Social anxiety was measured by 15 items of the Social Inadequacy subscale of the Dutch Personality Questionnaire (28) (Cronbach's alpha $=0.87$ ). One of the items was: 'I get nervous when I'm going to meet people' (true/not true/?). Scores were dichotomised using gender-specific norms for sum scores (28); scores above the norm were categorised as 'perceiving social anxiety'. Self-esteem was measured with Rosenberg's ten-item Self-Esteem Questionnaire ( $\mathrm{n}=1397$; Cronbach's alpha $=0.90)$. Participants reported the extent to which they agreed or disagreed with ten statements with seven-point Likert scales (scores ranging from $1=$ totally disagree to $7=$ totally agree). One of the items was: 'I feel I do not have much to be proud of' (reversed). Scores were dichotomised by categorising those with sum scores less than 53 as 'low self-esteem' (lowest tertile).

\section{Health behaviours}

Alcohol use was measured with the question 'On how many of the past seven days did you have a drink containing alcohol?' More than two times a week was categorised as 'alcohol use $>2$ days a week'. Participants who reported to be current smokers were categorised as 'current smokers'. Physical activity was measured by two questions 'Looking back on the last 7 days, on how many of those days did you perform a strenuous physical activity such as lifting heavy loads, digging, aerobics or cycling?' and 'Looking back on the last 7 days, on how many of those days did you perform a moderately intensive physical activity such as carrying light loads, cycling at a normal pace or a doubles game of tennis?'. Participants scoring zero (= no physical activity in the past seven days) on both items were categorised as 'inactive'. Obesity was defined as a body 
mass index $(\mathrm{BMI}) \geq 30$, calculated as self-reported weight $(\mathrm{kg})$ divided by height (m) squared.

\section{Covariates}

Covariates were age (years), sex and ethnicity (Dutch (= reference category) or first or second-generation immigrant with Western or non-Western background).

\section{Statistical analyses}

Firstly, associations between socioeconomic status (income, education and occupation) and perceived classism were examined by $\chi^{2}$ tests and by logistic regression analyses adjusted for the covariates age, sex and ethnicity. Secondly, the effect of perceived classism on health outcomes, perceived inferiority and health behaviours was examined using logistic regression analyses with additional adjustments for age, sex, ethnicity (model 2) and income (model 3). Finally, sensitivity analyses were performed (e.g. adjustments for education and occupation instead of income, an assessment of dose-response associations of perceived classism). All analyses were performed with IBM SPSS Statistics for Windows, Version 22.0 (IBM corp., Armonk, NY).

\section{Results}

Almost one fifth of the participants perceived some form of classism (280 (18.2\%) out of 1540 people; Table 1). The two groups differed in age and sex; the group perceiving classism was, on average, younger (49.5 years vs. 54.4 years) and included more men (53.6\% vs. $45.4 \%)$. Participants who perceived classism were also more likely to report health problems and feelings of inferiority than their counterparts (e.g. $26.4 \%$ vs. $15 \%$ reporting less than good health, and $23.6 \%$ vs. $14.3 \%$ reporting social anxiety). As regards health behaviours, the groups only differed significantly in smoking behaviour, as 25.7 $\%$ of the participants who perceived classism smoked, compared to $19.0 \%$ of the participants who perceived no classism.

Respondents in the lowest income and occupation group were significantly more likely to experience classism than those with the highest SES ( $22.0 \%$ vs. $13.3 \%$, and $27.5 \%$ vs. $19.1 \%$, respectively) (Table 2 ). Adjusted for 


\section{Chapter 5}

age, sex and ethnicity, the lowest income and occupation group had 1.88 (95\% $\mathrm{CI}=1.34-2.63)$ and $1.57(95 \% \mathrm{CI}=1.00-2.46)$ times higher odds of perceiving classism than their better-off counterparts. Associations with education were not statistically significant. A gradient-like association was found for income.

Table 1 Baseline characteristics. Source: Longitudinal Internet Studies for the Social Sciences panel, the Netherlands, 2013.

\begin{tabular}{|c|c|c|c|c|}
\hline & & $\begin{array}{l}\text { Total } \\
(n=1540)\end{array}$ & $\begin{array}{l}\text { Perceived classism } \\
(\mathrm{n}=280)\end{array}$ & $\begin{array}{l}\text { No perceived } \\
\text { classism } \\
(n=1260)\end{array}$ \\
\hline \multicolumn{2}{|l|}{ Age, mean (SD) } & $53.47(15.56)$ & $49.46(15.47)$ & $\begin{array}{l}54.36 \\
(15.45)^{* *}\end{array}$ \\
\hline Men & & 46.9 & 53.6 & $45.4^{*}$ \\
\hline Non-Dutch & & 11.2 & 14.3 & 10.5 \\
\hline \multirow[t]{3}{*}{ Income $^{\mathrm{a}}$} & High & 33.2 & 24.3 & $35.2 *$ \\
\hline & Moderate & 33.1 & 35.0 & 32.7 \\
\hline & Low & 33.7 & 40.7 & 32.1 \\
\hline \multirow[t]{3}{*}{ Occupational level } & High & 15.3 & 16.1 & $15.2 * *$ \\
\hline & Moderate & 69.1 & 60.4 & 71.0 \\
\hline & Low & 15.6 & 23.6 & 13.8 \\
\hline \multirow[t]{3}{*}{ Educational level } & High & 34.0 & 36.4 & 33.4 \\
\hline & Moderate & 34.4 & 33.9 & 34.4 \\
\hline & Low & 31.7 & 29.6 & 32.1 \\
\hline Less than good health & & 17.1 & 26.4 & $15.0^{* *}$ \\
\hline Impeded by health & & 14.4 & 23.9 & $12.2 * *$ \\
\hline Worse subjective health & & 18.6 & 23.6 & $17.5^{*}$ \\
\hline Negative emotions & & 4.8 & 10.4 & $3.6^{* *}$ \\
\hline Shame & & 8.1 & 20.4 & $5.3 * *$ \\
\hline Social anxiety & & 16.0 & 23.6 & $14.3^{* *}$ \\
\hline Low self-esteem ${ }^{\mathrm{a}}$ & & 30.8 & 40.9 & $28.7 * *$ \\
\hline Currently smoking & & 20.2 & 25.7 & $19.0^{*}$ \\
\hline Alcohol use $>2$ days a week & & 38.1 & 35.7 & 38.7 \\
\hline Inactivity & & 25.0 & 24.3 & 25.2 \\
\hline $\mathrm{BMI}>30$ & & 15.1 & 16.8 & 14.7 \\
\hline
\end{tabular}

${ }^{a}$ Tertiles, ${ }^{\mathrm{b}}$ Agricultural professions $(\mathrm{n}=26)$ excluded, because it was unclear whether they were farm workers (i.e. low status) or independent farmers (i.e. high status), ${ }^{*}$ p-value $\chi^{2}<0.05, * *$ p-value $\chi^{2}<0.001$ 


\section{Perceived classism and health}

Table 2 Association between socioeconomic status and perceived classism, $\mathrm{n}=1540$. Source: Longitudinal Internet Studies for the Social Sciences panel, the Netherlands, 2013.

\begin{tabular}{|c|c|c|c|c|c|c|}
\hline & & \multicolumn{5}{|c|}{ Perceived classism } \\
\hline & & \multicolumn{2}{|c|}{ Model 1} & \multicolumn{3}{|c|}{ Model 2} \\
\hline & & $\%^{\mathrm{a}}$ & OR & $95 \% \mathrm{CI}$ & OR & $95 \%$ CI \\
\hline Total & & 18.2 & & & & \\
\hline \multirow[t]{3}{*}{ Income } & High & 13.3 & Ref & & Ref & \\
\hline & Moderate & 19.2 & 1.55 & $(1.11-2.17)$ & 1.53 & $(1.09-2.15)$ \\
\hline & Low & 22.0 & 1.83 & $(1.32-2.55)$ & 1.88 & $(1.34-2.63)$ \\
\hline \multirow[t]{3}{*}{ Occupational level } & High & 19.1 & Ref & & Ref & \\
\hline & Moderate & 15.9 & 0.80 & $(0.56-1.15)$ & 0.87 & $(0.59-1.26)$ \\
\hline & Low & 27.5 & 1.61 & $(1.05-2.48)$ & 1.57 & $(1.00-2.46)$ \\
\hline \multirow[t]{3}{*}{ Educational level } & High & 19.5 & Ref & & Ref & \\
\hline & Moderate & 18.0 & 0.90 & $(0.66-1.23)$ & 0.87 & $(0.64-1.19)$ \\
\hline & Low & 17.0 & 1.01 & $(0.73-1.40)$ & 1.01 & $(0.73-1.40)$ \\
\hline
\end{tabular}

Model 1= unadjusted OR, Model 2=model $1+$ adjustment for age, sex and ethnicity, ${ }^{a}$ percentage agreed with at least one of the items

Table 3 shows that, adjusted for age, sex, ethnicity and income (model 3), people who perceived classism had 2.44 times higher odds $(95 \% \mathrm{CI}=1.76-3.38)$ of reporting less than good health, 2.43 times higher odds $(95 \% \mathrm{CI}=1.74-3.41)$ of feeling impeded by health problems, 1.71 times higher odds $(95 \% \mathrm{CI}=1.24$ 2.36) of reporting worse health compared to a year ago, and 2.97 times higher odds $(95 \% \mathrm{CI}=1.80-4.90)$ of reporting negative emotions, compared to those who perceived no classism.

Table 3 Association between perceived classism and health outcomes, $n=1540$. Source: Longitudinal Internet Studies for the Social Sciences panel, the Netherlands, 2013.

\begin{tabular}{llllllllll}
\hline & \multicolumn{3}{l}{$\begin{array}{l}\text { Health } \\
\text { Less than good } \\
\text { health }\end{array}$} & \multicolumn{3}{l}{ Impeded by health } & \multicolumn{2}{l}{$\begin{array}{l}\text { Worse subjective } \\
\text { health }\end{array}$} & \multicolumn{3}{l}{$\begin{array}{l}\text { Perceived negative } \\
\text { emotions }\end{array}$} \\
& OR & $(95 \% \mathrm{CI})$ & OR & $(95 \% \mathrm{CI})$ & OR & $(95 \% \mathrm{CI})$ & OR & $(95 \% \mathrm{CI})$ \\
Model 1 & 2.04 & $(1.50-2.77)$ & 2.26 & $(1.64-3.12)$ & 1.45 & $(1.06-1.98)$ & 3.12 & $1.92-5.07$ \\
Model 2 & 2.53 & $(1.83-3.50)$ & 2.59 & $(1.86-3.62)$ & 1.66 & $(1.21-2.29)$ & 3.22 & $1.96-5.29$ \\
Model 3 & 2.44 & $(1.76-3.38)$ & 2.43 & $(1.74-3.41)$ & 1.71 & $(1.24-2.36)$ & 2.97 & $1.80-4.90$ \\
\hline
\end{tabular}

Model 1=unadjusted OR, model 2=model $1+$ adjustment for age, sex and ethnicity, model 3=model $2+$ adjustment for income

Similarly, Table 4 shows that, adjusted for age, sex, ethnicity and income (model 3), people who perceived classism also had significantly higher odds of reporting feelings of shame ( $\mathrm{OR}=4.64,95 \% \mathrm{CI}=3.08-6.98)$, social anxiety 


\section{Chapter 5}

$(\mathrm{OR}=1.69,95 \% \mathrm{CI}=1.22-2.34)$ and low self-esteem $(\mathrm{OR}=1.65,95 \% \mathrm{CI}=1.23$ 2.22) than those who did not report perceiving classism.

Table 4 Association between perceived classism and perceived inferiority, $\mathrm{n}=1540^{\mathrm{a}}$. Source: Longitudinal Internet Studies for the Social Sciences panel, the Netherlands, 2013.

\begin{tabular}{lllllll}
\hline \multicolumn{3}{l}{ Perceived inferiority } \\
& \multicolumn{3}{l}{ Perceived shame } & \multicolumn{2}{l}{ Perceived social anxiety } & \multicolumn{2}{l}{ Low self-esteem } \\
& OR & $(95 \% \mathrm{CI})$ & OR & $(95 \% \mathrm{CI})$ & OR & $(95 \% \mathrm{CI})$ \\
Model 1 & 4.55 & $3.11-6.66$ & 1.85 & $1.35-2.54$ & 1.72 & $1.29-2.29$ \\
Model 2 & 4.68 & $3.12-7.00$ & 1.72 & $1.28-2.45$ & 1.75 & $1.31-2.35$ \\
Model 3 & 4.64 & $3.08-6.98$ & 1.69 & $1.22-2.34$ & 1.65 & $1.23-2.22$ \\
\hline
\end{tabular}

Model 1=unadjusted OR, model 2=model $1+$ adjustment for age, sex and ethnicity, model 3=model $2+$ adjustment for income, ${ }^{a}$ Self-esteem $\mathrm{n}=1397$

The association between perceived classism and smoking was significant in the unadjusted model and in the model adjusted for age, sex and ethnicity $\left(\mathrm{OR}_{\text {unadjusted }}=1.48,95 \% \mathrm{CI}=1.09-2.00\right)$, but lost its significance after adjusting for income. Associations between perceived classism and alcohol use, inactivity and BMI were not statistically significant (Table 5, model 3).

Table 5 Association between perceived classism and health behaviours, $n=1540$. Source: Longitudinal Internet Studies for the Social Sciences panel, the Netherlands, 2013.

\begin{tabular}{|c|c|c|c|c|c|c|c|c|}
\hline & \multicolumn{8}{|c|}{ Health behaviours } \\
\hline & \multicolumn{2}{|c|}{$\begin{array}{l}\text { Alcohol use }>2 \\
\text { days a week }\end{array}$} & \multicolumn{2}{|c|}{ Current smokers } & \multicolumn{2}{|c|}{ Inactive } & \multicolumn{2}{|c|}{$\mathrm{BMI} \geq 30$} \\
\hline & OR & $(95 \% \mathrm{CI})$ & OR & $(95 \% \mathrm{CI})$ & OR & $(95 \% \mathrm{CI})$ & OR & $(95 \% \mathrm{CI})$ \\
\hline Model 1 & 0.88 & $0.67-1.16$ & 1.48 & $1.09-2.00$ & 0.95 & $0.71-1.29$ & 1.17 & $0.83-1.66$ \\
\hline Model 2 & 0.99 & $0.74-1.31$ & 1.40 & $1.03-1.90$ & 1.02 & $0.75-1.39$ & 1.25 & $0.88-1.79$ \\
\hline Model 3 & 1.05 & $0.78-1.40$ & 1.35 & $0.99-1.84$ & 0.99 & $0.73-1.36$ & 1.21 & $0.85-1.74$ \\
\hline
\end{tabular}

In additional analyses, we first examined the interactions between perceived classism and age, sex, ethnicity and SES; these were not statistically significant (all $\mathrm{p}>0.10$ ). Secondly, we alternatively adjusted for occupation and education (instead of income) in the associations between perceived classism and the outcomes (not tabulated). These analyses did not yield different results, although the association between perceived classism and smoking remained statistically significant after adjusting for education $(\mathrm{OR}=1.43,95 \% \mathrm{CI}=1.05$ 1.95). Thirdly, dose-response associations were found between perceived 


\section{Perceived classism and health}

classism (categorised into three groups based on sum score tertiles) and health outcomes and perceived inferiority measures (not tabulated). Finally, analyses with only one randomly selected participant per household $(n=1352)$ confirmed the pattern of findings presented above.

\section{Discussion}

Almost one in five of the participants of a Dutch internet panel perceived some kind of classism, with the lowest income and occupation group most likely to report it $(22.0 \%$ and $27.5 \%$, respectively). Low education was not associated with perceived classism. Perceptions of classism were strongly associated with poor physical and mental health and perceptions of inferiority. Perceived classism was not associated with unhealthy behaviours.

Our results might provide support for the relevance of the relative deprivation theory in social epidemiology (29). Inequalities in society, whether large or small, together with prevailing ideologies of social mobility and individual responsibility, might nourish feelings of inferiority and perceptions of classism in lower SES groups $(1,16)$. The concept of relative deprivation might also explain why we found no differences in perceived classism between groups based on educational level. When comparing one's status with that of relevant others, one might typically look at the more visible indicators of status, like someone's possessions (e.g. expensive cars as an indicator of someone's wealth) or occupation (1). More visible indicators of status, or in this case the visible lack of it, might be more prone to stigmatisation, and these might be more difficult to conceal to others than a low level of education (30).

In view of its relation with poor physical and mental health, and its highest prevalence in the lowest SES groups, perceived classism might even be a relevant but largely neglected factor in social epidemiology and particularly in research to explain the persistent socioeconomic health inequalities $(14,17,31$, 32). Moreover, if classism, as an antecedent of perceived classism, is a relevant factor, it will be very difficult to achieve its prevention by public health programmes aimed at tackling socioeconomic inequalities in health, as classism is embedded in hard-to-change, ingrained ideologies. A more practical approach might be to create opportunities for individuals to cope differently with the experience of classism. Our next, as yet unpublished, qualitative work will 


\section{Chapter 5}

highlight the most important healthy and unhealthy ways of coping with classism. Intervention measures may take these into account in trying to reduce health inequalities. Most importantly, however, social epidemiology needs more longitudinal research on how exactly classism (enacted or perceived) is linked to socioeconomic inequalities in health and how much it contributes to these inequalities.

There is a lack of comparable international data on classism; most data stem from qualitative studies or from studies among specific populations (e.g. students (10)). We therefore cannot conclude that people in a rather egalitarian country, such as the Netherlands (24), perceive more or less classism than people in, for example, the US. More research is needed to study the prevalence of classism in different parts of the world, using the same measurement instruments. In addition, by measuring perceived classism worldwide, it would for example be possible to assess how the prevalence of perceived classism and its relation to health vary between countries differing in terms of socioeconomic inequality (e.g. income inequality), ideologies (e.g. meritocratic vs. egalitarian) and opportunities for social mobility $(3,17,33-38)$.

Moreover, if the role of classism and its experience in individual and population health is further substantiated, time trends in classism within countries also become relevant. If perceived classism were measured regularly, unintended effects of changing national policies could become clear. For example, the Dutch welfare state is changing into what politicians call a 'participation society', which emphasises taking individual responsibility. This might increase negative attitudes towards people who are not able to participate (39), resulting in more people perceiving stigmatisation, because of their lack of participation, education, income or employment.

Although our study confirmed the association between perceived classism, health and perceived inferiority, we could not confirm the association between perceived classism and unhealthy behaviours. This might indicate that unhealthy behaviours are not included in the pathways relating perceived classism to poor health. An alternative pathway by which perceived classism affects health might involve physiological stress responses, related to neurochemical, endocrine and immunological functioning, which are associated with both physical and mental health problems $(16,19,31,32,40)$. This also needs further examination in future studies. 
The major strength of our study was the use of a large representative Dutch Internet panel (41). Where necessary, computers and an Internet connection were provided to people - most often people from low SES groups, elderly people or people with non-Dutch ethnic backgrounds. Nevertheless, some methodological issues have to be discussed. First, as we used cross-sectional data, we cannot draw any causal conclusions. Poor health and feelings of inferiority could be causes of perceived classism, rather than consequences. Similarly, there might be personality characteristics, e.g. relating to negative affectivity, that are confounders of the cross-sectional associations, particularly as measures were based on self-reports. Hence our recommendation to corroborate our hypotheses in longitudinal research, which would enable us to more validly study the relevant causal processes. Secondly, the non-responders in our study (21\%) differed significantly from the respondents in terms of age $(\mathrm{M}=39.20, \mathrm{SD}=16.17$ vs. $\mathrm{M}=50.79, \mathrm{SD}=17.24)$, and participants who were excluded from the analyses because of missing data were also significantly younger ( $\mathrm{M}=43.40, \mathrm{SD}=19.37$ vs. $\mathrm{M}=53.47, \mathrm{SD}=15.56$ ), and were more likely to perceive classism $(24.3 \%$ vs. $18.2 \%)$ and to belong to the lower income and education group ( $49.5 \%$ vs. $33.7 \%$, and $40.3 \%$ vs. $31.7 \%$, respectively). This pattern may have resulted in underestimated associations.

\section{Conclusion}

Despite living in a rich and relatively egalitarian country, almost $20 \%$ of the participants in a Dutch Internet panel perceived some kind of classism. The lowest income and occupation groups were most likely to perceive classism. Comparable international data are needed to assess between-country differences in perceived classism and the role of country characteristics, like the prevailing ideologies or the opportunities for social mobility. Furthermore, because of the strong associations we found between SES, perceived classism, poor health and perceptions of inferiority, future longitudinal research should shed further light on the role of perceived classism in social epidemiology. 


\section{Chapter 5}

\section{Acknowledgement}

We would like to thank Dr Kristin Mickelson for her feedback on the reverse translation we used to check the Dutch translation of the questionnaire our back translation. We also wish to thank CentERdata (Tilburg University, the Netherlands) for collecting the LISS panel data through its MESS project, which is funded by the Netherlands Organization for Scientific Research. Data are available from their website www.lissdata.nl. 


\section{References}

1. De Botton A. Statusangst [Status anxiety]. Amsterdam: Olympus 2004.

2. Kraus MW, Tan JJX. Americans overestimate social class mobility. J Exp Soc Psychol. 2015;58:101-11.

3. Dahl E, Fritzell J, Lahelma E, Martikainen P, Kunst AE, Mackenbach JP. Welfare state regimes and health inequalities. In: Siegrist J, Marmot M, editors. Social inequalities in health New evidence and policy implications. Oxford: Oxford University Press 2006.

4. Liu WM. Introduction to Social Class and Classism in Counseling Psychology. The Oxford Handbook of Social Class in Counseling. Oxford Oxford University Press.; 2013.

5. Collins SB. An understanding of poverty from those who are poor. Action Res. 2005;3(1):9-31.

6. Hirschl T, Rank M, Kusi-Appouh D. Ideology and the Experience of Poverty Risk: Views About Poverty Within a Focus Group Design. J Poverty. 2011;15(3):350-70.

7. McIntyre L, Officer S, Robinson LM. Feeling poor: The felt experience of low-income lone mothers. Affilia. 2003;18(3):316-31.

8. Ravensbergen F, VanderPlaat M. Barriers to citizen participation: the missing voices of people living with low income. Community Dev J. 2010;45(4):389-403.

9. Underlid K. Poverty and experiences of insecurity. A qualitative interview study of 25 long-standing recipients of social security. Int J Soc Welfare. 2007;16(1):65-74.

10. Langhout RD, Rosselli F, Feinstein J. Assessing Classism in Academic Settings. Rev High Ed. 2007;30(2):145-84.

11. Krieger N, Rowley DL, Herman AA, Avery B. Racism, sexism, and social class: implications for studies of health, disease, and well-being. Am J Prev Med. 1993.

12. Pascoe EA, Smart Richman L. Perceived discrimination and health: a meta-analytic review. Psychol Bull. 2009;135(4):531-54.

13. Caputo RK. The effects of socioeconomic status, perceived discrimination and mastery on health status in a youth cohort. Soc Work Health Care. 2003;37(2):17-42. 


\section{Chapter 5}

14. Fuller-Rowell TE, Evans GW, Ong AD. Poverty and health. Psychol Sci. 2012;23(7):734-39.

15. Mickelson KD, Williams SL. Perceived stigma of poverty and depression: examination of interpersonal and intrapersonal mediators. $\mathrm{J}$ Soc Clin Psychol. 2008;27(9):903-30.

16. Roy J-P. Socioeconomic status and health: a neurobiological perspective. Med Hypotheses. 2004;62(2):222-7.

17. Simons AMW, Groffen DAI, Bosma H. Income-related health inequalities: does perceived discrimination matter? Int J Public Health. 2013;58(4):513-20.

18. Adler NE. Health Disparities Through a Psychological Lens. Am Psychol. 2009;64(8):663-73.

19. Courtwright AM. Justice, stigma, and the new epidemiology of health disparities. Bioeth. 2009;23(2):90-6.

20. Ritsher JB, Otilingam PG, Grajales M. Internalized stigma of mental illness: psychometric properties of a new measure. Psychiatry Res. 2003;121(1):31-49.

21. Twenge JM, Campbell WK. Self-esteem and socioeconomic status: a meta-analytic review. Pers Soc Psychol Rev. 2002;6(1):59-71.

22. Walker R, Kyomuhendo GB, Chase E, Choudhry S, Gubrium EK, Nicola JY, et al. Poverty in global perspective: is shame a common denominator? J Soc Policy. 2013;42(02):215-33.

23. Williams DR. Race, socioeconomic status, and health the added effects of racism and discrimination. Ann N Y Acad Sci. 1999;896(1):173-88.

24. Organisation for Economic Co-operation and Development (OECD). Divided We Stand: Why Inequality Keeps Rising: OECD Publishing; 2011.

25. CentERdata. Guidelines Tilburg: Tilburg University; 2011 [November 22, 2011]. Available from:

http://www.lissdata.nl/assets/uploaded/References_LISS.pdf.

26. Vrooman C, Hoff S, Otten F, Bos W. Armoedemonitor 2007 [Poverty monitor 2007]. The Hague Netherlands Institue for Social Research (SCP) and Statistics Netherlands (CBS); 2007.

27. Izard CE, Libero DZ, Putnam P, Haynes OM. Stability of emotion experiences and their relations to traits of personality. J Pers Soc Psychol. 1993;64(5):847. 


\section{Perceived classism and health}

28. Luteijn F, Starren J, Van Dijk H. Nederlandse Persoonlijkheidsvragenlijst, Herziene uitgave [Dutch Personality Questionnaire]. Lisse, NL: Swets \& Zeitlinger BV. 1985.

29. Wilkinson RG, Pickett KE. The problems of relative deprivation: why some societies do better than others. Soc Sci Med. 2007;65(9):1965-78.

30. Quinn DM. Concealable versus conspicuous stigmatized identities. In: Levin S, Van Laar C, editors. Stigma and group inequality: Social psychological perspectives2006. p. 83-103.

31. Hatzenbuehler ML, Phelan JC, Link BG. Stigma as a fundamental cause of population health inequalities. Am J Public Health. 2013;103(5):81321.

32. Krieger N. Discrimination and Health Inequities. Int J Health Serv. 2014;44(4):643-710.

33. Bosma H, Simons A, Groffen D, Klabbers G. Stigmatisation and socioeconomic differences in health in modern welfare states. Eur $\mathbf{J}$ Public Health. 2012;22:616-7.

34. Bullock H. Justifying inequality: a social psychological analysis of beliefs about poverty and the poor. Santa Cruz: National Poverty Center 2006.

35. Rüsch N, Todd A, Bodenhausen G, Corrigan P. Do people with mental illness deserve what they get? Links between meritocratic worldviews and implicit versus explicit stigma. Eur Arch Psychiatry Clin Neurosci. 2010;260(8):617-25.

36. Swierstra T, Tonkens E. De schaduwzijde van de meritocratie: de respectsamenleving als ideaal [The downside of meritocracy: a respectful society as an ideal]. Social Democr. 2011;68(7):37-44.

37. Underlid K. Poverty and experiences of social devaluation: A qualitative interview study of 25 long-standing recipients of social security payments. Scand J Psychol. 2005;46(3):273-83.

38. Williams WR. Struggling with poverty: implications for theory and policy of increasing research on social class-based stigma. Anal Soc Issues Public Policy. 2009;9(1):37-56.

39. Hindriks F. Gedeelde verantwoordelijkheid in een verdeelde samenleving [Shared responsibility in a divided society] Inaugural speech, Groningen, the Netherlands2015 [October 26, 2015]. Available from: http://www.rug.nl/staff/f.a.hindriks/oratie-frank-hindriks.pdf. 


\section{Chapter 5}

40. Baum A, Garofalo JP, Yali AM. Socioeconomic status and chronic stress. Does stress account for SES effects on health? Ann N Y Acad Sci. 1999;896:131-44.

41. De Vos K. Representativeness of the LISS-panel 2008, 2009, 2010: CentERdata; 2010 [April 18, 2012]. Available from: http://www.lissdata.nl. 


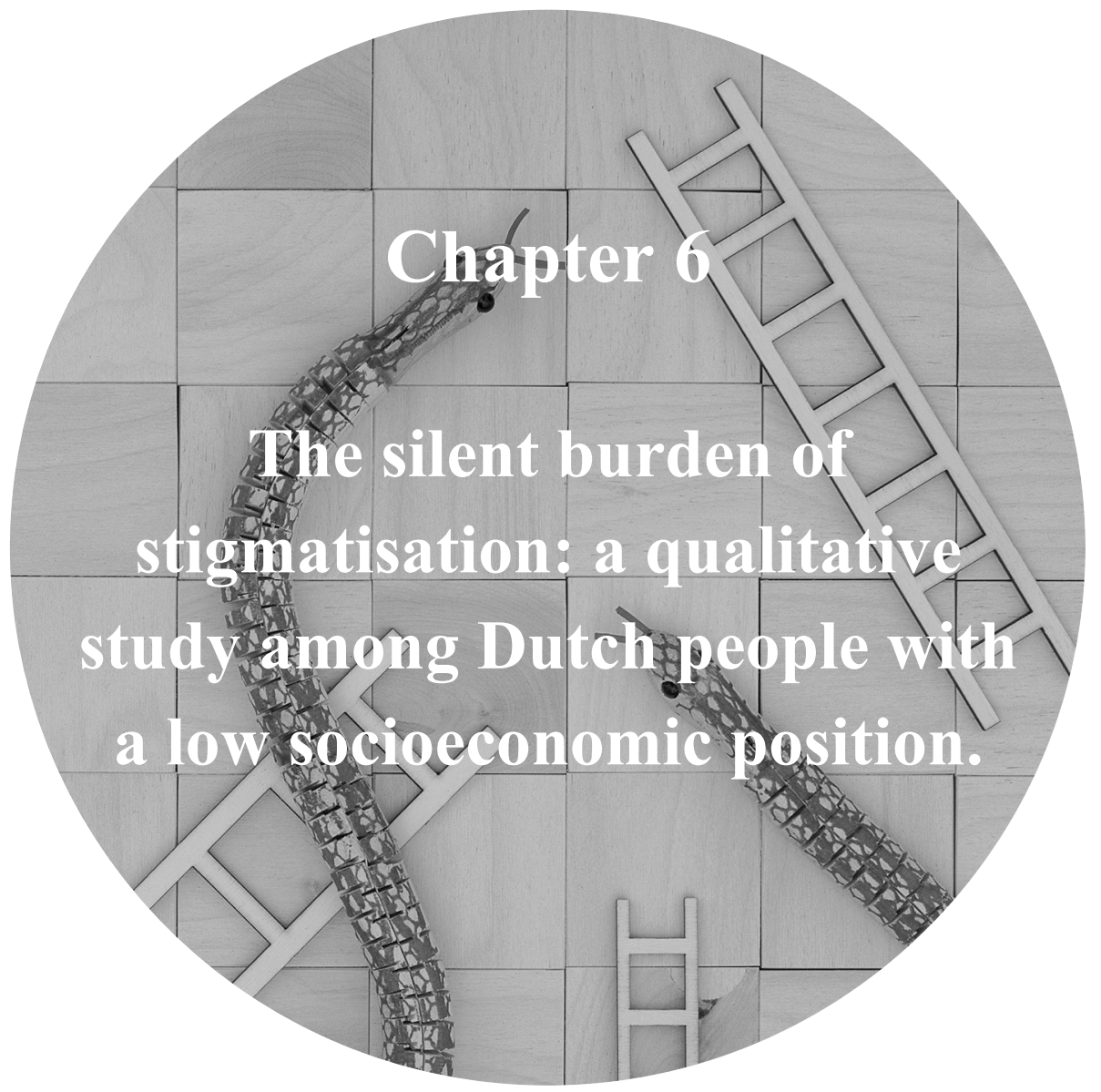

Published as:

Simons AMW, Houkes I, Koster A, Groffen DAI, Bosma H. The silent burden of stigmatisation: a qualitative study among Dutch people with a low socioeconomic position. BMC Public Health. 2018;18(1):443. 


\section{Chapter 6}

\section{Abstract}

Background. In-depth qualitative research into perceived socioeconomic position-related stigmatisation among people living at the lower end of our socioeconomic hierarchy is necessary for getting more insight in the possible downside of living in an increasingly meritocratic and individualistic society

Methods. Seventeen interviews were conducted among a group of Dutch people with a low socioeconomic position to examine their experiences with stigmatisation, how they coped with it and what they perceived as consequences.

Results. Social reactions perceived by participants related to being inferior, being physically recognisable as a poor person, and being responsible for their own financial problems. Participants with less experience of living in poverty, a heterogeneous social network and greater sense of financial responsibility seemed to be more aware of stigmas than people with long-term experience of poverty, a homogeneous social network and less sense of financial responsibility. Perceived stigmatisation mainly had emotional consequences. To maintain a certain level of self-respect, participants tried to escape from reality, showed their strengths or confronted other people who expressed negative attitudes towards them.

Conclusions. Despite the good intentions of policies to enhance self-reliance, responsibility and active citizenship, these policies and related societal beliefs might affect people at the lower end of our socioeconomic hierarchies by making them feel inferior, ashamed and blamed, especially when they cannot meet societal expectations or when they feel treated disrespectfully, unjustly or unequally by social workers or volunteers of charity organisations. 


\section{Introduction}

Despite all the efforts to reduce the (health) gaps between rich and poor, modern Western societies are still being challenged by socioeconomic inequalities and significant health inequalities $(1,2)$. At the same time these societies are increasingly permeated by the belief that economic and social success can be achieved through talent and effort $(3,4)$. The downside of this increasingly accepted meritocratic belief in earned success and individual responsibility might be that people at the lower end of Western societies are stigmatised (3-5); they might be regarded as lazy, incapable or unmotivated (6-9). Stigmatisation occurs when, within social interactions, a personal attribute is recognised as different (e.g. not wearing the right brand or being unemployed), and the person is devalued because of this attribute. Perceived stigmatisation is the stigmatised person's subjective experience of this devaluation (10). In this paper, perceived stigmatisation will refer to perceived devaluation based on attributes related to someone's socioeconomic position (SEP) (e.g. low income, unemployment, being a social benefit recipient, and/or living in poverty/poor material circumstances).

Previous research has shown that social benefit recipients and people living in poverty often perceive negative judgements and feel degraded, isolated, devalued, blamed and looked down upon (11-17). We found that over $18 \%$ of the general Dutch population perceived some kind of SEP-related stigmatisation, and that people in the lowest income and occupational groups were significantly more likely to perceive stigmatisation (respectively, $22.0 \%$ and $27.5 \%$ ) (18). However, further in-depth research into perceived SEP-related stigmatisation and its consequences is necessary to understand this possible downside of living in an increasingly meritocratic and individualistic society.

Research into various forms of stigmatisation (e.g. racism) has shown that perceived stigmatisation can have serious physiological and psychological health consequences for the stigmatised individual (19-26). Some studies found that perceived SEP-related stigmatisation is also associated with poor self-rated health, negative emotions and feelings of inferiority $(16,23)$. The consequences of stigmatisation (e.g. for health) depend, inter alia, on how people perceive social situations and how they cope with these perceptions $(21,25,27,28)$. Different coping strategies for both material deprivation (i.e. poverty) and related stigmatisation were found in a number of studies: overcompensating positive 


\section{Chapter 6}

behaviours, violence out of self-protection, not caring about what others think, withdrawing or self-isolating, concealing poverty (e.g. by purchasing expensive items to keep up appearances), and cognitive distancing (27, 29-32). Sometimes it even seemed that people who experienced long-term poverty appeared to be quite satisfied with the situation (the 'satisfaction paradox' (33)). Studies into poverty showed that to protect themselves from the stress related to living on a low income or being unemployed for a long time, people may adapt their standards in order to lessen dissatisfaction and disappointments in life and to become more satisfied with their situation $(33,34)$.

'Who is born for a dime, will never be worth a quarter' was the mainstream idea in Dutch society for a long time. However, in the 1960s the Dutch government developed a generous welfare system and a more egalitarian and easier accessible educational system. As a consequence, inequalities decreased and educational levels rose $(35,36)$. Society became more open and individualised, and meritocratic beliefs started to arise: 'who was born for a dime, could with some talent and effort - become worth a quarter' (37-39). In the 1980s the decrease in inequalities came to an end and increased again (40). At the same time some changes were made to the welfare system: financial cuts were necessary and free market policies/market competitiveness were introduced, which strengthened the meritocratic way of thinking and increased the focus on selfreliance (41). A large-scale benefit fraud in the 1990s strengthened the negative beliefs about the (undeserving) poor (42). In the following years, just as in many other European countries, responsibility for one's own situation, selfreliance and active citizenship became increasingly important $(43,44)$. The strengthened meritocratic beliefs, individualisation of society, and the growing emphasis on own responsibility, self-reliance and participation, all might have strengthened the negative beliefs about people in lower SEP groups. Therefore, the present study aims to provide more insight into the understudied experience of SEP-related stigmatisation from the perspective of low-SEP groups in the Netherlands $(18,45)$.

Knowing more about the experiences of these people at the lower end of our society might provide tools to enhance the effectiveness of policies (e.g. regarding employment) and professional help to, for example, social benefit recipients or people with financial problems. Since the perception of stigmatisation is a subjective experience, a qualitative study is the most appropriate approach to study perceived stigmatisation in low-SEP groups. Therefore, this 
qualitative study sought to address the following research questions: (1) What are the experiences of people from lower-SEP groups with SEP-related stigmatisation? (2) How do people from lower-SEP groups cope with SEP-related stigmatisation? and (3) What are the perceived consequences of SEP-related stigmatisation?

\section{Methods}

\section{Design}

A qualitative design with semi-structured individual interviews was used to examine the experiences of SEP-related stigmatisation in a lower-SEP group.

\section{Participants and context}

In 2014, a convenience and purposive sample of people from lower-SEP groups (varying in age, gender and source of income/social benefits) was recruited via a charity organisation that supports poor and often unemployed people by offering easily accessible financial, material or informational support, in a middlesized city in the southern part of the Netherlands. People in this city are more likely to live on a minimum income than the average Dutch population (46). People were eligible for this study if they lived on a low income (e.g. had a lowpaid job, lived on social benefits or were unemployed), were 18 years or older, and spoke Dutch or the regional dialect. We conducted 16 interviews with 17 persons (one married couple was interviewed). For more information about the sample characteristics, see Table 1.

All interviewees were dependent on social benefits and most of them received disability benefit or work and social assistance. Four people were currently in debt rehabilitation. In the Netherlands, people are eligible for debt rehabilitation when they are no longer able to handle their debts. A personal administrator is then assigned by a court for a certain period to control their finances and help them pay off their debts. After this period, the remaining debts are waived and if necessary people may receive ongoing support from a personal administrator (47).

The life courses of most of our interviewees can be described as 'hard': interviewees spoke about growing up in large families or orphanages, being exposed to family problems (e.g. poverty, psychiatric problems, child abuse, 


\section{Chapter 6}

divorce and loss of a spouse), earlier debts in adult life and struggles with (psychiatric) illnesses. At the moment of the interviews, none of the interviewees had a job and most of them were long-term unemployed. Jobs of interviewees who had recently worked could be categorised into the lower occupational classes/ working class (48). Although most interviewees see themselves as 'poor' and think to be seen as 'poor', we could not judge if they really lived under the poverty line, however they almost all lived in a quite poor financial situation in which they lacked the resources to afford basic necessities (e.g. food, clothes, and health care).

Table 1 Sample characteristics $(n=17)$

\begin{tabular}{lll}
\hline Characteristic & N $(\%)$ & \\
\hline Men & 7 & $(41.2)$ \\
Age (range) & $32-83$ years & \\
Household type & & \\
$\quad$ Single & 11 & $(64.7)$ \\
$\quad$ Single with child(ren) & 3 & $(17.6)$ \\
With partner & 1 & $(5.9)$ \\
$\quad$ With partner and child(ren) & 2 & $(11.8)$ \\
Having a job & - & - \\
Receiving social benefits & 17 & $(100)$ \\
$\quad$ Unemployment Benefit & 1 & $(5.9)$ \\
Disability benefit & 6 & $(35.3)$ \\
Old-Age Pension & 3 & $(17.6)$ \\
Work and Social Assistance & 6 & $(35.3)$ \\
Unknown & 1 & $(5.9)$ \\
Currently & & \\
Requested & 4 & $(23.5)$ \\
In the past & 1 & $(5.9)$ \\
Never & 3 & $(17.6)$ \\
Debt Rehabilitation & 9 & $(52.9)$ \\
Yes & & \\
No & 5 & $(29.4)$ \\
Additional support from financial administrator (currently) & 12 & $(70.6)$ \\
\hline
\end{tabular}

\section{Procedure and data collection}

Participants were recruited by means of posters and flyers with easy-to-read information in the shop and coffee corner of the charity organisation. They received detailed information after signing up for the study, or on request. The interviews took place at a location chosen by the participant (e.g. at the participant's home or at the charity organisation), and all participants gave their in- 
formed consent. The semi-structured interviews were conducted by the first author and lasted on average 70 minutes (ranging from 25 to 150 minutes). During the interviews a topic list was used, which was based on the research questions and literature, and included demographics, family composition, living situation, financial situation, social reactions, dealing with social reactions and health. Interviewees also had the opportunity to tell their own story. Topics like stigmatisation and shame were not primed during the interviews. As an incentive, the participants received a shopping voucher of 25 euros. The charity organisation received 250 euros for their collaboration. All interviews were audiotaped and the records were transcribed verbatim. The study protocol was approved by the medical ethics committee azM/UM in Maastricht, the Netherlands (reference number METC 13-4-077, November 2013).

\section{Analysis}

The transcripts were analysed thematically by the first author, using the six phases described by Braun and Clarke (49). To ensure valid results, the members of the research team participated in a number of peer review sessions, in which several transcripts were read in advance and codes, themes and other important observations were discussed. Analysis was supported by NVivo software.

\section{Results}

Figure 1 shows the four themes that emerged from the data and the relation between the themes: stigma awareness (1) was an overarching theme that influenced the perceived negative social reactions (2) and feelings of shame (3) among the participants, and the ways in which they tried to maintain selfrespect (4) when perceiving social reactions or feeling ashamed. 


\section{Chapter 6}

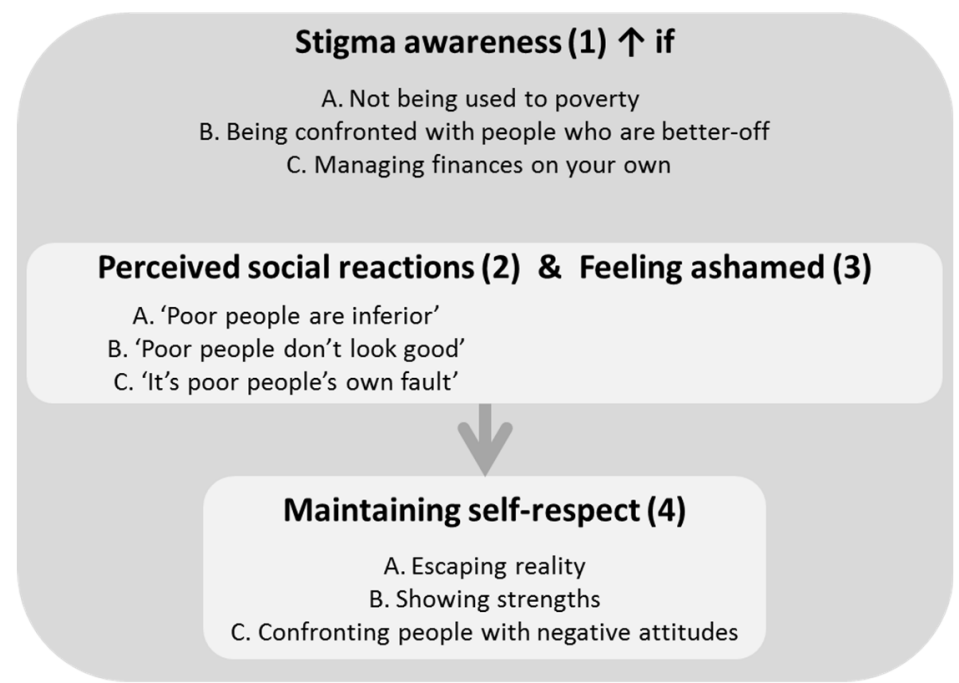

Fig. 1 Relation between the themes: Stigma awareness, perceived social reactions, feeling ashamed and maintaining self-respect.

\section{Stigma awareness}

Not all participants seemed equally aware of the existing stigmas related to poverty, unemployment or social benefit recipients or of the stigmatising social reactions they got related to their SEP. Differences in participants' socioeconomic background (A), composition of their social network (B) and the responsibility they took for their financial management (C) seemed to influence how aware they were of social reactions regarding their financial situation and how they expressed feelings of stigmatisation within their stories.

\section{A. Not being used to living on a low income}

Interviewees had different socioeconomic backgrounds. About half of the interviewees had grown up in poverty and were used to living on a low income. A number of older interviewees had been born in or just after the Second World War, and grew up in orphanages. Others had never had severe financial problems in the past and had to learn how to cope with these new circumstances. This last group seemed to be more aware of negative social reactions in their environment and the injustice of society, and perceived negative social reactions more often. Interviewees who were more used to living on a low income seemed to have got used to their way of living and, although their stories told us 


\section{Silent burden of stigmatisation}

that they were aware of stigmas, they perceived less negative reactions - or were less aware of them - and felt less shame.

"When I was young we went to the nuns and fathers at the hospital to get food, then you were 'that kind of a family' [...] You know, I grew up like that and that's why I fight, I don't feel ashamed, because I already went through it as a child." (A, f68, grew up in poverty)

Besides their socioeconomic background, the participants' present social network also seemed to influence the degree of awareness of negative social reactions.

\section{B. Being confronted with better-off people}

Adjusting to living on a low income was also reflected in the social networks of the interviewees. Interviewees who had grown up in poverty seemed to have a more homogeneous network of other people on low incomes, and were less confronted with people who were better off, while interviewees with a more heterogeneous network experienced more confrontations with people who were better off and were more aware of social reactions or feelings of inferiority.

"And so, like my friends [on higher incomes], they think that I'm a capitalist, because I bought a cupboard for 35 euros, but they don't know that I then have to live on peanut butter sandwiches for a week. They don't need to know." (G,

For interviewees with a heterogeneous network it also seemed more difficult to feel part of a group; they did not belong to the group of people with no financial worries, but neither to the group of people who were in debt and/or debt rehabilitation.

\section{Managing finances on one's own}

Living on a low income seemed even harder when interviewees took full responsibility for their own financial management. It was particularly those participants who managed their own payments and savings who mentioned 'the injustice of society'. Having to struggle with their financial problems on their own - while others got financial, material or informational support - felt unfair, even though they felt proud about managing everything themselves. They some- 


\section{Chapter 6}

times even felt punished for their efforts to prevent debts; they were denied access to additional financial help (e.g. 'no debts, no problems, no help') and perceived a lack of understanding, especially from people working at the municipality, local credit bank or Employee Insurance Agency (i.e. social workers, with often a higher professional education in Social work or Social Legal Services) or from volunteers of charity organisations. It was frustrating for interviewees who were free of debts but who were living on a low income without additional support, to see people in debt rehabilitation who received more support (e.g. foodbank, clothes bank, getting things for free or getting interest-free loans) and in the end had more to spend each month than they had. They also felt more stress because of all the bills that had to be paid and the lack of financial support.

"I think...I mean people who work hard to stay on their feet, to stay out of debt, pay for everything, but live on almost nothing...they are not being noticed." ( $G$,

"You [people in debt rehabilitation] should be glad for all the help you get; I have to do it all myself, and you get so tired of it." (R, f52)

Interviewees who had financial assistance seemed to give up part of their own responsibility. They admitted that having financial assistance was sometimes 'easy' and relieved them of the monthly payment stress.

"I'll go on receiving financial support. You get 85 euros each week and you don't have to do anything. They pay for things, that's easy." (E, m50)

Thus, participants who took a lot of responsibility and tried to cope with all the financial difficulties themselves were disappointed about the way they were treated by social workers and volunteers.

Interviewees' socioeconomic background and social network also seemed to play a role in the barrier to giving up financial responsibility and asking for financial support. Participants who had grown up in a more financially stable situation perceived a high barrier to asking for help, and they were more inclined to try to cope with the situation themselves.

"I don't want to be dependent, that's what I fight for, not being dependent. I don't want that." (G, f56) 
This overarching theme of differences in stigma awareness also played a more or less important role in the next three themes and subthemes.

\section{Perceived social reactions}

Almost all participants perceived social reactions regarding their financial situation, although in different ways. While some interviewees mentioned negative social reactions explicitly, most of them did not mention negative reactions or perceived stigmas directly, but expressed for example how hard they always worked. This could indicate that they were aware of stigmas relating to poor people or people on social benefits, for example about 'the poor being lazy', but were less aware of the social reactions based on these stigmas. As described in the first overarching theme, this could depend on peoples' experiences with poverty or living on a low income. Perceived social reactions were categorised into three subthemes.

\section{A. 'Poor people are inferior'}

In contacts with people in society (e.g. neighbours or people in the street), social workers and volunteers of charity organisations (e.g. at the foodbank), participants experienced reactions or treatments that made them feel they were worth less than others because of their financial situation - sometimes even less than others who were also living on a low income - and they felt looked down upon. It was particularly those who were struggling with living on a low income, taking responsibility for their own financial affairs and without receiving additional financial support (e.g. special benefits), but were able to avoid debts, who experienced unequal treatment at the foodbank, the second-hand shop of a charity organisation or the municipal authorities.

"...that month that I went [to the foodbank], you go along the tables and they put food on it and I get a carton of yogurt and a carton of pudding from the 'Aldi' [cheap supermarket] while someone else gets, for example, 3 or 4 cartons of 'Mona' pudding [premium brand] ... Why? Why don't they distribute it

$$
\text { fairly?" }(M, f 53)
$$

Interviewees felt looked down on in social situations, but could not always mention why or what was happening at the moment. It was more like a feeling, without something actually happening. 


\section{Chapter 6}

"When you visit people with nice pearl necklaces, you feel that... without them talking about it, you feel it, I at least do. I feel it..." (G, f56)

For some participants the 'status' of their neighbourhood was important; living in a 'good' neighbourhood made them feel better because people saw them differently, more favourably.

"People do ask 'where do you live?' but simultaneously they think they can tell you where you live. Telling where you come from can have a different impact, in conversations or at work for example. I notice that. [...] Yes, people give you different 'looks'. Yes different...pleasant." (D, f57, living in a 'good' neighbourhood)

Sometimes, interviewees also felt that others believe they did not deserve luxury or nice things because of their financial situation, although they themselves think they did, especially because of all the personal and financial struggles.

"I got this apartment, and I took over the tiled floor and the washing machine, so I got a real nice apartment, but the people in the hallway they're jealous, but I can't help I'm the lucky one, but then I think 'I've lived in a shelter for 4 years, so what's wrong with this?" $(R, f 52)$

In addition to direct experiences of negative social reactions regarding inferiority, participants often anticipated and feared getting negative reactions. The same is true for the next subtheme.

\section{B. 'Poor people don't look good'}

Interviewees expressed how they took care of their appearance (e.g. clothes) to avoid negative social reactions, to fit in with peers, or to feel better about themselves.

"In the evening, I washed my clothes and then I put them on again the next day [...] nobody would notice, as long as they were clean and I showered" (A, f68)

Some expressed a lack of interest in wearing appropriate or expensive clothes themselves: they would rather use the money for other things, like 


\section{Silent burden of stigmatisation}

clothes for their children to prevent bullying or going out with friends, or they argued that their lack of interest in wearing appropriate clothes was not because of their financial situation but because they found new clothes unnecessary.

"I can wear the same trousers for 2 years, I don't care. But it's different for my children, they go to school and might be bullied you know." (L, $f$ ?)

"I don't care [about clothes]... I always think 'you guys, go ahead and spend your money on them...I can't, but I have enough clothes, I don't need new clothes every two months, that's not necessary' [..] I just wear my work clothes." $(O, m 60)$

Interviewees also proudly showed or told how good their homes looked, even with second-hand furniture.

"I furnished my whole house with stuff from [the shop of the charity organisation] and from second-hand shops and I furnished it very nicely." (C, m61)

For some it was frustrating and sometimes shameful that they could not afford furniture, wallpaper, paint, or decorations to make their house into a home, but they put their circumstances into perspective and said they were glad to have place of their own.

"I had a nice house, you know, with everything, television, bedrooms... a widescreen TV on the wall and now I'm watching a small one. It doesn't hurt, because I saw the other side of the medal too [...] I'm thankful for having a roof over my head and I eat and drink every day." $(B, m 51)$

Participants' stories showed that their financial situation and the awareness of the necessity to keep up appearances was often a difficult combination, as they wanted to take care of their appearance, but did not always have the financial means to do so. The participants' background or social network seemed to play a less important role in these experiences than in those regarding inferiority; they all seemed to be aware of the necessity of trying to look presentable. 


\section{Chapter 6}

C. 'It's poor people's own fault'

Participants mentioned negative reactions regarding their unemployment. Some emphasised how hard they were working at the moment (e.g. as a volunteer) and how active they were, or they wanted to show how hard they had always worked by listing all the jobs they had in the past. Or they emphasised that their current situation (e.g. unemployment) was not their fault (e.g. not because of laziness or not being willing to work).

"I'm always busy. I worked before, because I took every job that I could, I even worked in industry, at a fast food restaurant, in shifts, I worked there for a few months. I also worked for a farmer harvesting asparagus and a little bit in the catering industry. [...] Because I'm always busy, I won't get comments like 'they're always sitting around doing nothing.'." (D, f57)

Participants often felt blamed and felt the pressure to justify why they were not in work; although they wanted to work, they often felt unable to work because of health problems or family commitments.

"I've been on benefits since 2007, first my children were small and I had to cope with a lot myself because of my problems in the past. Then I got two children and I was unable to work, that's how it went." (L, $f$ ?)

Another group of interviewees seemed to show the fear of being blamed by ascribing the cause of their financial problems and lack of work to bosses, the government, low benefits, the euro or foreigners taking their jobs.

"The euro, health insurance and the taxman cause problems for a lot of people, not only for me [...] It was not my fault that I got into debt, that's the worst part of it. If I had just gone on holiday, bought cars, etc., then you know why you're in debt, but I got into debt another way... and that's difficult to say." (K, f36)

Some interviewees also expressed their negative attitude towards working (for money or for a boss), especially after some negative experiences with former employers.

"I will never work for the high and mighty in the Netherlands again. This is the third employer here in the Netherlands who has fired me, even though I also put 
in 100\% effort. [...] I have to apply for a job four times a month... and I do that! I apply, send off the applications, done...but I won't work anymore." (B,

Interviewees also experienced social reactions that gave them the feeling that they were responsible for their own financial situation, or they perceived a lack of understanding of their financial hardship and the support they were receiving.

"My daughter was ill [...] she didn't work, so yeah I paid for her medication, I paid her rent and all other expenses, so my savings were gone...then the people at the municipality [when applying for additional social benefits] told me 'You shouldn't have done that'. I shouldn't have helped my daughter, I should have saved up the money." (M, f53)

Although most of the participants described experiences of or the fear of experiencing negative social reactions regarding their own responsibility, those with long-term experience of living on a low income or being unemployed seemed to be more likely to blame others for their situation.

\section{Feeling ashamed.}

Participants' feelings of shame also seemed to differ with their background and the composition of their social network; those with long-term experience of living on a low income and those with a more socially homogeneous network (in terms of SEP) expressed less shame.

Shame was reported to occur in various situations: for example when remembering their successful past:

"Shame...yes... think of it this way...I always worked on my career [being a successful DJ] [...] ...then going down [in income/status], while people know you had bags of money in the past." (E, $m 50)$

Or when others uncovered their previous or current poor financial situation:

"On television they [the interviewers] would just say 'O I heard you also used to beg in the street?" (A, f68) 


\section{Chapter 6}

Or when they were unable to pay for gasoline, when people saw their homes or when they could not give something in return after being given something.

"I used to live in a very dirty apartment, I had no money to do it up [for the film crew]. I got a stand from the second-hand shop, put a vase from the secondhand shop on top, with roses in it that I couldn't really afford [...] bought a poster. And I said 'would you please film me in that corner there, cause I don't have the money to do it up. I've only just moved in here. Would you please film that part?'” (A, f68, who was interviewed for TV)

It was also embarrassing when they had to tell their story over and over again.

“...you have to tell your story again and again and explain what's the matter [...]. But after a while it stops you from doing things because you get fed up, you're tired of telling your story once again, explain your situation again, as you're seen as a beggar, you're just begging in fact." ( $R, f 52)$

Some also expressed that they did not feel ashamed or that it was not necessary to feel ashamed about their financial situation, because they were used to it, did not care, said they were lucky with all the help, or because it was not really a problem since many people had debts.

“... I don't care about that [wearing second-hand clothes], I'm not ashamed about it. There are people who feel ashamed about that. But I'm not." (H, f82)

\section{Maintaining self-respect}

Having to tell their story over and over again to justify why they need help, losing their autonomy in life because of their limited resources and dependence on others, being deprived of privacy, and being treated unequally or without respect appeared to affect interviewees' self-respect. This was most noticeable in the strategies interviewees used to cope with social reactions; maintaining self-respect appeared to be the main goal of their strategies. Their strategies seemed to differ with participants' backgrounds and social network. For example, those who were more used to living on a low income and who had a more homogeneous social network (in terms of SEP) seemed to be more likely to cope by denying, playing tough and attaching less value to certain aspects of 
life, whereas those who were not used to living on a low income and had a more heterogeneous network were more likely to try to conceal their situation and maintain their self-respect by showing how proud they were of their achievements and emphasising their positive characteristics. They were also more likely to actively confront people who show negative attitudes. The coping strategies could be roughly categorised into three subthemes:

\section{A. Escaping reality}

Interviewees tried to deny or conceal their difficult situation, to themselves or to others; they would conceal their financial problems to family and friends, deny perceiving negative social reactions and attach less value to status symbols to protect themselves from feeling bad.

\section{Concealing financial problems}

Most interviewees tried to conceal their financial problems by taking care of their appearance and behaviour in public, by living in a better neighbourhood, or by just not telling family members and friends about their financial problems.

"I never really talk about my, err, finances, you know. Because, well, I want to feel like I still have a bit of pride about myself, you know." (G, f56)

They also tried to hide their situation by looking for excuses, by staying at home and avoiding social contact, or by avoiding shops.

"It regularly happens that we say 'we don't feel like it' even though we really would like to do it, but we can't." (P, m50)

Denial of negative social reactions

Some interviewees denied perceiving negative reactions regarding their financial situation when they were asked about negative social reactions. However, indirectly, and perhaps also unconsciously, they mentioned the need to look good or appropriate or blamed others for their financial situation. For example, one man when asked if he got any reactions regarding his living situation, since he was living on small income in a quite high SEP neighbourhood, denied this. However, a few seconds later he told about a conflict with his neighbour who had complained about him not taking care of his animals: 


\section{Chapter 6}

"No, not really. [...] You don't come into contact with people there [in his neighbourhood]. [...] And I had a cat and a dog, and then the woman next doors started to feed my cat. And at a certain moment I got a note through the letterbox saying I should feed my cat better. [...] I got angry and I didn't speak to her again." (C, m61)

Attaching less value to SEP indicators

During the interviews some participants expressed a negative attitude towards working (again) or money, and denied the importance of a high educational level.

"Yeah, she was advised to take HAVO (a higher level of secondary school) but that was doubtful, so she went for MAVO (a lower level). She knowns what she wants to be in the future anyway. [...] When you take HAVO, that means you can go into $H B O$ (a higher level of tertiary education), which would be nice, but MBO (a lower level, accessible with a MAVO diploma) will also get her there."

They seemed to attach less value to aspects in life that are important for a high position in society.

\section{B. Showing strengths}

By playing tough, emphasising positive characteristics, showing pride, and collecting objects, participants seemed to cope with the lack of status symbols like money or big cars.

Playing tough

A few male interviewees did not mention feelings of inferiority directly, but their behaviour during the interviews seemed to show otherwise; they showed 'macho behaviour', aggression or emphasised how strong, self-confident or smart they were.

"Then my employer fired me and I ran away to avoid killing him, [...] I had already come across him once before, when he was a bit drunk and I looked for a piece of wood ... and struck at him, but fortunately I didn't hit him. " $(B, \mathrm{m51})$ 
By 'playing tough' they seemed to protect their self-respect from being damaged by others.

Emphasising positive characteristics and showing pride

Interviewees also seemed to try to maintain their self-respect by emphasising their positive characteristics (e.g. being loved, sociable and empathic).

"I know lots of people and they all love me. So that's nice, right?" (Q, f73)

Some were proud of their achievements (past or present), of how they handled their difficult financial situation, and of how they furnished their homes with things they found, bought in second-hand shops, or were given by others.

"Honestly, can't I be a bit proud of the fact that I have avoided that [i.e. getting into debt]" (G, f56)

A number of interviewees also proudly told about or showed their collections of music (e.g. CDs or DJ equipment), books, statues and figurines, or pets. And although it sometimes cost them a lot of money, their collections or pets meant a lot to them. These material things seemed very important to them, especially when they had only few possessions.

"You might get rid of it, but then somebody else will get the credits. So I'm not gonna do that." (E, m50, about his DJ/music collection)

Emphasising positive characteristics and showing pride made interviewees feel good about themselves and seemed to improved their self-respect.

\section{Confronting people who show negative attitudes}

Besides trying to escape reality or trying to maintain self-respect by showing their strengths, some interviewees also tried to confront others regarding their negative social reactions or negative attitudes. One man challenged people to be more specific regarding statements they made or opinions they expressed. 


\section{Chapter 6}

"'Just tell me where?' if they say 'There're enough jobs!' 'Well then, just give me an address and I'll go there.' 'Well, I can't.' So well, there's no work then, is there?!" $(P, m 50)$

One woman wanted to start a radio program to give homeless people a voice and enable them to share their experiences and stories, with the intention of opening up listeners' eyes.

"So people will understand if they see somebody walking by, that it's not just ..." $(R, f 52)$.

She even went to the town council to talk with politicians about the unequal treatment at the foodbanks.

"I can't stand injustice. [...] I'm very quiet and calm, but when I see injustice, [...] I get angry. [...] I went to the town council and I know this woman and then I tell her about it, hoping she'll do something about it [i.e. injustice at the foodbank]." (R, f52)

Another woman wanted to go on participating in society so she could show that people who were unemployed were not lazy or unwilling to work and prevent negative reactions.

"No, not as such [about social reactions to her unemployment], but that's because I'm always busy, you know, so I don't get these comments like 'Well, they're sitting around all day doing nothing.'." (D, f57)

Confronting people regarding their attitudes or beliefs seemed to be an effective way of coping for some interviewees; however, it also seemed hard for participants to confront people, especially when social reactions were not expressed very directly. 


\section{Discussion}

The aim of this study was to examine in greater depth the experiences of SEPrelated stigmatisation in Dutch social benefit recipients. From the 17 individual semi-structured interviews, four themes emerged: (1) awareness of stigma, (2) perceived social reactions, (3) feeling ashamed, and (4) maintaining selfrespect. These themes enabled us to answer our research questions: (1) What are the experiences of people from lower-SEP groups with SEP-related stigmatisation? (2) How do people from lower-SEP groups cope with SEP-related stigmatisation? and (3) What are the perceived consequences of SEP-related stigmatisation?

Our study showed that people at the lower end of the social hierarchy in the Netherlands feel stigmatised because of their SEP. Participants perceived the stigma of being inferior, being physically recognisable as a poor person, and being responsible for their own financial problems. Participants often talked (directly or indirectly) about perceived or anticipated negative social reactions regarding their SEP, or they used compensation strategies to cope with (real or anticipated) negative reactions and to maintain their self-respect. Similar results were found in recent studies by Kampen, Elshout and Tonkens $(39,50)$, who found that long-term unemployed Dutch people struggled with self-esteem and self-respect, and that they also felt inferior, looked down upon and ashamed.

Our interviewees differed in their awareness of negative reactions regarding their SEP. This is also called stigma consciousness: they might all be aware of their stigmatised status, however people might focus more or less on their stigmatised status and expect more or less stigmatising social reactions (51). Participants seemed more aware if they had had less experience of poverty or living on a low income in the past, had a heterogeneous social network (in terms of SEP) and tried to manage their own finances. Injustice in society was particularly felt by participants who wanted to be independent and took responsibility for their own finances. They felt that their efforts were not being recognised and that they were treated unequally by social workers and volunteers of charity organisations, particularly compared to other people who lived on a low income but who did not take responsibility for their own financial matters. Participants who had experienced poverty or living on a low income in the past and those with homogeneous social network (in terms of SEP) seemed to be more used to living on a low income. The 'satisfaction paradox' can explain why we 


\section{Chapter 6}

found less stigma awareness among participants with long-term experience of living on a low income. Learned helplessness, low control beliefs and the cognitive dissonance of wanting a more satisfying life but being unmotivated because of disappointments in prior unsuccessful attempts can explain this satisfaction paradox in this group. $(33,34,52)$. When people become less active and lose motivation (e.g. not looking for work, not taking responsibility for their financial management) because they found out that their efforts had no effect, they may adjust to their situation by resolving the cognitive dissonance through lowering their standards, and this lowering of standards could result in less stigma awareness. On the other hand, when people see 'satisfied poor people' in society this might also enhance stigmatisation, as their circumstances might be perceived as being their own choice (e.g. not being in work or living in poverty) (33). Another issue that could make participants less aware of negative social reactions regarding their socioeconomic situation could be the high prevalence of other problems in the family. Most interviewees' families could be categorised as multi-problem families; they were struggling not only with financial problems but also with severe health problems, psychiatric problems, behavioural problems of family members, children being taken into care, or tensions between family members. It is possible that they were more aware of negative social reactions (stigmas) regarding these other problems (e.g. being bad parents or psychiatric patients) than of reactions regarding their financial situation) (16).

The goal of participants' strategies to cope with classism was to maintain some level of self-respect, which could have been damaged by living at the lower end of the social hierarchy in a meritocratic society. Swierstra and Tonkens (4) and Elshout (39) described a number of ways of maintaining selfrespect in a world where self-respect of people in lower positions is undermined because it is believed that they deserve their low SEP and have to be ashamed of themselves. We recognised some of them in our study: criticising ideology (e.g. blaming others for not having equal chances in life), shortcuts and changing the rules (e.g. stealing to earn respect and to have money), and refusing to take part in the competition (e.g. no longer being willing to work). The coping strategies found in our study are consistent with strategies found in previous research into coping with poverty and related stigmatisation, for example compensating behaviour like aggression, denial and concealing and withdrawing or self-isolating $(27,29-32)$. The 'satisfaction paradox' can also explain some of the coping strategies we found in participants with long-term experience of 
poverty, for example, attaching less value to certain aspects of life resembles lowering one's standards in life, making a disadvantaged life easier to accept. In our study the consequences of perceived SEP-related stigmatisation were not directly mentioned. Perceived stigmatisation affected emotions (e.g. anger, frustration, shame, stress etc.) and self-respect, but they did not mention consequences to physical health. When physical health consequences were mentioned, they were often related to stress, lifestyle and their financial situation (e.g. smoking because of stress, not being able to buy fruits and vegetables or to pay for necessary healthcare). Nevertheless, it is known that emotions like anger and frustration, feelings of stress and lack of social participation can also negatively affect people's physical health $(19,24)$. Participants' interpretations of social situations and their coping strategies determined how stressful a situation was to them. This might also explain the role of the participants' socioeconomic background: people with long-term experience of poverty may have learned better how to cope with stigmatisation in order to reduce the stressful consequences $(28,33,34)$.

During the interviews it also became obvious that participants compared their situation and the way they were treated with people in similar circumstances. Participants felt frustration and injustice when they were treated unequally by social workers or volunteers of charity organisations. There was a strong focus on who gets what and how much (e.g. food from the foodbank or additional benefits from the government). These observations were consistent with De Botton's theory of status anxiety, which focuses on comparisons between close peers instead of people who are more different (3).

SEP-related stigmatisation is also known as classism: the marginalisation of those who are perceived to be in a different social class (53). However, we chose not to use this term in this study because it refers especially to stigmatisation and discrimination based on 'class', although it is used in a broader sense in other studies $(54,55)$. In this study, we did not focus on class as the most important SEP indicator. Interviewees' experiences with stigmatisation were related to different indicators of SEP (56): being unemployed, receiving social benefits, being poor, living in poor material circumstances, having an inferior status in society. Further, people often do not know why they are stigmatised (16). Moreover, to experience stigmatisation, their stigmatised identity has to be disclosed: becoming visible to or known by others (e.g. living in poor material circumstances, visiting the food bank or being unemployed) (57). Only 


\section{Chapter 6}

looking at 'class' would narrow our view on the experiences with stigmatisation too much.

\section{Implications}

Although interest in and awareness of the struggles characterising the daily lives of people living in (long-term) poverty or unemployment is rising (58), this might be one of the first scientific studies into perceived SEP-related stigmatisation in the Netherlands. We discussed what our results meant for society, however, our ideas about the implementation need further support by additional studies into SEP-related stigmatisation in the Netherlands (e.g. a study into the prevailing SEP-related stigmas in the Dutch society).

Just as in many other Western societies, there has been increasing emphasis on individualisation and self-reliance in Dutch society in recent years; people are expected to take responsibility for themselves and to participate in society (44), These expectations will increase the stigmatisation of people who are unable to take full responsibility in this respect (39). As our participants' stories showed, the lack of money or work is not the only problem in their lives, and the pressure to work, participate and take responsibility will not lead to a solution for their situation: it will in fact increase participants' struggles with feelings of inferiority and blame. Policies aiming at activating citizens and enhancing self-reliance have good intentions, but can also create collateral damage in the already difficult lives of people at the lower end of our socioeconomic hierarchy; they might feel treated disrespectfully, unjustly or unequally by social workers who base their approach on policies and societal beliefs $(39,59)$. Finding a balance between helping and impairing the situation of people at the lower end of our socioeconomic hierarchy in Western societies requires thinking about ways to motivate them to participate and take responsibility while simultaneously ensuring a respectful, just and fair approach and avoiding stigmatisation (59). Thereby, social workers and volunteers working in charity organisations should also be aware and act upon varying abilities of people in taking own responsibility and to comply with regulations and agreements; financial problems are often not the only problem they face and failures to comply may be due to more than a lack of motivation or ability (59).

This study also underlines the need for further research into perceived SEP-related stigmatisation as a possible explanation for the hard-to-change socioeconomic health inequalities in modern Western societies. When our be- 
liefs affect how we as society, including social workers and other professionals, approach people at the lower end of the socioeconomic hierarchy, interventions aimed at reducing the health gap might be unsuccessful or hurt people in lowSEP groups even more, especially when interventions (unintentionally) enhance stigmatisation. SEP-related stigmatisation might be a refractory problem in Western societies, but creating awareness of our (unconscious) stigmatising beliefs and its consequences will be the first step towards changing how we think about and approach this vulnerable group (60).

\section{Methodological reflections}

The strength of this study was the interviewing method. Even though there was a topic list, participants had the opportunity to tell their story, which provided rich data. Perceived SEP-related stigmatisation was not primed in the interviews, in order to prevent socially desirable answers or fierce denial.

This study had some limitations as well. First, due to our open method of interviewing we did not gather detailed information on life course and employment history of the interviewees (as this was not the main research question). It is important to collect this information in future research to be able to relate their experiences with stigmatisation and their background more accurately. Second, since most of the participants were also clients of the charity organisation-four participants were only recruited via the charity organisation but not clients-they may already have broken through a barrier of shame. We assume that experiences of SEP-related stigmatisation might be even worse in low-SEP groups which are not visible to charity organisations, because they might avoid charity organisations due to perceived stigma and shame. This group might be the working poor (61); over $40 \%$ of people living in poverty in the Netherlands have a paid (part-time) job or are self-employed (62), however they make less use of financial support offered by the government $(61,63)$. Because we missed this group, we cannot generalise our results to all low SEP groups. Third, since this study was conducted in the Netherlands, our results cannot be simply generalised to other countries. However, trends of individualisation and a focus on self-reliance are found in many Western societies $(43,44)$, so the stories of our participants could well resemble those found in other parts of Europe. Fourth, as we found during the interviews, only a few participants told us directly or without priming about the negative social reactions they had encountered. During the analysis we were aware of the risk of our subjective interpretation of the 


\section{Chapter 6}

participants' stories; our backgrounds and values as researchers may have been quite different from those of our participants and may have led to biased interpretation of the data. However, we tried to minimise our subjectivity by discussing the interviews in our research team (i.e. peer review).

\section{Conclusion}

On top of all the daily struggles of living on a low income with severe family problems, our participants had to deal with the experience of SEP-related stigmatisation. Almost all participants perceived social reactions related to being inferior, being physically recognisable as a poor person, and being responsible for their own financial problems. They also experienced feelings of shame. The awareness of SEP-related stigmatisation differed with participants' SEP background, social network and sense of responsibility. Maintaining self-respect in an increasingly meritocratic society was an important goal for them when dealing with SEP-related stigmatisation. It will be important to remember that, despite the good intentions, policies enhancing self-reliance, everyone's own responsibility and active citizenship can affect people at the lower end of our socioeconomic hierarchy by making them feel inferior, ashamed and blamed. This will be even worse in situations where they cannot meet the high societal expectations or when they feel treated disrespectfully, unjustly or unequally by social workers and charity organisations.

\section{Acknowledgement}

We thank all the participants for sharing their stories and the charity organisation for providing the opportunity to recruit our participants. 


\section{References}

1. Organisation for Economic Co-operation and Development (OECD). Health at a Glance: Europe 2014. OECD Publishing; 2014.

2. Pickett KE, Wilkinson RG. Income inequality and health: A causal review. Soc Sci Med. 2015;128:316-26.

3. De Botton A. Statusangst [Status anxiety]. Amsterdam: Olympus 2004.

4. Swierstra T, Tonkens E. Meritocratie en de erosie van zelfrespect [Meritocracy and the erosion of self respect]. Krisis. 2006;3:3-23.

5. Saunders P. Unequal but fair: a study of class barriers in Britain. London: IEA Health and Welfare Unit; 1996.

6. Lott B. The social psychology of class and classism. Am Psychol. 2012;67(8):650-8.

7. Kwate NO, Meyer IH. The myth of meritocracy and African American health. Am J Public Health. 2010;100(10):1831-4.

8. McCoy SK, Major B. Priming meritocracy and the psychological justification of inequality. J Exp Soc Psychol. 2007;43(3):341-51.

9. Cozzarelli C, Wilkinson AV, Tagler MJ. Attitudes toward the poor and attributions for poverty. J Soc Issues. 2001;57(2):207-27.

10. Bos AE, Pryor JB, Reeder GD, Stutterheim SE. Stigma: Advances in Theory and Research. Basic Appl Soc Psych. 2013;35(1):1-9.

11. Collins SB. An understanding of poverty from those who are poor. Action Res. 2005;3(1):9-31.

12. Ravensbergen F, VanderPlaat M. Barriers to citizen participation: the missing voices of people living with low income. Community Dev J. 2010;45(4):389-403.

13. Underlid K. Poverty and experiences of insecurity. A qualitative interview study of 25 long-standing recipients of social security. Int J Soc Welfare. 2007;16(1):65-74.

14. Hirschl T, Rank M, Kusi-Appouh D. Ideology and the Experience of Poverty Risk: Views About Poverty Within a Focus Group Design. J Poverty. 2011;15(3):350-70.

15. McIntyre L, Officer S, Robinson LM. Feeling poor: The felt experience of low-income lone mothers. Affilia. 2003;18(3):316-31.

16. Fuller-Rowell TE, Evans GW, Ong AD. Poverty and health. Psychol Sci. 2012;23(7):734-39. 


\section{Chapter 6}

17. Simons AMW, Groffen DAI, Bosma H. Income-related health inequalities: does perceived discrimination matter? Int J Public Health. 2013;58(4):513-20.

18. Simons AMW, Koster A, Groffen DAI, Bosma H. Perceived classism and its relation with socioeconomic status, health, health behaviours, and perceived inferiority: the Dutch LISS-panel. Int J Public Health. 2017;62(4):433-40.

19. Meyer IH, Schwartz S, Frost DM. Social patterning of stress and coping: Does disadvantaged social status confer more stress and fewer coping resources? Soc Sci Med. 2008;67(3):368-79.

20. Liu WM. Social class, classism, and mental and physical health. Social class and classism in the helping professions: research, theory, and practice. California: Sage Publicationa, Inc.; 2010.

21. Pascoe EA, Smart Richman L. Perceived discrimination and health: a meta-analytic review. Psychol Bull. 2009;135(4):531-54.

22. Caputo RK. The effects of socioeconomic status, perceived discrimination and mastery on health status in a youth cohort. Soc Work Health Care. 2003;37(2):17-42.

23. Mickelson KD, Williams SL. Perceived stigma of poverty and depression: examination of interpersonal and intrapersonal mediators. $\mathbf{J}$ Soc Clin Psychol. 2008;27(9):903-30.

24. Krieger N, Kosheleva A, Waterman PD, Chen JT, Koenen K. Racial discrimination, psychological distress, and self-rated health among USborn and foreign-born Black Americans. Am J Public Health. 2011;101(9):1704-13.

25. Clark R, Anderson NB, Clark VR, Williams DR. Racism as a stressor for African Americans: A biopsychosocial model. Am Psychol. 1999;54(10):805.

26. Matthews KA, Gallo LC, Taylor SE. Are psychosocial factors mediators of socioeconomic status and health connections? Ann N Y Acad Sci. 2010;1186(1):146-73.

27. Henry PJ. Low-status compensation: A theory for understanding the role of status in cultures of honor. J Pers Soc Psychol. 2009;97(3):451-66.

28. Miller CT, Kaiser CR. A theoretical perspective on coping with stigma. J Soc Issues. 2001;57(1):73-92. 
29. Reutter LI, Stewart MJ, Veenstra G, Love R, Raphael D, Makwarimba E. "Who do they think we are, anyway?": perceptions of and responses to poverty stigma. Qual Health Res. 2009;19(3):297-311.

30. Underlid K. Poverty and experiences of social devaluation: A qualitative interview study of 25 long-standing recipients of social security payments. Scand J Psychol. 2005;46(3):273-83.

31. Hamilton K. Low-income families and coping through brands: inclusion or stigma? Sociol. 2012;46(1):74-90.

32. Bosma H, Groffen D, van den Akker M, Kempen G, van Eijk J. Better health reports when the grass is greener on your side of the fence? A cross-sectional study in older persons. Int $\mathrm{J}$ Public Health. 2011;56(4):449-53.

33. Olson GI, Schober BI. The satisfied poor: development of an intervention-oriented theoretical framework to explain satisfaction with a life in poverty. Soc Ind Res. 1993;28(2):173-93.

34. Sakamoto A, Rarick J, Woo H, Wang SX. What underlies the Great Gatsby Curve? Psychological micro-foundations of the "vicious circle" of poverty. Mind Soc. 2014;13(2):195-211.

35. Bovens M, Dekker P, Tiemeijer W. Gescheiden werelden? Een verkenning van sociaal-culturele tegenstellingen in Nederland [Separated worlds? An exploration of socio-cultural differences in the Netherlands]. The Hague Netherlands Institute for Social Research (SCP); 2014.

36. De Beer P. Over werken in de postindustriële samenleving [Working in a post industrial society]. The Hague: Netherlands Institute for Social Research (SCP). 2001.

37. Council for Social Development (RMO). Nieuwe ronde, nieuwe kansen. Sociale stijging en daling in perspectief. [New game, new chances. Upward and downward social mobility in perspective]. The Hague; 2011.

38. Schnabel P, Keuzenkamp S, Breedveld K. In het zicht van de toekomst [In sight of the future]. The Hague Netherlands Institute for Social Research (SCP); 2004.

39. Elshout J. A Call for Respect. Experiences of Unemployed Workers in a Meritocratising Society (Dissertation). Amsterdam: University of Amsterdam; 2016.

40. Salverda W. De tektoniek van de inkomensongelijkheid in Nederland [The tectonics of income inequality in the Netherlands]. In: Kremer M, 


\section{Chapter 6}

Bovens M, Schrijvers E, Went R, editors. Hoe ongelijk is Nederland? Een verkenning [How unequal is the Netherlands? An exploration]. Amsterdam: Amsterdam University Press; 2014. p. 39-58.

41. Shildrick T, Rucell J. Sociological perspective on poverty. York: Joseph Rowntree Foundation; 2015.

42. Engbersen G. Fatale remedies: Over de onbedoelde gevolgen van beleid en kennis (Fatal remedies: About the unintended consequences of policy and knowledge). Amsterdam: Amsterdam University Press; 2009.

43. Abrahamson P. European welfare states beyond neoliberalism: toward the social investment state. Dev Soc. 2010;39(1):61-95.

44. Hilberink SR, Cardol M. Agency in the twenty-first century: the emperor's new clothes. Disabil Soc. 2013;28(4):569-73.

45. De Kinderombudsman [Ombudsman for children]. Kinderen in armoede in Nederland [Children in poverty in the Netherlands]. The Hague: De Kinderombudsman/Verwey-Jonker Instituut; 2013.

46. Statistics Netherlands/Netherlands Institute for Social Research (CBS/SCP). Armoedesignalement 2014 (Poverty monitor 2014). The Hague, the Netherlands; 2014.

47. Raad van Rechtsbijstand. Schulden oplossen met de WSNP [Solving debts with the WSNP]. 's Hertogenbosch, the Netherlands 2013.

48. Rose D, Harrison E. The European socio-economic classification: a new social class schema for comparative European research. Eur Soc. 2007;9(3):459-90.

49. Braun V, Clarke V. Using thematic analysis in psychology. Qual Res Psychol. 2006;3(2):77-101.

50. Kampen T, Elshout J, Tonkens E. The fragility of self-respect: emotional labour of workfare volunteering. Soc Policy Soc. 2013;12(03):427-38.

51. Pinel EC. Stigma consciousness: the psychological legacy of social stereotypes. J Pers Soc Psychol. 1999;76(1):114.

52. Bosma H, Van Jaarsveld C, Tuinstra J, Sanderman R, Ranchor A, Van Eijk JTM, et al. Low control beliefs, classical coronary risk factors, and socio-economic differences in heart disease in older persons. Soc Sci Med. 2005;60(4):737-45.

53. Liu WM. Introduction to Social Class and Classism in Counseling Psychology. The Oxford Handbook of Social Class in Counseling. Oxford Oxford University Press.; 2013. 
54. Langhout RD, Rosselli F, Feinstein J. Assessing Classism in Academic Settings. Rev High Ed. 2007;30(2):145-84.

55. Thompson MN, Subich LM. Development and exploration of the experiences with classism scale. J Career Assess. 2013;21(1):139-58.

56. Krieger N, Williams DR, Moss NE. Measuring social class in US public health research: concepts, methodologies, and guidelines. Annu Rev Public Health. 1997;18(1):341-78.

57. Quinn DM, Earnshaw VA. Concealable stigmatized identities and psychological well-being. Soc Personal Psychol Compass. 2013;7(1):4051.

58. Wildeboer Schut JM, Hoff S. Een lang tekort; langdurige armoede in Nederlands [A long shortage; long-term poverty in the Netherlands]. The Hague: Netherlands Institute for Social Research (SCP); 2016.

59. Theunissen A. Schuldhulpverlening in perspectief [Debt counselling in perspective] (Dissertation). Utrecht: Utrecht University; 2015.

60. Devine PG, Forscher PS, Austin AJ, Cox WTL. Long-term reduction in implicit race bias: A prejudice habit-breaking intervention. J Exp Soc Psychol. 2012;48(6):1267-78.

61. Stimulansz. Bestrijden van armoede onder zelfstandigen (Poverty reduction among self-employed persons). Rotterdam 2010.

62. Hoff S, Wildeboer Schut JM, Goderis B, Vrooman C. Armoede in kaart 2016 (Mapping poverty 2016). The Hague: Netherlands Institute for Social Research (SCP); 2016.

63. Bos M, Van der Vet O. Werkende armen (Working poor). The Hague: Municipality of The Hague (SZW); 2013. 



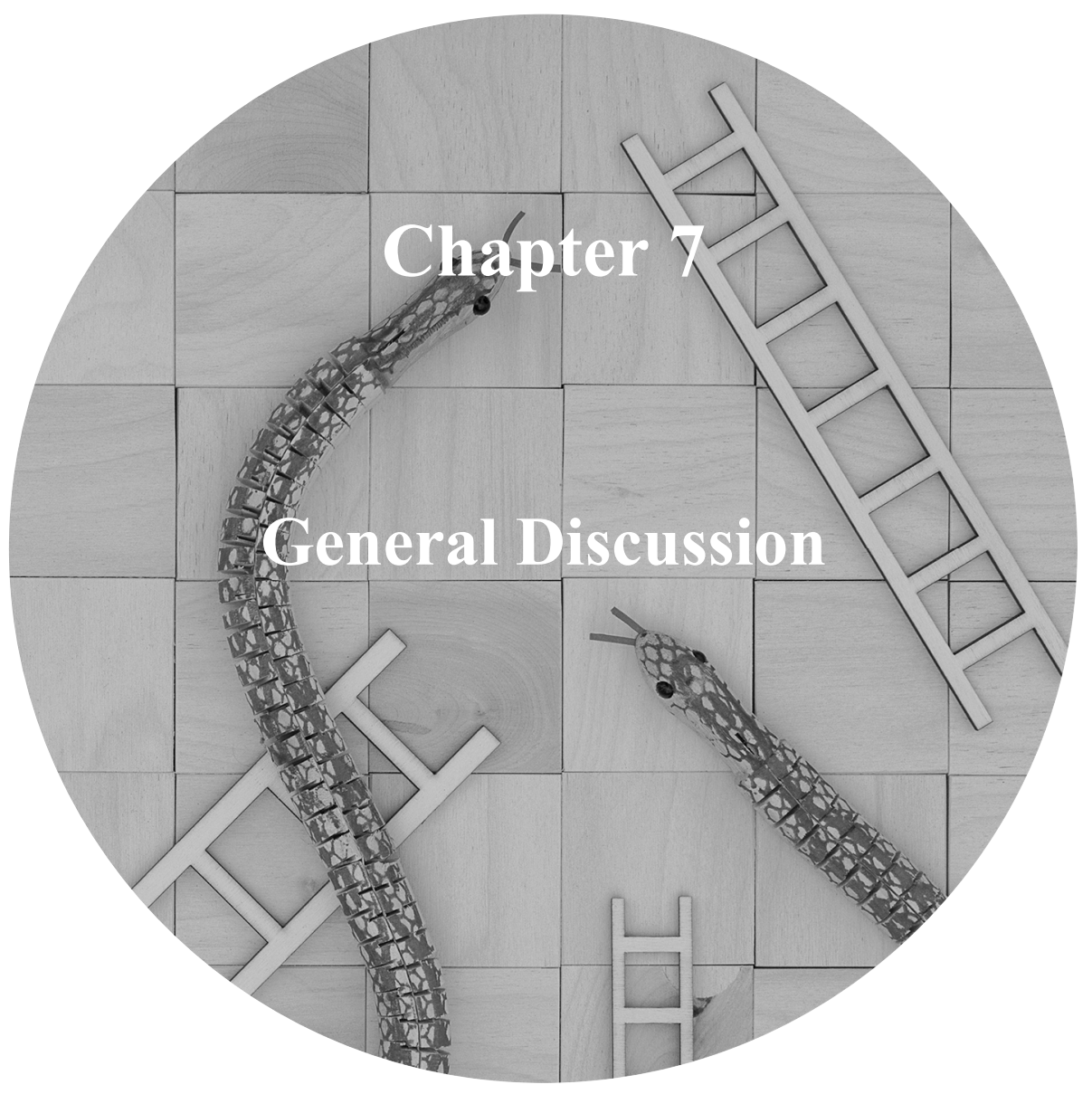





\title{
General discussion
}

In this chapter, the main findings and some conceptual and methodological considerations will be discussed. Furthermore, related implications and recommendations for future research will be addressed.

\begin{abstract}
Aims
Previous research showed that socioeconomic health inequalities were not the smallest in countries with advanced welfare arrangements, such as the Nordic countries (1-5). Different factors were suggested as possible explanations for this puzzling paradox (6-9). In this thesis, we examined the role of unhealthy homogenisation and did a first exploration of the role of perceived classism and thus of its potential as an additional explanation for above paradox. More specifically, the aims of this thesis were, first, to better understand the role of unhealthy homogenisation during social mobility and its contribution to country differences in socioeconomic health inequalities and, second, to get an in-depth understanding of perceived classism in the Netherlands and its association with health and health inequalities.
\end{abstract}

\section{Reflection on main findings}

\section{Unhealthy homogenisation unlikely to solve the puzzle}

The first research question of this thesis was to understand whether unhealthy homogenisation during social mobility could partially explain the country differences in socioeconomic health inequalities. In Chapter 2, we assessed the associations between social mobility and socioeconomic inequalities in mortality in a number of European countries. The results showed that more socially mobile countries and countries with smaller income inequalities had wider relative and absolute socioeconomic inequalities in all-cause mortality, particularly among women. Our findings thus confirmed the suggested positive association between social mobility and socioeconomic health inequalities $(6,7)$. In our second study, we found significant health effects on income mobility in our multilevel analyses: income growth was less for unhealthy people (Chapter 3). However, we did not find stronger selection effects in more socially mobile countries. Unhealthy homogenisation is thus important, but from our data we 


\section{Chapter 7}

cannot conclude that unhealthy homogenisation was stronger in more socially mobile counties.

Since the Black Report in the 1980s, interest in the role of the selection perspective raised (10). However, there is still debate about whether, in addition to the causation perspective, this selection perspective actually plays a relevant role in explaining health inequalities (11). Results of studies into the health effects on inter- and intragenerational mobility and health inequalities have been inconsistent $(12,13)$; some studied showed that (childhood) health affected changes in (adult) SEP and/or health inequalities (14-16), while other studies showed no or only limited effects of health or health inequalities, or reported inconsistent findings (17-19) . This probably also depends on the different designs and the outcomes (e.g. inter- or intragenerational mobility, different SEP indicators like class, income or occupational level) that were used in these studies (10). Although we did not examine whether health selection actually explains country-level socioeconomic health inequalities, our results still indicate that direct selection should not be neglected so easily as a candidate explanatory factor for socioeconomic differences in health within countries.

We expected unhealthy homogenisation to be stronger in more socially mobile countries, since their increased opportunities for upward mobility might have increased the scope for health selection $(3,7,20)$. Our results, however, did not confirm our expectation. Country differences in policy and welfare arrangements might have simultaneously affected the scope for health selection. In countries with good social protection measures, employees would be better protected against loss of income (or work) due to health problems $(6,9,21)$. More mobile countries, such as the Nordic countries, might somehow have been protected by these measures. Social protection might thus have suppressed the unhealthy homogenisation in more mobile countries. When we controlled for social protection measures, this could, however, not be confirmed. However, findings have to be interpreted carefully, as we used a rather crude measure of social protection and the variation between the selected countries might have been too small.

We cannot fully rule out health selection and unhealthy homogenisation as a possible explanation for wider socioeconomic health inequalities in countries with advanced welfare arrangements. We only looked at direct health effects. There is still the possibility that the unhealthy homogenisation of low SEP is manifested in other ways. Recently, Mackenbach once more suggested that, 


\section{General discussion}

because of increased mobility, the current low SEP groups might be smaller and more socially disadvantaged, but also have a more unfavourable composition of personality traits and cognitive abilities $(22,23)$. It might be that this type of homogenisation still contributes to the socioeconomic differences in health in more mobile countries, including the Nordic countries (22). An important issue that we did not examine yet relates to our assumption that health selection widens health inequalities: healthy people are upwardly mobile and less healthy people are downwardly mobile (24). Other scholars, for example Bartley and Plewis, however, suggest that selection might equally well narrow the socioeconomic gap in health $(25,26)$. They argue that the health status of mobile people still differs from the health status of the group they join: upwardly people are less healthy and downwardly people are healthier than they group they join.

\section{Perceived classism as an additional burden}

The second research question addressed the health effects of perceived classism in the Netherlands. We found that the lowest SEP groups more often perceived classism than people in higher SEP groups. In Chapter 4, 7.9\% of the lowest income group and $5.2 \%$ of the highest income group perceived themselves discriminated against. In Chapter 5, we found that $18.2 \%$ of the Dutch society perceived some kind of classism, while $22 \%$ of the lowest income and $27.5 \%$ of the lowest occupation group perceived classism. In Chapter 6, our qualitative study, people from low SEP groups got the opportunity to tell their experiences with SEP-related stigmatisation. Our participants experienced social reactions that related to them being inferior, being physically recognisable as a poor person, and being responsible for their financial problems. Participants also experienced feelings of shame related to their SEP.

The consequences of perceived classism were studied in Chapter 4, 5 and 6. In Chapter 4, the health consequences of perceived discrimination were quite small; people perceiving discrimination had a 1.58 higher odds of feeling hindered by health problems, but no significant higher odds of reporting less than good health. This effect appeared confounded by the higher number of immigrants in the group that perceived discriminated against. Chapter 5, a cross-sectional study looking deeper into the associations between perceived classism and health outcomes, however, indicated significant health consequences of perceived classism. People who perceived classism reported poorer physical and psychological health and feelings of inferiority. We did not find an 


\section{Chapter 7}

association with health behaviours; only smoking showed an association with perceived classism (only unadjusted).

Physical health consequences were less obvious in our qualitative study (Chapter 6). Perceived stigmatisation caused negative emotions (e.g. anger, shame, and frustration) and stress, and negatively affected self-respect in our participants. This in turn might have had negative health consequences, for example via physical stress responses or poor health behaviours (27-29). Different coping strategies were used to maintain some level of self-respect; people tried to escape reality (e.g. concealing their financial problems, denying negative social reactions), showed their strengths (e.g. pride, 'macho behaviour') or they tried to confront others with their negative or blaming social reactions. Despite the associations found between SEP, perceived classism, and health, we could not find substantial evidence for a mediating contribution of perceived discrimination to the association between low SEP and poor health (Chapter 4). Important to note is that perceived discrimination in that Chapter might have been a less valid proxy for perceived classism.

Our results are in line with previous research on stigmatisation of people in lower SEP groups, such as conducted in the Netherlands by Kampen and colleagues (30), Swierstra and Tonkens (31), Elshout (32), Theunissen (33), and in in other countries (e.g. in the UK (34) and the Nordic countries $(35,36)$ ). Classism and self-respect in low SEP are thus important issues in the Netherlands and, in all probability, in other European countries as well. These issues will not become less important in the future. With a further individualisation of society, a stronger focus on self-reliance, own responsibility, and participation (e.g. via mandatory activation projects), and prevailing expectations of social mobility on the one hand and cuts in welfare arrangements and a less personal approach on the other hand, people at the lowest rungs of our socioeconomic ladder will have to face even harder times.

When the opportunities for upward mobility are only dependent on one's own efforts and cognitive abilities and not on one's socioeconomic - or cultural family background - there might be some truth to the negative labelling of low SEP. However, ascription still cannot be ruled out: the family that you grew up in and particularly the educational and income level of your parents are still important enabling factors for a successful path into the future $(37,38)$. In such circumstances, classism is certainly not necessarily based on true circumstances. Next to that, however, negative stigmas do not become less damaging 


\section{General discussion}

when part of them is based on the truth; they still contain devaluing messages and even when they apply to some people (e.g. people who really unwilling work), they do not apply to all people in low SEP groups (39).

\section{Intertwining of unhealthy homogenisation and classism}

Unhealthy homogenisation and classism are studied in this thesis as two different pathways to health inequalities (see Figure 1 in Chapter 1). However, they could be more intertwined than we first expected. Discrimination, stigmatisation, and social exclusion related to poor health and low SEP could cause a negative spiral for the most disadvantaged groups in our societies (40). For example, when people end up in a lower SEP group because of health problems, they have to deal with classism affecting self-respect and (psychological) health, and they will be hindered by health problems and classism in getting ahead on the socioeconomic ladder (e.g. when finding a job). In a negative spiral, unhealthy homogenisation and classism might ultimately keep lower SEP groups stuck into their disadvantaged and unhealthy position. Classism can limit social mobility in different ways, from teachers expecting less of low SEP students to stereotype threats causing people to underperform because they are stressed and afraid of confirming prevailing stereotypes (41-44).

\section{Further considerations}

When interpreting our results, a number of conceptual and methodological limitations have to be considered

\section{Concepts and definitions}

Some terminology regarding SEP and classism differed between the chapters in this thesis. While conducting and publishing the results of our studies, new insights made us overthink the use of some concepts. We started using socioeconomic status (SES). However, when studying classism, we eventually preferred the more neutral term socioeconomic position $(45,46)$ and thereby avoided a possible reference to status and prestige conceptualisations of socioeconomic grouping. This was especially important in our studies into classism in which we were interested in all kinds of SEP indicators, not only status or prestigebased ones. Based on a reviewer comment, we also changed 'classism' (chapter 


\section{Chapter 7}

5) into SEP-related stigmatisation in Chapter 4 to make it more clear that we include stigmatisation regarding all kinds of SEP indicators (i.e. education, material deprivation, being a social benefit recipient, etc.), not only regarding social class in a strict sense. The use of 'discrimination' in Chapter 4 was due to the restrictions of the dataset measuring discrimination instead of stigmatisation.

\section{Design}

In three of our studies into unhealthy homogenisation (Chapter 3 using EUSILC data) and classism (Chapter 4 and 5 using LISS data), we used data from international and national representative surveys, with large samples: over 56,000 European participants in EU-SILC and over 1,500 Dutch participants in LISS. In our studies into health selection, the major drawback was that not all data-resources (EU-SILC (47), ISSP (48) or Mackenbach's results (3)) included the same selection of countries. As a consequence, we ended up with a smaller number of countries in these studies, which could have made our results more sensitive to the composition of the included countries.

The generalisability of our studies varied. The large representative samples of EU-SILC and LISS made it possible to generalise our result to all people in the selected countries. However, as mentioned above, the studies into unhealthy homogenisation were based on a small group of European countries. Generalising our results to countries outside Europe (e.g. the US) might also be difficult, because countries might have very different welfare arrangements. This even accounts for countries within Europe, especially since we missed some relevant countries (e.g. the UK). Our studies into perceived classism (Chapters 4-6) were all conducted among Dutch participants and therefore it could be difficult to generalise our results to other countries. On the other hand, relevant trends regarding an increasing individualisation, a stronger focus on self-reliance, and intensifying neoliberal and meritocratic policies and ideologies are not typical of the included countries in our study $(49,50)$. It is thus unclear to what extent the findings remain restricted or not to the included countries and participants. In our qualitative study, we recruited people from low SEP groups via a charity organisation. Because the charity organisation was overrepresented by (long-term) unemployed people receiving social benefits, we missed the working poor and precariat in our sample. The working poor and precariat were hard-to-reach groups; they are less visible by social workers be- 


\section{General discussion}

cause they make less use of financial support because of shame and anticipated negative social reactions $(51,52)$. Therefore, our results could probably not be generalised to this group.

In this thesis, both cross-sectional and longitudinal studies were used. One study using LISS data (Chapter 4) was based on cross-sectional data examining the associations between perceived classism and health. We therefore cannot draw decisive conclusions about causality. Furthermore, negative affectivity could have been a problem by overestimating the relevant associations (53). In our longitudinal studies, attrition could have biased our results in an opposite direction. Attrition was more prevalent among younger participants, immigrants, participants from lower SEP groups and people who more often perceived discrimination. This could have led to underestimated results.

Our qualitative study was designed as an interview study with semistructured interviews, following a topic list that was primarily based on literature. The interviews had a quite open structure. By allowing participants to focus on what they found was important in their life (related to SEP), we collected quite in-depth stories. Because it was impossible to get such in-depth data on all topics, it is possible that we sometimes missed important information (e.g. their work history).

\section{Measures}

The use of secondary data in this thesis has some drawbacks. We had to rely on the availability of data and how they were measured. When studying unhealthy homogenisation, we were not able to include childhood SEP and childhood health to assess intragenerational mobility, because EU-SILC did not allow linking these data. Furthermore, data on (perceived) classism were lacking, both on a national and international level, or were not measured as we would like to. It was thus impossible to make international comparisons of (perceived) classism, and to study its associations with social mobility, health and health inequalities.

Because of this scarcity of data on classism, our first study using LISS data was based on a single item measuring whether people thought they belonged to a discriminated group. This item had some drawbacks: we could not be sure whether people really felt discriminated against and why they felt discriminated. Ethnic background became thus an important confounder. However, we might have missed some other relevant confounders. Our qualitative study 


\section{Chapter 7}

showed that many participants of low SEP groups had to deal with multiple problems within their families, for example being a single mum or being a psychiatric patient, which are often associated with low SEP, health and stigmatisation as well. For our second study into classism we were able to add our own questionnaire about perceived classism to the existing survey of the LISS panel (54). To our knowledge, this was the first questionnaire implemented in the Netherlands to validly measure perceived classism.

We might have also missed some confounders in our studies into unhealthy homogenisation. Confounders could have been country-level policies (e.g. level of neo-liberal policies, level of social protection, income inequalities and GDP). We adjusted for GDP, GINI and spending on social protection in our study using EU-SILC data. In Chapter 2, using ISSP and Mackenbach data, no adjustments were made because of the already small sample of included countries. We do not know how this affected our results.

Finally, in our qualitative study, the experiences of stigmatisation and shame were not primed to avoid socially desirable answers. As a consequence, we had to search for both implicit and explicit experiences of stigmatisation in their stories, and since we all had a background in social science and belonged to a higher SEP group, this could have led to biased interpretations of the data. We tried to be aware of this problem as much as possible, but cannot exclude a bias.

\section{Implications and future research}

\section{Unhealthy homogenisation}

Our studies on unhealthy homogenisation showed a significant direct effect of health on income mobility in most countries. Simultaneously, we know SEP also has considerable consequences for health $(12,55-68)$. The selection and causation perspectives therefore should not be viewed as separate pathways to health inequalities (10). Interventions should thus also not be solely based on one of the pathways. The selection perspective has often been neglected in interventions aimed at tackling socioeconomic differences in health $(69,70)$. Such interventions might benefit from, for example, preventing health selection in the labour market by raising awareness and disseminating information about disability- and health-related discrimination in the labour market (10). The austerity 


\section{General discussion}

measures after the financial crisis often negatively affected the disabled, ill and poor people. Austerity measures should be avoided when these result in financial cuts in welfare arrangements aimed at the protection of vulnerable groups (71).

Future studies are needed to assess homogenisation of "unhealthy" personality traits and lower cognitive abilities in the lower SEP groups as a contributor to health inequalities. We also need to assess the selection and causation perspective, including the behavioural, material and psychosocial mediators, simultaneously. Preferably, studies should start in childhood and follow-up people during the life-course. Our study in chapter 3 only focused on intragenerational mobility, however, future studies - to even better assess the effects of health selection-should include both intra- and intergenerational mobility. There are already some promising developments. For example, a health inequality module was recently included in the European Social Survey, including childhood circumstances (72). Furthermore, more insight is needed into the role of policy changes in European countries in explaining country differences in health inequalities (e.g. the neoliberal influences on social policies). Many studies examining country differences in health inequalities are using welfare typologies to group countries. However, even within the same welfare type, countries differ in policies and they might have undergone policy changes in the last decades that have affected health inequalities differently $(6,73,74)$.

\section{Perceived Classism}

'Show people the truth, then the world will change...I think'

This was a quote of one of our participants in Chapter 6 and she might be right. Our results showed that perceived classism is a burden for Dutch people at the bottom of our socioeconomic ladder. Reducing classism on a macro-level and its effects for the lower SEP groups will be challenging. Such distal social trend and its possible connection with wider and global economic, political, and ideological developments, such as neoliberalism, meritocracy, and individualisation, indicate that classism might be difficult to tackle. To the extent that it contributes to the persistence or widening of socioeconomic differences in health, such differences might thus be less amenable to change. As a distal factor on the macro-level, it might even be responsible for the sometimes disappointing out- 


\section{Chapter 7}

comes of interventions that are often aimed at solely changing lifestyles of people in lower SEP groups (34). Still, we want to suggest some strategies to tackle the negative beliefs about lower SEP groups and to limit the negative effects of classism for stigmatised individuals as much as possible.

It will be necessary that the Dutch society in general, volunteers at charity organisations, professionals working with low SEP members and policymakers become aware of the existence of classism and its negative effects for people in lower SEP groups (75). On a societal level, making people aware of the existence of classism, the effects of classism, and their own (negative) beliefs should already start at (primary) school by educating about diversity, forming positive beliefs and challenging stereotypical beliefs (44, 76). Preventing stigmatising messages in the media and providing more thought-provoking programs about SEP-related topics will also be necessary (77). Ingrained and strong-held beliefs might be changed only when correct information is provided (e.g. regarding the causes of poverty), while at the same time people are triggered to discuss the topic with others and to challenge their own beliefs (77, 78). More importantly, diversity, classism and challenging beliefs, have to be recurring topics in the education of professionals working with low SEP groups. Next to making others aware of classism and their own (negative) SEP-related beliefs, people from low SEP groups need to be more often involved in educational programs of professionals, and in the development of public health programs and social policies $(34,44,75)$.

Instead of changing macro-level beliefs, it might be easier to help people in lower SEP groups to better cope with perceived classism and to maintain their self-respect. A personal and respectful approach by professionals might already help clients to keep their self-respect and to limit the negative effects of perceived classism (79). Interventions focussing on how to deal with stress due to financial hardship might help people to better cope with different stressors related to their disadvantaged position in society, including perceived classism. Interventions should also focus on children in low SEP families. They not only have to deal with material deprivation, but also with the financial stress of their parents and anticipation of SEP-related bullying at school $(80,81)$. However, we have to be aware that by too much focussing on 'learning how to cope with classism', we run the risk of blaming the victim: we should simultaneously look for measures that tackle the underlying societal problem and its damaging influences (75). 


\section{General discussion}

Although this thesis provided a good first insight into perceived classism and its consequences for health, we still lack knowledge about its mediating role within socioeconomic health inequalities. Therefore, we recommend further research into the mediating role of perceived classism using longitudinal studies, preferably international studies. Likewise, reliable and valid measures of classismboth enacted and perceived - needs to be included in studies that simultaneously measure health, health determinants, SEP indicators, social mobility patterns, and prevailing ideologies (e.g. meritocratic beliefs). These studies will help to better understand whether classism contributes to the explanation of the paradoxical finding of wider socioeconomic health inequalities in countries with more advanced welfare arrangements.

\section{Conclusion}

As possible downsides of social mobility and the increasing meritocratic and neoliberal ideologies, we explored whether unhealthy homogenisation and perceived classism might contribute to socioeconomic differences in health within and between countries. In various European countries, we showed that poor health affected individual income mobility, indicating that direct selection should not belittled as a possible contribution to socioeconomic differences in health. Although socioeconomic differences in health were larger in more mobile countries, we could not confirm that direct selection caused low SEP groups to become more homogeneous regarding their health status in these countries. Perceived classism was common among Dutch lower SEP groups and had substantial negative consequences for their health. As direct selection, classism is thus clearly also an understudied health determinant in relation to socioeconomic differences in health. To better understand the persisting socioeconomic differences in health and the differences between countries therein, further studies into unhealthy homogenisation and classism are still needed, especially addressing mobility-related homogenisation regarding cognitive abilities and personality characteristics and addressing classism, for how it is enacted and perceived, for how it bridges the wider macro context with damaging individual experiences and for how and why countries might differ in these developments. 


\section{Chapter 7}

\section{References}

1. Eikemo TA, Bambra C, Joyce K, Dahl E. Welfare state regimes and income-related health inequalities: a comparison of 23 European countries. Eur J Public Health. 2008;18(6):593-9.

2. Eikemo TA, Huisman M, Bambra C, Kunst AE. Health inequalities according to educational level in different welfare regimes: a comparison of 23 European countries. Sociol Health Illn. 2008;30(4):565-82.

3. Mackenbach JP, Stirbu I, Roskam AJR, Schaap MM, Menvielle G, Leinsalu M, et al. Socioeconomic inequalities in health in 22 European countries. N Engl J Med. 2008;358(23):2468-81.

4. Popham F, Dibben C, Bambra C. Are health inequalities really not the smallest in the Nordic welfare states? A comparison of mortality inequality in 37 countries. J Epidemiol Community Health. 2013;67(5):412-8.

5. McNamara CL, Toch-Marquardt M, Balaj M, Reibling N, Eikemo TA, Bambra C. Occupational inequalities in self-rated health and noncommunicable diseases in different regions of Europe: findings from the European Social Survey (2014) special module on the social determinants of health. Eur J Public Health. 2017;27(suppl_1):27-33.

6. Bambra $\mathrm{C}$. Health inequalities and welfare state regimes: theoretical insights on a public health 'puzzle'. J Epidemiol Community Health. 2011;65(9):740-5.

7. Mackenbach JP. The persistence of health inequalities in modern welfare states: the explanation of a paradox. Soc Sci Med. 2012;75(4):761-9.

8. Huijts T, Eikemo TA. Causality, social selectivity or artefacts? Why socioeconomic inequalities in health are not smallest in the Nordic countries. Eur J Public Health. 2009;19(5):452-3.

9. McCartney G, Collins C, Mackenzie M. What (or who) causes health inequalities: Theories, evidence and implications? Health Policy. 2013;113(3):221-7.

10. West P. Rethinking the health selection explanation for health inequalities. Soc Sci Med. 1991;32(4):373-84.

11. Mackenbach JP, Bakker MJ. Reducing inequalities in health: a European perspective. London: Routledge; 2003. 


\section{General discussion}

12. Mackenbach JP. Socioeconomic inequalities in health in high-income countries: the facts and the options. Oxford Textbook of Global Public Health: Oxford University Press; 2015.

13. Kröger H, Pakpahan E, Hoffmann R. What causes health inequality? A systematic review on the relative importance of social causation and health selection. Eur J Public Health. 2015;25(6):951-60.

14. van de Mheen H, Stronks K, Looman C, Mackenbach JP. Role of childhood health in the explanation of socioeconomic inequalities in early adult health. J Epidemiol Community Health. 1998;52(1):15-9.

15. Foverskov E, Holm A. Socioeconomic inequality in health in the British household panel: Tests of the social causation, health selection and the indirect selection hypothesis using dynamic fixed effects panel models. Soc Sci Med. 2016;150(Supplement C):172-83.

16. Hemmingsson T, Lundberg I. Can large relative mortality differences between socio-economic groups among Swedish men be explained by risk indicator-associated social mobility? Eur J Public Health. 2005;15(5):518-22.

17. Lundberg O. Childhood living conditions, health status, and social mobility: a contribution to the health selection debate. Eur Sociol Rev. 1991;7(2):149-62.

18. Heggebø K. Unemployment in Scandinavia during an economic crisis: Cross-national differences in health selection. Soc Sci Med. 2015;130:115-24.

19. Van de Mheen H, Stronks K, Schrijvers CT, Mackenbach J. The influence of adult ill health on occupational class mobility and mobility out of and into employment in the Netherlands. Soc Sci Med. 1999;49(4):509-18.

20. Bosma H, Simons A, Groffen D, Klabbers G. Stigmatisation and socioeconomic differences in health in modern welfare states. Eur $\mathrm{J}$ Public Health. 2012;22:616-7.

21. Campos-Matos I, Kawachi I. Social mobility and health in European countries: Does welfare regime type matter? Soc Sci Med. 2015;142:2418.

22. Mackenbach JP. Nordic paradox, Southern miracle, Eastern disaster: persistence of inequalities in mortality in Europe. Eur J Public Health. 2017;27(suppl_4):14-7. 


\section{Chapter 7}

23. Mackenbach JP. New trends in health inequalities research: now it's personal. Lancet. 2010;376(9744):854-5.

24. Boyle PJ, Norman P, Popham F. Social mobility: evidence that it can widen health inequalities. Soc Sci Med. 2009;68(10):1835-42.

25. Bartley M, Plewis I. Does health-selective mobility account for socioeconomic differences in health? Evidence from England and Wales, 1971 to 1991. J Health Soc Behav. 1997:376-86.

26. Blane D, Harding S, Rosato M. Does social mobility affect the size of the socioeconomic mortality differential?: evidence from the Office for National Statistics Longitudinal Study. J R Stat Soc Series A Stat Soc. 1999;162(1):59-70.

27. Meyer IH, Schwartz S, Frost DM. Social patterning of stress and coping: Does disadvantaged social status confer more stress and fewer coping resources? Soc Sci Med. 2008;67(3):368-79.

28. Krieger N, Kosheleva A, Waterman PD, Chen JT, Koenen K. Racial discrimination, psychological distress, and self-rated health among USborn and foreign-born Black Americans. Am J Public Health. 2011;101(9):1704-13.

29. Zilioli S, Imami L, Ong AD, Lumley MA, Gruenewald T. Discrimination and anger control as pathways linking socioeconomic disadvantage to allostatic load in midlife. J Psychosom Res. 2017;103:83-90.

30. Kampen T, Elshout J, Tonkens E. The fragility of self-respect: emotional labour of workfare volunteering. Soc Policy Soc. 2013;12(03):427-38.

31. Swierstra T, Tonkens E. Meritocratie en de erosie van zelfrespect [Meritocracy and the erosion of self respect]. Krisis. 2006;3:3-23.

32. Elshout J. A Call for Respect. Experiences of Unemployed Workers in a Meritocratising Society (Dissertation). Amsterdam: University of Amsterdam; 2016.

33. Theunissen A. Schuldhulpverlening in perspectief [Debt counselling in perspective] (Dissertation). Utrecht: Utrecht University; 2015.

34. Smith KE, Anderson R. Understanding lay perspectives on socioeconomic health inequalities in Britain: a meta-ethnography. Sociol Health Illn. 2017.

35. Underlid K. Poverty and experiences of social devaluation: A qualitative interview study of 25 long-standing recipients of social security payments. Scand J Psychol. 2005;46(3):273-83. 


\section{General discussion}

36. Kallio J, Blomberg H, Kroll C. Social workers' attitudes towards the unemployed in the Nordic countries. Int J Soc Welfare. 2013;22(2):21929.

37. Breen R, Jonsson JO. Inequality of opportunity in comparative perspective: recent research on educational attainment and social mobility. Annu Rev Sociol. 2005;31(1):223-43.

38. Sundell A. Nepotism and meritocracy QoG Working Paper Series. 2014.

39. Lee YT, McCauley C, Jussim L. Stereotypes as valid categories of knowledge and human perceptions of group differences. Soc Personal Psychol Compass. 2013;7(7):470-86.

40. Bambra C, Netuveli G, Eikemo TA. Welfare state regime life courses: the development of western European welfare state regimes and age-related patterns of educational inequalities in self-reported health. Int J Health Serv. 2010;40(3):399-420.

41. Croizet JC, Claire T. Extending the concept of stereotype threat to social class: the intellectual underperformance of students from low socioeconomic backgrounds. Pers Soc Psychol Bull. 1998;24(6):588-94.

42. Figlio DN. Names, expectations and the black-white test score gap (Working Paper No. 11195). National Bureau of Economic Research; 2005.

43. Hardaway CR, McLoyd VC. Escaping poverty and securing middle class status: how race and socioeconomic status shape mobility prospects for African Americans during the transition to adulthood. J Youth Adolesc. 2008;38(2):242-56.

44. Durante F, Fiske ST. How social-class stereotypes maintain inequality. Curr Opin Psychol. 2017;18:43-8.

45. Krieger N, Williams DR, Moss NE. Measuring social class in US public health research: concepts, methodologies, and guidelines. Annu Rev Public Health. 1997;18(1):341-78.

46. Marmot M. Social justice, epidemiology and health inequalities. Eur J Epidemiol. 2017;32(7):537-46.

47. European Commission. European Union Statistics on Income and Living Conditions: microdata longitudinal UDB SILC 2010 rev. 2. 2013.

48. ISSP Research Group. International Social Survey Programme: Social Inequality IV - ISSP 2009. Cologne: GESIS Data Archive; 2012. 


\section{Chapter 7}

49. Abrahamson P. European welfare states beyond neoliberalism: toward the social investment state. Dev Soc. 2010;39(1):61-95.

50. Hilberink SR, Cardol M. Agency in the twenty-first century: the emperor's new clothes. Disabil Soc. 2013;28(4):569-73.

51. Stimulansz. Bestrijden van armoede onder zelfstandigen (Poverty reduction among self-employed persons). Rotterdam2010.

52. Bos M, Van der Vet O. Werkende armen (Working poor). The Hague: Municipality of The Hague (SZW); 2013.

53. Denollet J. Negative Affectivity. In: Gellman MD, Turner JR, editors. Encyclopedia of Behavioral Medicine. New York, NY: Springer New York; 2013. p. 1304-5.

54. CentERdata/LISS. Does stigmatisation "explain" why low socioeconomic status is related to poor health? 2013 [January 25,2018]. Available from: https://www.dataarchive.lissdata.nl/study_units/view/372.

55. Pasqualini M, Lanari D, Minelli L, Pieroni L, Salmasi L. Health and income inequalities in Europe: What is the role of circumstances? Econ Hum Biol. 2017;26:164-73.

56. Robertson T, Benzeval M, Whitley E, Popham F. The role of material, psychosocial and behavioral factors in mediating the association between socioeconomic position and allostatic load (measured by cardiovascular, metabolic and inflammatory markers). Brain Behav Immun. 2015;45:419.

57. Aldabe B, Anderson R, Lyly-Yrjanainen M, Parent-Thirion A, Vermeylen G, Kelleher CC, et al. Contribution of material, occupational, and psychosocial factors in the explanation of social inequalities in health in 28 countries in Europe. $\mathrm{J}$ Epidemiol Community Health. 2011;65(12):1123-31.

58. Boylan JM, Robert SA. Neighborhood SES is particularly important to the cardiovascular health of low SES individuals. Soc Sci Med. 2017; 188:60-8.

59. Bambra C. Work, worklessness and the political economy of health inequalities. J Epidemiol Community Health. 2011;65(9):746-50.

60. McNamara CL, Balaj M, Thomson KH, Eikemo TA, Bambra C. The contribution of housing and neighbourhood conditions to educational inequalities in non-communicable diseases in Europe: findings from the 
European Social Survey (2014) special module on the social determinants of health. Eur J Public Health. 2017;27(suppl_1):102-6.

61. Schrijvers CTM, van de Mheen HD, Stronks K, Mackenbach JP. Socioeconomic inequalities in health in the working population: the contribution of working conditions. Int J Epidemiol. 1998;27(6):1011-8.

62. Huisman M, Kunst A, Mackenbach J. Educational inequalities in smoking among men and women aged 16 years and older in 11 European countries. Tob Control. 2005;14(2):106-13.

63. Huijts T, Gkiouleka A, Reibling N, Thomson KH, Eikemo TA, Bambra C. Educational inequalities in risky health behaviours in 21 European countries: findings from the European social survey (2014) special module on the social determinants of health. Eur J Public Health. 2017;27(suppl_1):63-72.

64. Peña $S$, Mäkelä $P$, Valdivia G, Helakorpi S, Markkula N, Margozzini P, et al. Socioeconomic inequalities in alcohol consumption in Chile and Finland. Drug Alcohol Depend. 2017;173:24-30.

65. Stronks K, van de Mheen H, Looman CWN, Mackenbach JP. The importance of psychosocial stressors for socio-economic inequalities in perceived health. Soc Sci Med. 1998;46(4-5):611-23.

66. Buttrick NR, Oishi S. The psychological consequences of income inequality. Soc Personal Psychol Compass. 2017;11(3).

67. Bosma H, Van Jaarsveld C, Tuinstra J, Sanderman R, Ranchor A, Van Eijk JTM, et al. Low control beliefs, classical coronary risk factors, and socio-economic differences in heart disease in older persons. Soc Sci Med. 2005;60(4):737-45.

68. Wilkinson RG, Pickett KE. The problems of relative deprivation: why some societies do better than others. Soc Sci Med. 2007;65(9):1965-78.

69. Pons-Vigués M, Diez È, Morrison J, Salas-Nicás S, Hoffmann R, Burstrom B, et al. Social and health policies or interventions to tackle health inequalities in European cities: a scoping review. BMC Public Health. 2014;14(1): 198 .

70. Mackenbach JP, Bakker MJ. Tackling socioeconomic inequalities in health: analysis of European experiences. Lancet. 2003;362(9393):140914.

71. Ruckert A, Labonté R. Health inequities in the age of austerity: The need for social protection policies. Soc Sci Med. 2017;187:306-11. 


\section{Chapter 7}

72. Eikemo TA, Bambra C, Huijts T, Fitzgerald R. The first pan-European sociological health inequalities survey of the general population: the European Social Survey rotating module on the social determinants of health. Eur Soc Rev. 2017;33(1):137-53.

73. Bergqvist K, Yngwe MÅ, Lundberg O. Understanding the role of welfare state characteristics for health and inequalities-an analytical review. BMC Public Health. 2013;13(1):1234.

74. Brennenstuhl S, Quesnel-Vallée A, McDonough P. Welfare regimes, population health and health inequalities: a research synthesis. J Epidemiol Community Health. 2012;66(5):397-409.

75. Heijnders M, Van Der Meij S. The fight against stigma: An overview of stigma-reduction strategies and interventions. Psychol Health Med. 2006;11(3):353-63.

76. Kemple KM, Lee IR, Harris M. Young children's curiosity about physical differences associated with race: Shared reading to encourage conversation. Early Child Educ J. 2016;44(2):97-105.

77. van Eijk G. Een strijd om beelden: arm en rijk op tv [The battle for images: rich and poor on television]. Sociol. 2015;11(3):557-64.

78. Betton V, Borschmann R, Docherty M, Coleman S, Brown M, Henderson $\mathrm{C}$. The role of social media in reducing stigma and discrimination. $\mathrm{Br} \mathrm{J}$ Psychiatry. 2015;206(6):443-4.

79. Baumberg B. The stigma of claiming benefits: a quantitative study. J Soc Policy. 2016;45(2):181-99.

80. De Kinderombudsman [Ombudsman for children]. Kinderen in armoede in Nederland [Children in poverty in the Netherlands]. The Hague: De Kinderombudsman/Verwey-Jonker Instituut; 2013.

81. De Kinderombudsman [Ombudsman for children]. Alle kinderen kansrijk. Het verbeteren van de ontwikkelingskansen van kinderen in armoede. [All children are promising. Improving the development chances of children in poverty]. The Hague: De Kinderombudsman; 2017. 


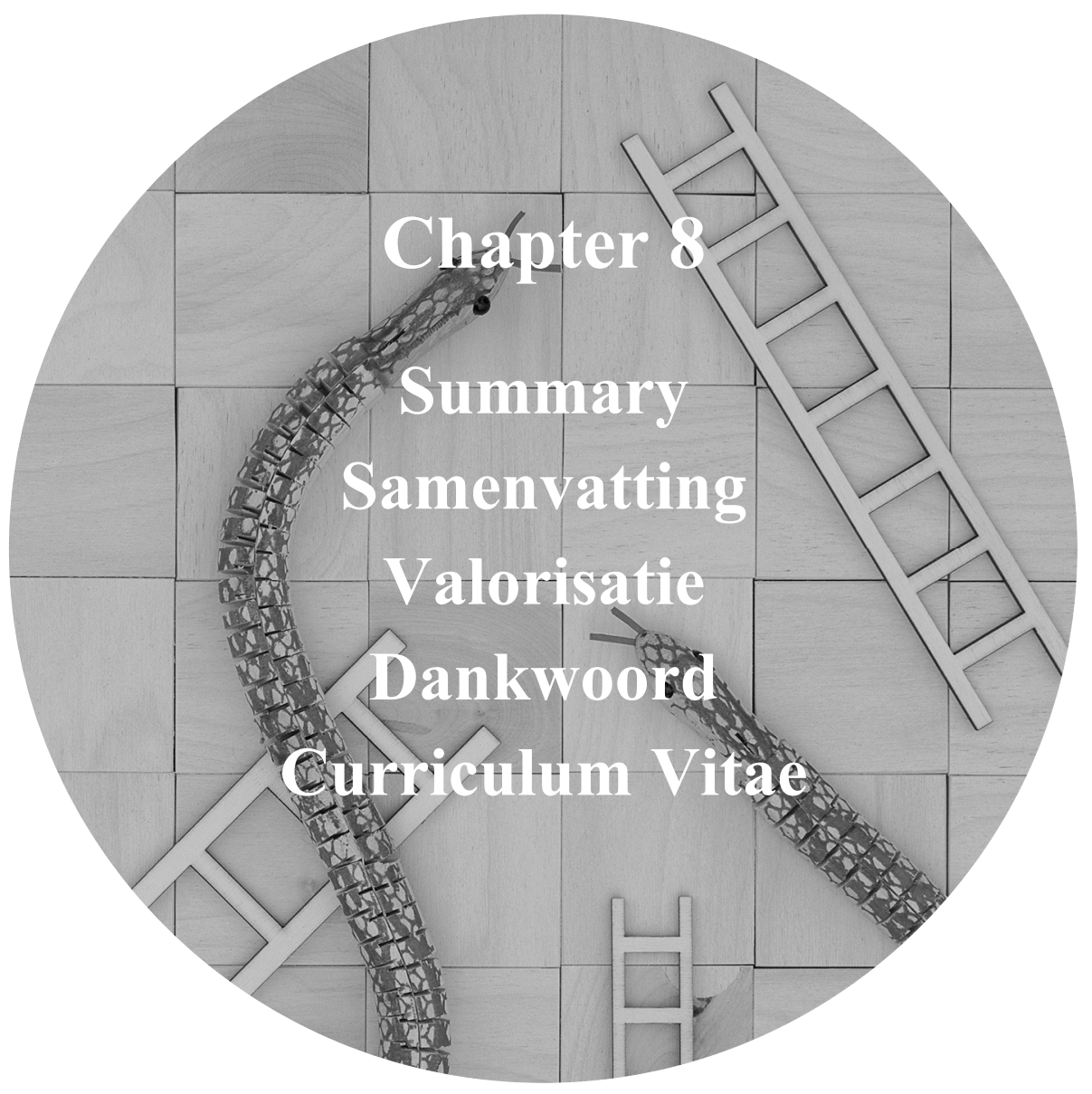





\section{Summary}

All over the world, people with a less advantaged socioeconomic position (SEP) are less healthy, die earlier and live shorter in good health compared to people in a more advantaged SEP. These inequalities are not only found between the extreme SEPs, but follow a social gradient in which the difference is found between all SEP groups. A lot of research is carried out to explain inequalities in health and different perspectives in explaining socioeconomic health inequalities are possible. The causation perspective assumes that a SEP influences health via material, behavioural and psychosocial factors. The selection perspective on the other hand assumes that health or health-related determinants (e.g. cognitive abilities or personality) affect SEP and future health. According to the selection perspective, unhealthy people might have fewer possibilities for upward mobility and might even move down the socioeconomic hierarchy, while for healthy people it might be easier to move upwards (i.e. direct health selection). Indirect health selection is possible via health-related determinants. A simultaneous upward mobility of healthier people with higher abilities and "favourable" personalities and downward mobility of less healthy people with lower abilities and less "favourable" personalities might create more homogeneous SEP groups in terms of health, cognitive ability and personality (i.e. unhealthy homogenisation). This might widen the health gap between SEP groups.

Although socioeconomic health inequalities are found all over the world, they are expected to be the widest in countries with large income inequalities and less advantaged welfare arrangements. However, previous research showed that health inequalities were not smallest in countries with the most advantaged welfare arrangements, such as the Nordic countries. Different explanations were suggested to explain this paradox. A proposed explanation was health selection during social mobility; since countries with more advanced welfare arrangements often also have more opportunities to social mobility, there might be more room for unhealthy homogenisation.

In this thesis, we also suggest an additional hypothesis explaining the paradox. The increased opportunities for social mobility combined with a stronger emphasis on self-reliance and individual responsibility, and a stronger societal belief in meritocracy (i.e. equal opportunities in achieving an economically successful life, based on personal merits like effort and abilities) might 


\section{Summary}

lead to classism. Classism is the marginalisation (i.e. stigmatisation, discrimination, labelling or prejudice) of those who are perceived to be in a different class, most often lower class. Perceived classism might have serious physical and mental health consequences and may therefore contribute to socioeconomic health inequalities, even in countries with well-advanced welfare arrangements.

The aims of this thesis were to 1) better understand the role of unhealthy homogenisation during social mobility and its contribution to explaining country differences in socioeconomic health inequalities and 2) to get an in-depth understanding of perceived classism in the Netherlands and its association with health and health inequalities. The research questions were:

1. Can unhealthy homogenisation during social mobility help to explain country differences in socioeconomic health inequalities?

a. Do countries with more social mobility have wider socioeconomic health inequalities than countries with less social mobility?

b. Does direct health selection play a role within countries?

c. Are direct health selection effects stronger in more socially mobile countries?

2. What are the health effects of perceived classism in the Netherlands?

a. Do people in lower SEP groups perceive more classism than people in higher SEP groups?

b. What are the consequences of perceived classism for people in low SEP groups?

c. Does perceived classism mediate the association between SEP and health?

Chapter 2 describes a study in which we examined the associations between country-level social mobility, income inequality and socioeconomic inequalities in mortality in 12 European countries, using country-level secondary data from Mackenbach and the International Social Survey Programme (ISSP). The results showed that social mobility was associated with larger socioeconomic differences in mortality, particularly in women. This study suggested that wider socioeconomic health inequalities might be a downside of increased social mobility in Western countries. 


\section{Summary}

Chapter 3 describes a study in which we examined unhealthy homogenisation on the individual level and the moderating role of social mobility in explaining country differences in health-related income mobility in 19 European countries. Longitudinal data from the EU-statistics on Income and Living Conditions (EUSILC) and ISSP data were used. The results showed that significant healthrelated mobility was found in over half of the included countries and the multilevel analyses showed that health had a significant effect on income mobility. However, the results did not show unhealthy homogenisation to be stronger in more socially mobile countries.

Chapter 4 describes a longitudinal study in which we investigated the role of perceived income-related discrimination within socioeconomic health inequalities by using representative survey data of the Dutch Longitudinal Internet Studies for the Social sciences (LISS). The results showed that poor health was more prevalent in the low income and discriminated group. Participants from the lower income were also more likely to perceive discrimination. However, no substantial evidence for a mediating effect of perceived discrimination on the income-health association was found. This study emphasised the importance of further studies into perceived classism.

Chapter 5 describes a cross-sectional study in which we further investigated perceived classism in different SEP groups in the Netherlands and its association with health and health behaviours, by using data from LISS. The results showed that over $18 \%$ of the Dutch population perceived some kind of classism. The lowest income and occupation groups perceived classism most often (respectively $22 \%$ and $28 \%$ ). Perceived classism was significantly associated with poor health, perceived negative emotions, feelings of shame, social anxiety, and low self-esteem. No associations were found with health behaviours (alcohol use, smoking, physical activity and BMI). This study showed the importance of perceived classism and its significant associations with health in the Netherlands.

Chapter 6 gives a more detailed insight into perceived classism and its consequences, by describing a qualitative study in which we conducted 17 semistructured interviews with people from lower SEP groups in the Netherlands. The results showed that participants perceived social reactions related to them 


\section{Summary}

being inferior, being recognisable as a poor person and being responsible for their own financial problems. Differences were found depending on their experience with poverty and the composition of their social network (in term of SEP): people with less experience with poverty and a heterogeneous network seemed more aware of negative social reactions. Perceiving negative social reaction mainly had emotional consequences. People used different coping strategies to maintain some level of self-respect, for example by concealing financial problems, by showing their strengths, or by confronting others with their negative attitudes.

Finally, chapter 7 provides a summary and discussion of the main findings. Furthermore, some conceptual and methodological limitations are considered and recommendations for implications and future research are made. We conclude that in various European countries, poor health affected individual income mobility, indicating that direct selection should be considered a possibly important contribution to socioeconomic differences in health. Although we found that socioeconomic differences in health were larger in more mobile countries, we could not confirm that unhealthy homogenisation was stronger in these countries. Perceived classism was common among Dutch lower SEP groups and had substantial negative consequences for their health. As direct selection, classism is thus clearly also an understudied health determinant in relation to socioeconomic differences in health. To better understand the persisting socioeconomic differences in health and the differences between countries therein, further studies into unhealthy homogenisation and classism are still needed. We especially need studies addressing mobility-related homogenisation regarding cognitive abilities and personality characteristics and addressing classism, for how it is enacted and perceived, for how it bridges the wider macro context with damaging individual experiences and for how countries might differ in these developments. 


\section{Samenvatting}

\section{Samenvatting}

Wereldwijd zijn mensen met een lagere sociaaleconomische positie (SEP) minder gezond, sterven ze op jongere leeftijd en leven ze minder lang in goede gezondheid dan mensen met een hogere SEP. Deze verschillen in gezondheid worden niet alleen gevonden tussen de extreem lage en extreem hoge SEP groepen, maar deze verschillen volgen een sociale gradiënt. Hierbij worden verschillen in gezondheid gevonden tussen alle SEP groepen, ongeacht hoe hoog beide groepen in de sociaaleconomische hiërarchie staan. Er is veel onderzoek gedaan naar verklaringen voor sociaaleconomische gezondheidsverschillen en verschillende verklarende perspectieven zijn hierbij mogelijk. Het causatieperspectief gaat ervan uit dat de sociaaleconomische positie invloed heeft op gezondheid via materiële zaken, leefstijl en psychosociale factoren. Het selectieperspectief daarentegen, gaat ervan uit dat gezondheid en gezondheid-gerelateerde determinanten (bijvoorbeeld cognitieve functies of persoonlijkheid) invloed hebben op SEP en gezondheid op lange termijn. Volgens het selectie perspectief hebben ongezonde mensen minder mogelijkheden tot opwaartse mobiliteit—ze kunnen zelfs afzakken in de sociaaleconomische hiërarchie - terwijl opwaartse mobiliteit makkelijker zal zijn voor mensen met een goede gezondheid. Directe selectie vindt plaats wanneer selectie is gebaseerd op gezondheid, indirecte selectie is mogelijk wanneer selectie plaatsvindt op basis van gezondheid-gerelateerde determinanten. Een gelijktijdige opwaartse mobiliteit van gezonde mensen met goede cognitieve functies en gunstige persoonlijkheden en neerwaartse mobiliteit van minder gezonde mensen met minder goede cognitieve functies en minder gunstige persoonlijkheden, kan leiden tot homogene SEP groepen qua gezondheid, cognitieve functies of persoonlijkheden. Deze ongezonde homogenisering van de lage SEP groepen kan hierdoor bijdrage aan de toenemende sociaaleconomische gezondheidsverschillen.

Hoewel sociaaleconomische gezondheidsverschillen overal ter wereld te vinden zijn, wordt verondersteld dat gezondheidsverschillen in landen met grotere inkomstverschillen en minder goede sociale regelingen groter zijn. Echter hebben eerdere studies onverwachte resultaten laten zien: anders dan verwacht bleken de sociaaleconomische gezondheidsverschillen helemaal niet het kleinst te zijn in landen met goede welzijnsregelingen, zoals de Noordse landen. Selectie-effecten lijken hierbij een mogelijke verklaring; landen met goede sociale 


\section{Samenvatting}

regelingen hebben vaak ook meer mogelijkheden tot opwaartse mobiliteit; dit geeft mogelijk meer ruimte voor selectie op basis van gezondheid (of gerelateerde determinanten), met ongezonde homogenisering van de lage SEP groepen als gevolg.

In dit proefschrift willen we een additionele verklaring voor de paradox introduceren. De toename in mogelijkheden tot sociale mobiliteit, de toegenomen maatschappelijke nadruk op zelfredzaamheid en eigen verantwoordelijkheid, en een steeds sterker geloof in meritocratie kan klassisme in de hand werken. Klassisme is de marginalisering (stigmatisering, discriminatie, stereotyperen, uitsluiten) van mensen die behoren tot een andere klasse, veelal een lagere SEP groep. Het ervaren van klassisme kan negatieve gevolgen hebben voor zowel fysieke als mentale gezondheid, waardoor ervaren klassisme kan bijdragen aan het verklaren van sociaaleconomische gezondheidsverschillen, zelfs in landen met goede welzijnsregelingen.

De doelen van dit proefschrift waren om 1) meer inzicht te verkrijgen in de rol van ongezonde homogenisering door sociale mobiliteit en de mogelijkheid van ongezonde homogenisering als verklaring voor internationale verschillen in sociaaleconomische gezondheidsverschillen, en 2) meer inzicht te krijgen in ervaren klassisme in Nederland en de associaties met gezondheid en gezondheidsverschillen. De onderzoeksvragen waren:

1. Kan ongezonde homogenisering door sociale mobiliteit bijdragen aan de verklaring van internationale verschillen in sociaaleconomische gezondheidsverschillen?

a. Hebben landen met meer sociale mobiliteit grotere sociaaleconomische gezondheidsverschillen dan landen met minder sociale mobiliteit?

b. Speelt directe gezondheidselectie een rol binnen landen?

c. Zijn directe gezondheidselectie effecten sterker in landen met meer sociale mobiliteit?

2. Wat zijn de gezondheidseffecten van ervaren klassisme in Nederland?

a. Ervaren mensen in lagere SEP groepen meer klassisme dan mensen in hogere SEP groepen?

b. Wat zijn de gevolgen van het ervaren van klassisme in de lagere SEP groepen?

c. Medieert ervaren klassisme de associatie tussen SEP en gezondheid? 
Hoofdstuk 2 beschrijft een onderzoek waarin we de relaties onderzocht hebben tussen sociale mobiliteit en sociaaleconomische verschillen in mortaliteit op landsniveau, in 2 Europese landen. Hierbij is gebruik gemaakt van secundaire data van Mackenbach en de International Social Survey Programme (ISSP). De resultaten lieten zien dat sociale mobiliteit geassocieerd werd met grotere verschillen in mortaliteit, vooral in vrouwen. Dit onderzoek suggereert dat grotere verschillen in gezondheid een keerzijde kunnen zijn van de toegenomen sociale mobiliteit Westerse landen.

Hoofdstuk 3 beschrijft een studie waarin we onderzocht hebben in welke mate ongezonde homogenisering op individueel niveau een rol speelt in 19 Europese landen en of sociale mobiliteit op landsniveau een modererende rol speelt binnen de associatie tussen gezondheid en inkomensmobiliteit. Hierbij werd gebruik gemaakt van longitudinale data van EU-statistics on Income and Living Conditions (EU-SILC) en ISSP data. De resultaten lieten zien dat gezondheidgerelateerde inkomensmobiliteit een significante rol speelt in meer dan de helft van de geïncludeerde landen. Resultaten lieten zien dat gezondheid een significant effect heeft op inkomensmobiliteit. Echter bleek uit dit onderzoek niet dat ongezonde homogenisering sterker was in meer mobiele landen.

Hoofdstuk 4 beschrijft een longitudinaal onderzoek naar de rol van ervaren inkomens-gerelateerde discriminatie binnen sociaaleconomische gezondheidsverschillen in Nederland. Hierbij werd gebruik gemaakt van longitudinale, representatieve data van de Longitudinal Internet Studies for the Social Sciences (LISS). De resultaten lieten zien dat een slechte gezondheid vaker voorkwam bij mensen met een laag inkomen en mensen die zich gediscrimineerd voelden. Mensen met een lager inkomen voelden zich ook vaker gediscrimineerd. Er werd echter minder bewijs gevonden voor een mediërend effect van ervaren discriminatie binnen de relatie tussen inkomen en gezondheid. Dit onderzoek benadrukte echter wel het belang van verder onderzoek naar ervaren klassisme.

In hoofdstuk 5 is ervaren klassisme verder onderzocht. Dit hoofdstuk beschrijft een cross-sectionele studie waarin we gekeken hebben naar ervaren klassisme binnen verschillende SEP groepen in Nederland en de relaties met gezondheid, en gezondheidsgedragingen. Hierbij werd gebruik gemaakt van LISS data. Uit het onderzoek kwam naar voren dat $18 \%$ van de Nederlandse bevolking enige 


\section{Samenvatting}

mate van klassisme ervaart. In de laagste inkomens- en beroepsgroep werd klassisme vaker ervaren, respectievelijk $22 \%$ en $28 \%$. Significante associaties met ervaren klassisme werden gevonden voor slechte gezondheid, negatieve emoties, schaamte, sociale angst en laag zelfvertrouwen. Er werden geen significante associaties gevonden met gezondheidsgedragingen (alcohol gebruik, roken, bewegen en BMI). Deze studie liet zien dat klassisme ook in Nederland wel degelijk wordt ervaren en dat het negatieve gevolgen kan hebben voor gezondheid

Hoofdstuk 6 beschrijft een kwalitatief onderzoek waarin we ervaren klassisme en de gevolgen nader onderzocht hebben. Er werden 17 semigestructureerde interviews met mensen uit lage SEP groepen afgenomen. De sociale reacties die mensen ervoeren hadden betrekking op: het minderwaardig worden geacht, herkend worden als 'arm' en het zelf verantwoordelijk worden geacht voor financiële problemen. Er werden verschillen gevonden in het ervaren van klassisme afhankelijk van de ervaring die mensen hadden met armoede of financiële problemen en de samenstelling van hun sociale netwerk (op gebied van SEP): mensen met minder ervaringen met armoede of financiële problemen in het verleden en een heterogeen netwerk leken zich meer bewust van negatieve sociale reacties. Het ervaren van negatieve sociale reacties had voornamelijk emotionele gevolgen. Verschillende copingstrategieën werden gebruikt om hun zelfrespect te behouden, bijvoorbeeld het verzwijgen van financiële problemen, het benadrukken van hun sterke punten of het confronteren van anderen met hun negatieve reacties.

In Hoofdstuk 7 worden de belangrijkste bevinden samengevat en bediscussieerd. Verder worden conceptuele en methodologische beperkingen besproken en aanbevelingen gedaan voor de implicaties van de resultaten en voor verder onderzoek. Ondanks de beperkingen van de verschillende studies in dit proefschrift, kunnen we concluderen dat een slechte gezondheid een negatief effect heeft op inkomensmobiliteit. Dit wijst erop dat de bijdrage van directe selectie aan sociaaleconomische gezondheidsverschillen niet onderschat mag worden. Ondanks dat we vonden dat sociaaleconomische gezondheidsverschillen groter waren in meer mobiele landen, konden we niet bevestigen dat directe selectie voor een sterkere ongezonde homogenisering van de lagere SEP groepen zorgt in meer mobiele landen. Ervaren klassisme kwam vaker voor binnen de lagere 


\section{Samenvatting}

SEP groepen in Nederland en had wezenlijk gevolgen voor de fysieke en mentale gezondheid. Evenals directe selectie is klassisme dus duidelijk een onderbestudeerde gezondheidsdeterminant binnen sociaaleconomische gezondheidsverschillen. Meer onderzoek naar ongezonde homogenisering van de lagere SEP groepen en ervaren klassisme is nodig om de aanhoudende sociaaleconomische gezondheidsverschillen en de internationale verschillen beter te kunnen begrijpen. Er is vooral ook onderzoek nodig naar de homogenisering van gezondheidgerelateerde determinanten (bijvoorbeeld cognitieve functies en persoonlijkheidsaspecten) en naar (ervaren) klassisme in de maatschappij, hoe klassisme samenhangt met de macrocontext en naar hoe landen hierin verschillen. 



\section{Valorisatie}

Valorisatie is het benutten van kennis. In dit proefschrift hebben we gekeken naar sociale mobiliteit, ongezonde homogenisering en ervaren klassisme als mogelijke verklaring voor sociaaleconomische gezondheidsverschillen. Hoewel de opgedane kennis in dit proefschrift niet direct relevant zal zijn voor de samenleving in termen van producten, instrumenten of interventies, kan deze kennis wel handvaten bieden voor de toekomstige ontwikkeling van interventies of besluitvormingen.

\section{Sociale mobiliteit en ongezonde homogenisering}

Uit onze studies bleek dat veranderingen in inkomen in de meeste landen wel degelijk afhankelijk is van gezondheid. Deze directe selectie op basis van gezondheid bleek echter niet sterker te zijn in meer mobiele landen. Ongezonde homogenisering kan op basis van ons onderzoek dus geen verklaring zijn voor de groter dan verwachte sociaaleconomische gezondheidsverschillen in de Noordse landen. Hoewel Nederland niet geïncludeerd was in onze studies naar sociale mobiliteit en ongezonde homogenisering, is het hoogstwaarschijnlijk dat, wanneer we kijken naar vergelijkbare landen in onze studies, ook in Nederland selectie op basis van gezondheid plaatsvindt.

Dit zal voor de praktijk betekenen dat Nederlandse werknemers beschermd moeten worden tegen selectieprocessen op basis van gezondheid. Voor de 'gezonde' werknemer is dit al grotendeels geregeld door de Wet verbetering poortwachter waarbij zowel werkgever en werknemer bij ziekteverzuim een vastgelegd stappenplan volgen met als doel het voorkomen van langdurig ziekteverzuim, en daarbij dus ook verlies van inkomen, en/of re-integratie. De werkgever is daarnaast verplicht twee jaar een groot deel van het loon door te betalen (Wet Uitbreiding Loondoorbetalingsplicht Bij Ziekte) (1), echter zal ziekte dus wel een (tijdelijke) invloed hebben op de hoogte van het inkomen van de werknemer. Voor mensen met een arbeidsongeschiktheidsuitkering zijn er verschillende regelingen die zowel hen als werkgevers beschermen. De recent ingevoerde Participatiewet moet er voor zorgen dat mensen met een arbeidsbeperking die kunnen werken (bijvoorbeeld mensen met Wajong uitkering; Wet arbeidsongeschiktheidsvoorziening jonggehandicapten), maar daarbij ondersteuning nodig hebben, aan het werk gaan zonder het recht op een uitkering 


\section{Valorisatie}

te verliezen. Er geldt tevens een 'no-risk' polis voor de werkgever bij ziekteverzuim van een werknemer wanneer deze vanuit een arbeidsongeschiktheidsuitkering aan het werk gaat (in de vorm van looncompensatie) (2). Hierdoor wordt zowel de positie van de werkgever als werknemer grotendeels beschermd tegen de nadelen van ziekteverzuim.

Sommige wijzigingen in wet- en regelgeving hebben echter ook negatieve gevolgen voor mensen met een arbeidsbeperking of arbeidsongeschikten. Er is de laatste decennia veel bezuinigd op sociale zekerheid. Om het aantal mensen dat gebruik maakt van een arbeidsongeschiktheidsuitkering terug te dringen en kosten te besparen zijn er verschillende wijzigingen doorgevoerd; de periode dat men een uitkering kan krijgen werd verkort en de hoogte van de uitkering verlaagd. Daarnaast komen mensen na de invoering van de WIA (Wet werk en inkomen naar arbeidsvermogen), als vervanger van de WAO (Wet op de Arbeidsongeschiktheidsverzekering), nu minder snel in aanmerking voor een arbeidsongeschiktheidsuitkering. Steeds meer mensen worden ook gezien als 'gedeeltelijk arbeidsongeschikt' en daarom toch geschikt bevonden voor bestaande functies op de arbeidsmarkt (3). Deze wijzigingen hebben echter tot gevolg dat gezondheid steeds negatievere gevolgen heeft voor het inkomen.

Voor mensen die onder de participatiewet vallen hebben een aantal wijzigingen ook negatieve gevolgen. Tot op heden hadden werkgevers bijvoorbeeld de mogelijkheid om loonkostensubsidie aan de vragen indien een werknemer in verband met zijn beperking minder productief kn zijn: de werkgever kreeg dan een vergoeding voor het verschil tussen het betaalde minimuminkomen/cao-loon en de daadwerkelijke loonwaarde (afhankelijk van iemands productiviteit) (4). Deze regeling zal mogelijk vervangen gaan worden door de mogelijkheid tot loondispensatie: de werkgever betaalt de werknemer naar loonwaarde (productiviteit), niet naar de geldende cao. Als de werknemer hierbij minder verdient dan het minimumloon kan er een aanvulling mogelijk zijn tot minimumloon via het UWV of de gemeente (5). Nadeel voor de werknemer is dat deze altijd minder zal verdienen dan iemand in een soortgelijke functie, daarnaast zullen de opbouw van pensioen en de hoogte van WW beperkt worden. Deze regelingen zorgen ervoor dat dat gezondheid nog steeds een sterke invloed heeft op de hoogte van het inkomen en beperkte mogelijkheden tot positieve inkomensveranderingen. Het College voor de Rechten van de Mens (6) waarschuwt dan ook terecht dat deze nieuwe regeling niet alleen gevolgen gaat hebben voor werknemers met een arbeidsbeperking op financieel gebied, maar 
dat het ook gevoelens van minderwaardigheid zal gaan veroorzaken doordat ze niet dezelfde behandeling krijgen als hun collega's zonder arbeidsbeperking. Het is daarom van groot belang om te anticiperen op de gevolgen die wijzigingen in wet- en regelgevingen hebben voor werknemers in geval van ziekte of arbeidsbeperking. Naast deze regelingen bestaat er in Nederland, net zoals in veel andere Europese landen, een wet die de positie van werknemers moet beschermen tegen discriminatie op basis van gezondheid (Wet gelijke behandeling op grond van handicap of chronische ziekte). Voor deze regelingen en wetten geldt echter dat er toegezien moet worden op het naleven en correct uitvoeren van bestaande wetten en regelingen zodat selectie op basis van gezondheid voorkomen wordt.

Naast de aandacht voor selectieprocessen bij werknemers, zal er wellicht ook meer aandacht moeten komen voor het effect van deze selectieprocessen op jongere leeftijd. De jeugdgezondheidszorg zal in samenwerking met het onderwijs moeten voorkomen dat op jonge leeftijd selectieprocessen op basis van gezondheid (zowel fysiek als psychisch) en gezondheidsdeterminanten (bijvoorbeeld persoonlijkheid, maar ook de sociale/sociaaleconomische leefomgeving) al een grote rol gaan spelen. Dit vereist gelijke kansen voor alle kinderen, zowel in gezondheid als in onderwijs. Professionals binnen het onderwijs zullen voldoende kennis moeten hebben over hoe gezondheid en de sociaaleconomische achtergrond van leerlingen schoolprestaties kunnen beïnvloeden, hoe dit beperkt kan worden en wat hun rol daarin is (bijvoorbeeld het niet laten beïnvloeden van beoordelingen van leerlingen door eigen vooroordelen). Echter zullen tevens wijzigingen in het schoolsysteem nodig zijn om te voorkomen dat (vroege) selectie op basis van gezondheid of achtergrond plaatsvindt en daarbij kansenongelijkheid, bijvoorbeeld door een latere selectie op onderwijsniveau waardoor kinderen meer ruimte krijgen om op de goede plek terecht te komen.

\section{Klassisme}

De samenleving waarin we op dit moment leven, verwacht van iedereen participatie, eigen regie, eigen verantwoordelijkheid en zelfredzaamheid, echter niet iedereen kan aan deze verwachtingen voldoen. Daarnaast geloven steeds meer mensen in sociale mobiliteit en meritocratie: iedereen krijgt gelijke kansen op een succesvol leven, afhankelijk van inzet en talent. Tezamen zijn het de ingrediënten voor klassisme. Onze studies laten zien dat in Nederland mensen met een lagere sociaaleconomische positie (SEP) klassisme ervaren en dat het con- 


\section{Valorisatie}

sequenties heeft voor hun gezondheid. In dit proefschrift hebben we niet uitgebreid kunnen onderzoeken in hoeverre (ervaren) klassisme de sociaaleconomische gezondheidsverschillen kan verklaren. Desondanks laten onze resultaten zien dat de attitudes en stigma's over mensen in lagere SEP groepen op macroniveau, zoals ervaren door lage SEP groepen, negatieve effecten hebben voor de gezondheid. Het veranderen van deze attitudes/stigma's op macroniveau zal echter niet eenvoudig zijn.

Om iets te kunnen veranderen aan de bestaande stigma's over bijvoorbeeld mensen in armoede, uitkeringsgerechtigden of werklozen, verdient 'klassisme' allereerst erkenning. Hoewel 'klassisme' in de laatste jaren af en toe naar voren komt in de Nederlandse media, staat het niet in de Dikke van Dale (7). Erkenning alleen al voor het bestaan van het begrip 'klassisme' zou al een eerste stap zijn om mensen bewust te maken van het bestaan van klassisme, om klassisme aan te kunnen pakken en de gevolgen van klassisme voor de lagere SEP groepen te kunnen beperken. Klassisme, de stigmatisering van lagere SEP groepen, en de gezondheidseffecten ervan verdienen ook meer (media) aandacht. In september 2016 heb ik de resultaten van het kwalitatieve onderzoek naar ervaren klassisme gepresenteerd bij een vrijwilligersorganisatie in Roermond die mensen bijstaat in armoede. Bij deze presentatie waren zowel cliënten als professionals vanuit de gemeente, zorg- en maatschappelijke sector aanwezig. De presentatie ging deels over de ervaringen van cliënten met een vrijwilligersorganisatie zoals die in Roermond, maar ook over de ervaringen van klanten met andere professionals en mensen in hun omgeving: de sociale reacties op hun financiële situatie. Naar aanleiding van mijn presentatie is er een interview geweest en dit interview is uitgezonden op een regionale zender van Roermond (RTV, 30-09-2016). Daarnaast zijn de resultaten van de studies naar klassisme onder de aandacht gebracht op (inter)nationale congressen en symposia.

De kennis uit dit proefschrift kan in combinatie met kennis over (de-) stigmatisering en (anti-)discriminatie van andere doelgroepen wel gebruikt worden om praktische toepassingen te ontwikkelen waarmee klassisme bespreekbaar gemaakt kan worden in de samenleving en waarmee bestaande vooroordelen/stigma's aangepakt kunnen worden. Deze praktische toepassingen zullen zich moeten richten op verschillende doelgroepen: de algemene bevolking, professionals en vrijwilligers die werken met mensen uit lage SEP groepen, (politieke)besluitvormers en mensen die werken in de media (bijvoorbeeld journalisten). Het is daarbij belangrijk dat mensen zich bewust worden van het bestaan 
van klassisme, hun eigen vooroordelen over bepaalde SEP groepen, hoe ze er naar handelen en wat de gevolgen van klassisme zijn. Dit kan aangepakt worden door anti-stigma programma's te integreren in het onderwijs.

Op jonge leeftijd, wanneer kinderen nog geen sterke vooroordelen gevormd hebben, is onderwijs in diversiteit belangrijk (niet specifiek klassisme). Kinderen leren daarbij dat iedereen anders is (dik/dun, getint/blank, arm/rijk, groot/klein, enz.). Een methode die hierbij gebruikt kan worden is 'anti-bias communication' (8). Hierbij worden kinderen uitgenodigd om onderwerpen zoals diversiteit te bespreken aan de hand van voorleesboeken of wanneer de situatie zich voordoet. De leraar speelt hierbij een belangrijke rol en daardoor moeten zij zich ook bewust zijn van hun eigen vooroordelen en moeten zij weten hoe ze diversiteit bespreekbaar kunnen maken.

Tijdens de opleiding van leraren, hulpverleners in de zorg- en maatschappelijke sector of mensen die werken in de media, ongeacht hoe ze in contact gaan komen met mensen in lage SEP groepen, is aandacht voor klassisme, of stigmatisering/discriminatie in bredere zin, ook gewenst. Anders dan bij kinderen, hebben volwassenen al attitudes gevormd en zullen vooroordelen over mensen met een lage SEP al bewust of onbewust aanwezig zijn. Tijdens de opleiding is het belangrijk dat het onderwerp bespreekbaar wordt gemaakt en dat er actief nagegaan wordt wat hun vooroordelen zijn en hoe dit hun handelen beïnvloedt of zou kunnen beïnvloeden. Naast feitelijke informatie en positieve voorbeelden, zorgen discussies ervoor dat vooroordelen getriggerd en uitgedaagd worden. Bij beroepen die veel cliënten- of patiëntencontact gaan hebben is contact met de doelgroep, in dit geval dus toekomstige cliënten/patiënten uit lage SEP groepen, ook een manier om positieve ervaringen op te doen en vooroordelen aan te pakken. Contact met toekomstige cliënten/patiënten uit lage SEP groepen kan professionals ook leren hoe ze empathie kunnen opbrengen voor deze doelgroep (bijvoorbeeld hoe ze mensen op een respectvolle manier kunnen benaderen). Daarnaast kunnen toekomstige professionals ook getraind worden in het reguleren van impulsief gedrag voortkomend uit vooroordelen of attitudes (9).

Voor mensen die in de media gaan werken, bijvoorbeeld als programmamaker, verslaggever of journalist, is het belangrijk om te leren hoe je stigmatisering in de media kunt voorkomen; bijvoorbeeld door bewust te zijn van je eigen vooroordelen, door te leren hoe je een programma kunt maken of artikel kunt schrijven zonder je eigen vooroordelen daarbij te laten beïnvloeden en 


\section{Valorisatie}

door wetenschappelijke kennis als basis te gebruiken. Attitudes van de algemene bevolking worden beïnvloed door wat ze lezen in de krant, op social media en wat ze zien op tv. Daarom is het belangrijk dat de boodschap die uitgezonden wordt geen stigma's bevat. Het betrekken van mensen uit lage SEP groepen in het onderwijs van professionals, bij het maken van mediaprogramma's /schrijven van artikelen en in (politieke) besluitvorming zorgt ervoor dat ze gehoord worden en persoonlijk contact kan zorgen voor positieve ervaringen en minder vooroordelen (9).

Het voorkomen van stigmatiserende boodschappen is echter niet alleen belangrijk in de media. Stigmatisering moet ook voorkomen worden in gezondheidspreventieprogramma's. Zo kan een interventie die gericht is op het gebrek aan kennis binnen een lage SEP groep stigmatiserend werken: bijvoorbeeld wanneer deze doelgroep wel weet wat 'gezond gedrag' is, maar bijvoorbeeld door hun financiële situatie geen gezonde voeding kan veroorloven of de prioriteit even niet heeft liggen bij 'gezond gedrag' maar bij 'het hoofd boven water houden'.

Het aanpakken van klassisme op macroniveau is belangrijk, echter moet er ook aandacht zijn voor de ervaring van klassisme binnen lage SEP groepen en de negatieve consequenties die het voor hen kan hebben. Onze studies naar ervaren klassisme benadrukken het belang van het voorkomen van (psychische) gezondheidsklachten door ervaren klassisme. Binnen de hulp-/zorgverlening aan mensen uit lagere SEP groepen, bijvoorbeeld door huisartsen, maatschappelijk werkers of psychologen, dienen professionals daarom rekening te houden met de invloed die ervaren klassisme kan hebben op iemands gezondheid. Het ervaren van klassisme moet bespreekbaar worden binnen de hulpverlening. Wellicht kunnen de resultaten van ons onderzoek fungeren als aanzet voor interventies die mensen uit lage SEP groepen leert omgaan met stress van het hebben van financiële problemen en het ervaren van klassisme. Naast interventies zou er ook meer aandacht kunnen zijn voor het bespreekbaar maken van ervaren klassisme binnen lage SEP groepen, bijvoorbeeld in buurthuizen of bij sociale projecten die zijn opgezet voor mensen met een afstand tot de arbeidsmarkt of voor mensen met een kleine beurs. Bij deze benadering zal er echter rekening gehouden moeten worden met het gevaar van 'blaming the victim': klassisme is immers vooral een maatschappelijk probleem, niet een individueel probleem. 


\section{Wetenschappelijke bijdrage}

De studies in dit proefschrift zijn gepresenteerd op zowel internationale als nationale congressen en gepubliceerd in internationale wetenschappelijke tijdschriften. Op deze manier hebben ze bijgedragen aan de kennisvermeerdering binnen de wetenschap en bieden ze de basis voor toekomstig onderzoek naar (ervaren) klassisme en ongezonde homogenisering. 


\section{Valorisatie}

\section{Referenties}

1. Stimulanz. Verzuiminterventie; Wet Verbetering Poortwachter. 2018. Geraadpleegd van https://stimulanz.nl/Over-stimulanz/Handigedownloads.

2. UWV. Factsheet De no-riskpolis. 2018. Geraadpleegd van https://www.uwv.nl/werkgevers/formulieren/aanvragen-factsheet-noriskpolis.aspx.

3. Verwer IJGM, Groothoff JW, van der Velden J, van der Gulden JWJ. Sociale zekerheid bij ziekteverzuim en arbeidsongeschiktheid in Nederland in historisch perspectief. Tijdschrift voor gezondheidswetenschappen. 2014;92(1):26-32.

4. UWV. Werknemer met uitkering; loonkostensubsidie. 2018. Geraadpleegd van https://www.uwv.nl/werkgevers/werknemer-met-uitkering/ voordelen-en-regelingen/detail/loonkostensubsidie.

5. UWV. Werknemer met uitkering; minder loon wajonger (loondispensatie). 2018. Geraadpleegd van

https://www.uwv.nl/werkgevers/werknemer-met-uitkering/voordelen-enregelingen/detail/minder-loon-wajonger-loondispensatie.

6. College voor de Rechten van de Mens. Brief aan Tweede Kamer over Hoofdlijnennotitie Loondispensatie Participatiewet, 12 april 2018. Geraadpleegd van http://cgblive.ilumy.com/publicaties/detail/38426.

7. Taalbank. Klassisme. 2016. Geraadpleegd van https://www.taalbank.nl/2016/11/10/klassisme/

8. Derman-Sparks L. Culturally relevant anti-bias education with young children. In Stephan WG, Vogt PG (Eds.), Education programs for improving intergroup relations: Theory, research, and practice. New York: Teachers College Press 2004.

9. Kok G, Gottlieb NH, Peters GJY, Dolan-Mullen P, Parcel GS, Ruiter RAC, Fernández ME, Markham C, Bartholomew LK. A taxonomy of behaviour change methods: an Intervention Mapping approach. Health Psychol Rev. 2016;10(3):297-312. 


\section{Dankwoord}

Oh Lord

This is so much harder than I thought But I will give them everything I've got One day I am gonna prove them wrong

(Lost Frequencies \& Zonderling, Crazy, 2018)

Er zijn veel momenten geweest de afgelopen jaren waarop ik dacht dat dit moment er nooit zou komen, maar het proefschrift is klaar! Maar alleen was mij dat nooit gelukt. Daarom wil ik een aantal mensen graag bedanken voor hun bijdrage.

Als eerste wil ik mijn promotieteam bedanken: mijn promotor Hans, copromotor Annemarie, maar ook Daniëlle die mijn copromotor was in de eerste jaren van het promotietraject. Hans, als HSRM-student klopte ik bij je aan met de vraag of je mijn begeleider wilde zijn bij het schrijven van mijn onderzoeksvoorstel en afstudeerscriptie. Dit deed je graag, mits ik wel voor een promotieplek wilde gaan na mijn master. Met een volmondige 'ja' dacht ik wel even 'waar heb ik me nu op vastgelegd?!' Maar het heeft goed uitgepakt. Ik wil je bedanken voor je grote betrokkenheid bij het promotieproject, deskundigheid, kritische blik op zowel inhoudelijke als tekstuele punten, maar vooral ook voor de mogelijkheden en vrijheid die je mij geboden hebt. Annemarie, na het vertrek van Daniëlle werd jij mijn copromotor. Met een frisse blik keek jij naar de geplande onderzoeken en artikelen. Jouw inbreng zorgde er dan ook voor dat we weer eens kritisch keken naar wat we aan het doen waren. Daarnaast wil ik je bedanken voor je deskundige inbreng, zeker wanneer het ging over statistische analyses, je waardevolle feedback en persoonlijke betrokkenheid. Daniëlle, je werd mijn tweede thesis begeleider, en later dus ook copromotor, toen je nog in America zat; ons eerste contact was dus via e-mail, maar daarom niet minder persoonlijk. Doordat het promoveren voor jou ook nog niet zo lang geleden was, vond ik het fijn om te kunnen leren van jouw ervaringen en kennis. Helaas hebben we het niet samen af kunnen ronden, maar dat doet niks af aan hoe 


\section{Dankwoord}

dankbaar ik ben voor je bijdrage. Hans, Annemarie en Daniëlle, ik weet zeker dat dit proefschrift er nooit was gekomen met een ander promotieteam, een ander project of andere vakgroep.

Daarnaast wil ik ook Inge graag bedanken voor haar waardevolle bijdrage aan het kwalitatieve artikel. Je hebt me wegwijs gemaakt in het doen van kwalitatief onderzoek en zeker bij het analyseren van de grote hoeveelheid aan transcripten was jouw kennis en gemeende interesse in de verhalen van de participanten zeer waardevol.

De leden van de beoordelingscommissie, prof. dr. Horstman, prof. dr. Huisman, prof. dr. van de Mheen, prof. dr Kempen en dr. Oenema, wil ik bedanken voor hun bereidheid zitting te nemen in de commissie en voor de tijd en energie die zij hebben gestoken in het beoordelen van mijn manuscript. Ook de overige leden van de corona wil ik graag bedanken voor hun inzet.

Dit proefschrift was er niet gekomen zonder de deelname van onze participanten. Ik wil hen dan ook graag bedanken voor hun inzet. Daarnaast wil ik de Vincentius Vereniging bedanken voor hun medewerking.

Dan zijn er nog mijn kamergenootjes, Yvonne, Karina, Ivon, Yvette, MarieJosé, Angelique Vermeiren en Jeroen die ik wil bedanken. Of het nu ging over onze onderzoeken/artikelen/analyses, over promoveren, over persoonlijke dingen of gewoon even over koetjes en kalfjes, het was altijd gezellig. Yvonne, we zagen elkaar niet elke dag, dus soms moest er even goed bijgekletst worden. Ik vond het altijd heel gezellig en ik wil je bedanken voor je steun in de afgelopen jaren. Karina, 'Oooo no, now I have to speak English all day!' that was my first thought when I heard that you were going to be my roommate for a year. But luckily that was not a problem at all and I enjoyed our time together. We had a very special goodbye in 2015 , knowing that we were both pregnant and due in the same week! Thank you for all your personal support. One day we will meet again! Angelique, ik vond het fijn dat ik mijn laatste loodjes met jou heb kunnen delen. Dankjewel voor je interesse, je openheid en steun.

En dan hebben we natuurlijk nog alle overige collega's van de vakgroep Sociale Geneeskunde. Wat ben ik blij dat ik op deze vakgroep terecht ben gekomen. Ik 
kijk met heel veel plezier terug op de vakgroepuitjes en -etentjes. Een aantal collega's wil ik in het bijzonder bedanken. Isel, jij was degene die het afronden van mijn proefschrift durfde te vergelijken met een bevalling. Nou, niks was minder waar. Maar geef mij toch maar een gewone bevalling hoor, deze duurde veel te lang! Ik wil je bedanken voor alle praktische hulp en gezellige kletsmomenten. Frans, bedankt dat je als vakgroepvoorzitter mij de mogelijkheid hebt gegeven bij Sociale Geneeskunde te promoveren. Ik zal je humor zeker niet vergeten! De buurtjes Elisabeth en Nicole, bedankt voor jullie persoonlijke betrokkenheid en gezelligheid. Angelique de Rijk, bedankt voor je openheid, gezelligheid en interesse in mijn werk. Natuurlijk ook bedankt voor je bereidheid zitting te nemen in de corona.

Mijn studentenleven begon niet in Maastricht, maar in Eindhoven. Aan die tijd heb ik een gezellig clubje vriendinnen overgehouden: het verpleegkunde-clubje. Ik wil jullie bedanken voor jullie steun in leuke en minder leuke tijden. Tijdens de opleiding koos ik ervoor om een andere weg in te slaan, maar desondanks hebben jullie altijd achter me gestaan, welke keuze ik ook maakte. Daarom heb ik jullie, Cheyenne en Tracy, ook gevraagd als mijn paranimfen; jullie wil ik achter me hebben staan tijdens de verdediging. Tracy, jouw welgemeende interesse en goede doorvraagtechnieken zorgden voor veel interessante gesprekken die mij vaak ook weer nieuwe inzichten gaven. Cheyenne, goede of slechte tijden, jij was/bent er altijd, zelfs nu we beide een eigen gezinnetje hebben en we niet bij elkaar in de buurt wonen. Dankjewel dames!

Dan hebben we nog de dames en heren van het kokkerelclubje. Dankjewel voor jullie gezelligheid, luisterend oor en adviezen. De Guido's wil ik in het bijzonder bedanken voor hun steun in de afgelopen jaren: van weekendjes weg vol goede gesprekken tot het uit de brand helpen met verdwenen manuscripten.

'Beter een goede buur dan een verre vriend', helemaal waar hè Margriet en Herman? Wat ben ik blij dat jullie onze buurtjes zijn. Dankjewel voor jullie hulp, zoals het verzorgen van de hondjes wanneer wij weer eens een lange dag maakten op het werk, maar vooral voor jullie betrokkenheid bij ons gezin.

Dankjewel Lisa voor het uit de brand helpen met het fotograferen van de cover. 


\section{Dankwoord}

Voor iedereen die ik niet bij naam heb genoemd, maar die direct of indirect wel betrokken is geweest: dankjewel voor jullie steun!

Familie 'de Moes', Mam en pap, Ashley en Miranda, Arjan en Berit, 'One day I am gonna prove them wrong', jaren geleden hadden we niet kunnen bedenken dat ik ooit zou gaan promoveren, maar hier ligt nu toch echt hét boekje! Maar dit boekje was er zonder jullie nooit gekomen. Dankjewel dat jullie er al die tijd voor ons zijn geweest; niet alleen voor mij, maar ook voor Gerrion en Quinn. En inderdaad Ashley, het zijn allemaal best normale mensen hier op de uni!

De 'Op het Veldjes', Tilly, Pierre en Nancy, wil ik ook bedanken voor alle steun de afgelopen jaren, van het werken in de tuin tot het kunnen aanschuiven met eten na een lange werkdag. Wellicht heb ik vanaf nu tijd om zelf wat meer te klussen ;)

Last but not least, Gerrion en Quinn. Gerrion, voor jou zijn de afgelopen jaren misschien wel pittiger geweest dan voor mij: ik moest dealen met de promotiestress, jij met mij. Dankjewel dat je ondanks alles mij bent blijven steunen en motiveren, zelfs op momenten dat ik de handdoek in de ring wilde gooien en geen zonnetje in huis was. Ik zie uit naar de komende jaren: zonder alle stress door verbouwingen en promoveren, lekker genietend van ons gezinnetje in òs Putbrooks paradieske. Quinn, voor jou heeft mama doorgezet, zodat we daarna 'boetuh' kunnen spelen zoveel als je wil. Mama is eindelijk 'klaaaar!' 


\section{Curriculum Vitae}

Audrey Simons - Op het Veld is geboren op 25 januari 1984 te Swalmen. Ze behaalde in 2002 haar VWO diploma aan het Stedelijk Lyceum in Roermond. $\mathrm{Na}$ haar propedeuse HBO-verpleegkunde behaald te hebben bij Fontys Hogescholen in Eindhoven, besloot ze in 2007 over te stappen naar de Universiteit Maastricht. Daar begon ze aan de bachelor Algemene Gezondheidswetenschappen met gezondheidsvoorlichting en -opvoeding als major en geestelijke gezondheidskunde als minor. Na het behalen van haar bachelor diploma in 2010 is ze de Health Science Research Master gaan volgen aan de Universiteit Maastricht, met social sciences als differentiatie. Tijdens deze master schreef ze samen met Prof. dr. Hans Bosma en dr. Daniëlle Groffen een onderzoeksvoorstel gericht op het verklaren van sociaaleconomische gezondheidsverschillen. In 2012 kreeg ze voor dit onderzoeksvoorstel een subsidie van het NWO Graduate Programme 2012 van de Nederlandse Organisatie voor Wetenschappelijk Onderzoek (NWO), ontvangen door Care and Public Health Research Institute CAPHRI. Ze kreeg een aanstelling als Phd-student bij de vakgroep Sociale Geneeskunde aan de Universiteit Maastricht. Gedurende haar PhD-traject was ze tevens betrokken bij het onderwijs in de bachelor Gezondheidswetenschappen. Audrey is getrouwd met Gerrion Op het Veld en samen hebben ze een zoontje Quinn (2016). 
